Prepared in cooperation with the National Park Service

\title{
Mapping the Natchez Trace Parkway
}

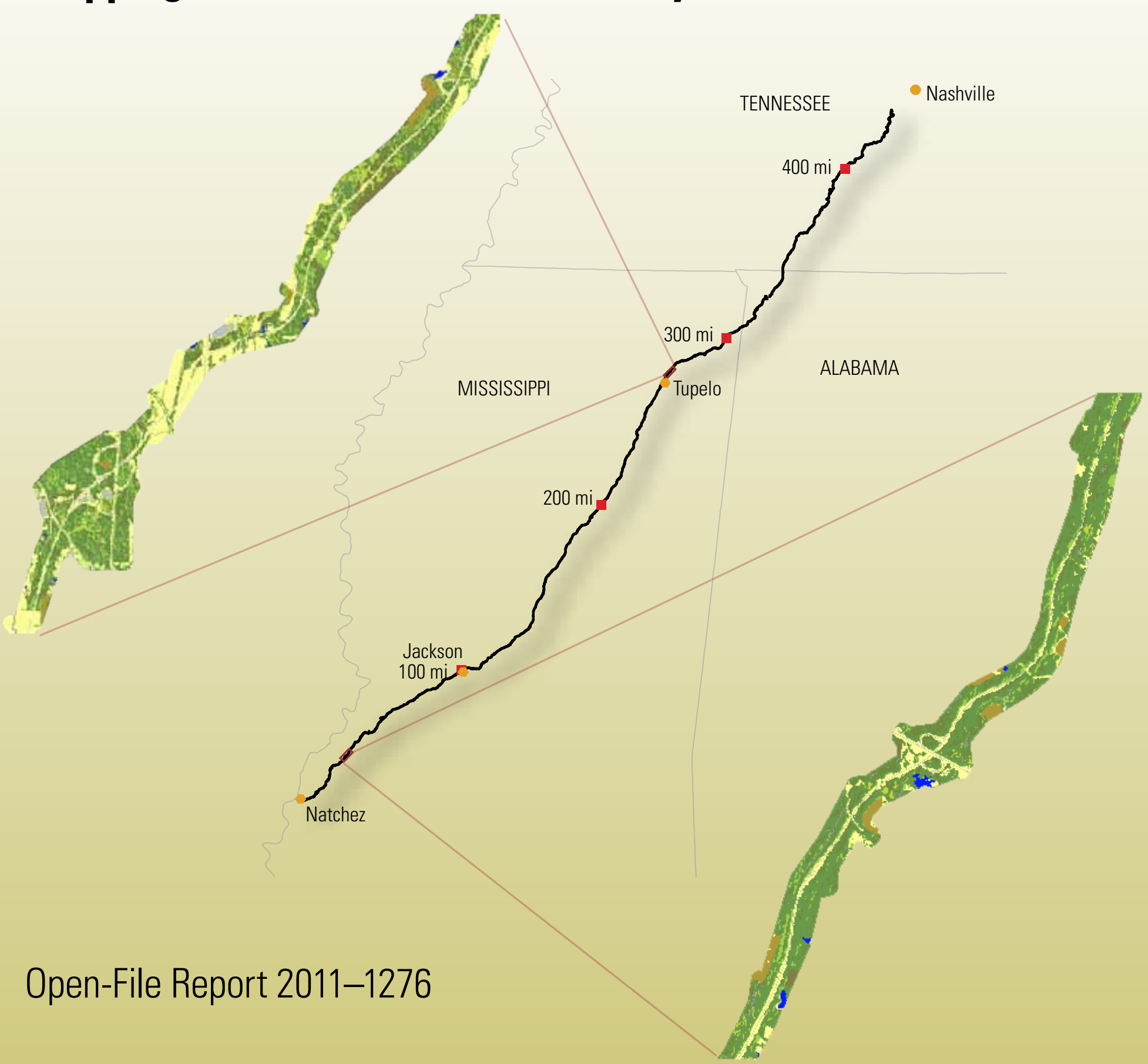





\section{Mapping the Natchez Trace Parkway}

By Amina Rangoonwala, Terri Bannister, and Elijah Ramsey III

Prepared in cooperation with the National Park Service

Open-File Report 2011-1276

U.S. Department of the Interior

U.S. Geological Survey 


\title{
U.S. Department of the Interior \\ KEN SALAZAR, Secretary \\ U.S. Geological Survey \\ Marcia K. McNutt, Director
}

\author{
U.S. Geological Survey, Reston, Virginia: 2011
}

For more information on the USGS - the Federal source for science about the Earth, its natural and living resources, natural hazards, and the environment, visit http://www.usgs.gov or call 1-888-ASK-USGS.

For an overview of USGS information products, including maps, imagery, and publications, visit http://www.usgs.gov/pubprod

To order this and other USGS information products, visit http://store.usgs.gov

Any use of trade, product, or firm names is for descriptive purposes only and does not imply endorsement by the U.S. Government.

Although this report is in the public domain, permission must be secured from the individual copyright owners to reproduce any copyrighted materials contained within this report.

Suggested citation:

Rangoonwala, Amina, Bannister, Terri, and Ramsey, Elijah, III, 2011, Mapping the Natchez Trace Parkway:

U.S. Geological Survey Open-File Report 2011-1276, 58 p. 


\section{Acknowledgments}

First and foremost, we thank Paul Conzelman and Martha Segura of the National Park Service for allowing us the opportunity to contribute to the landcover mapping of the Nations resources and Kurt Foote of the National Park Service for his guidance and vital help in our field reconnaissance. Partial funding for this work was provided through the U.S. National Park Service Agreement Number 14431A53200000.

We are grateful to Steve Hartley of the U.S. Geological Survey for his development of critical geographic information system (GIS) procedures and help in GIS processing. 



\section{Contents}

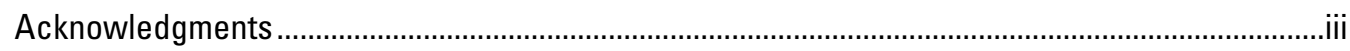

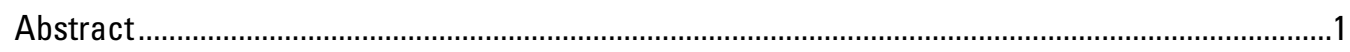

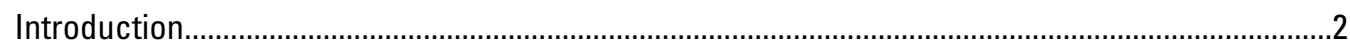

Imagery Spatial Resolution .........................................................................................

Seasonal Timing of Imagery Collection...............................................................................

Map Classification Accuracy Assessment ..........................................................................

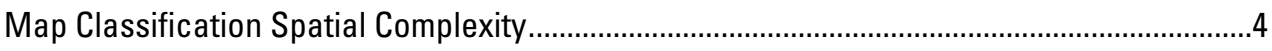

Parkway Spectral Varibility related to Mapping.....................................................................

Mapping Classification Procedures ......................................................................................

Supervised Landcover Mapping ...............................................................................

Unsupervised Landcover Mapping...........................................................................

Site Composition and Mapping Classification Confusion ...........................................................

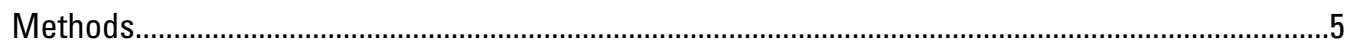

Photographic Image Data Collection ............................................................................

Creation of the Roadway Vector for the Natchez Trace Parkway..........................................8

Parkway Coverage Extracted from the CIR DOQ0 Mosaic ........................................................

A CIR Rendition Appropriate for Mapping Forest Stands ...................................................

Mapping “Irregular" Classes...........................................................................................

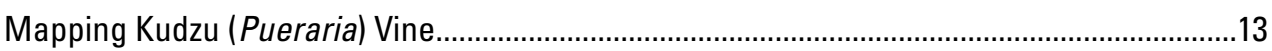

2004 Field-based Reconnaissance and Mapping Classification ............................................13

Formation of Spectrally Distinct Mapping Classes ………..........................................13

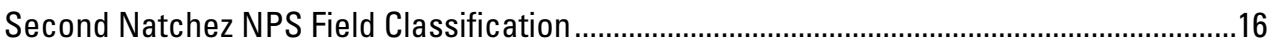

2005 NPS Field-Site Sampling Strategy ....................................................................16

Field-Site Selection for the Second NPS Landcover Classification...............................18

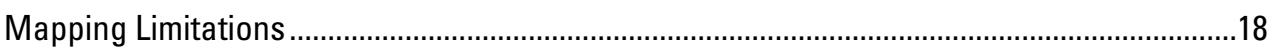

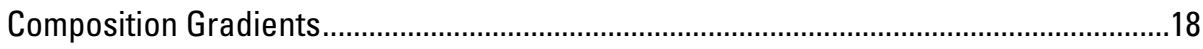

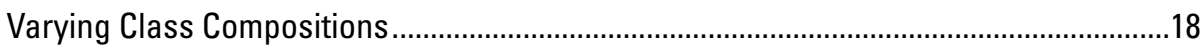

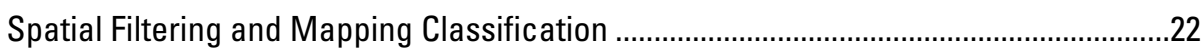

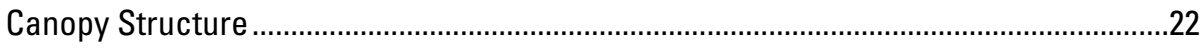

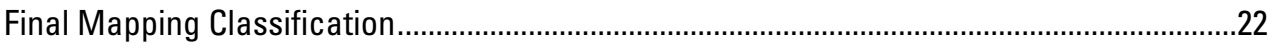

Removal and Replacement of Edge and Gap Shadows ................................................22

Detection and Isolation of the Mosaiced DO00 Cutlines.................................................25

Landscape Mapping Classification Logistics .............................................................25

Reduction of Mapping Artifacts after Mapping........................................................25

Field-Site Location and Accuracy Assessment of Mapped Classes .....................................31

Results and Discussion..........................................................................................................

Initial Image Mapping Classific ation .................................................................................

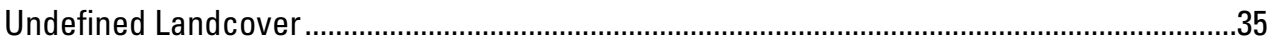

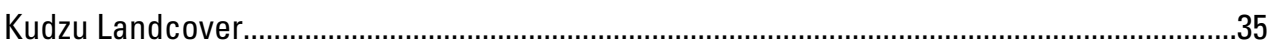

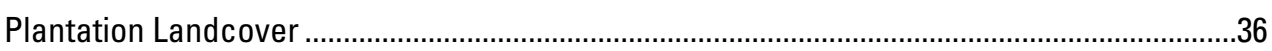

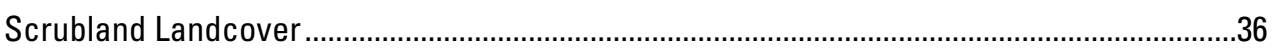

Addition of a USGS-defined Scrub-Shrub Class .......................................................... 


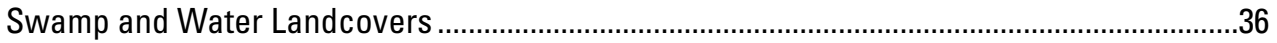

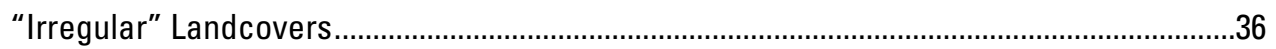

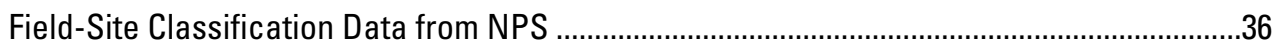

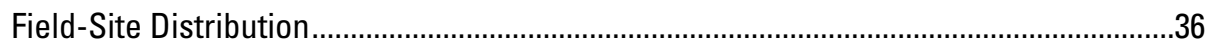

Physiognomic Class Descriptions for the NPS Landcover Classification..........................37

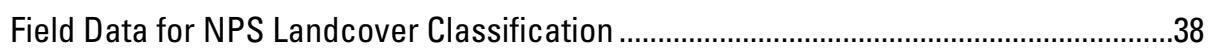

Spectral Relationships Among NPS-Defined Alliance Classes ................................................38

Correspondence of the USGS Landcover Map and the NPS Landcover

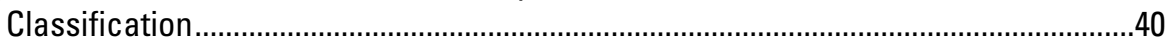

Parkway Landscape Overview Based on the USGS Map .....................................................40

Southern Section Map Description ........................................................................42

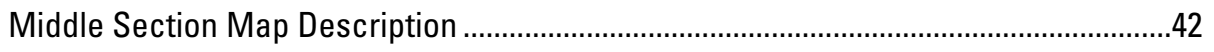

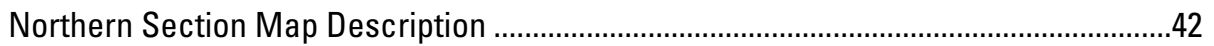

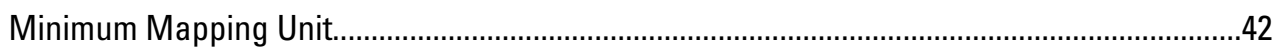

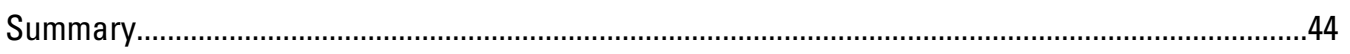

Landscape Classification Protocols and Metadata ………...................................................

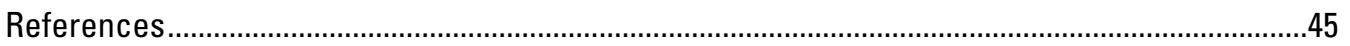

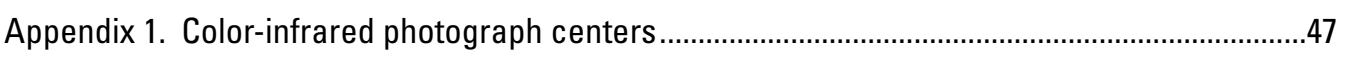

Appendix 2. Photography collection and processing ....................................................................57

\section{Figures}

1. Map of study area within the 715-km long Natchez Trace Parkway, which extends across Mississippi, Alabama, and Tennessee

2. Color-infrared imagery showing a section of the photographic coverage of the Natchez Trace Parkway transformed into a two-digital orthophoto quarter quadrangle format.

3. Diagram showing an overview of the Natchez Trace Parkway divided into 11 mosaic tiles (sections 1 to 7) for processing.

4. Color-infrared imagery of the roadway vector, the Natchez Trace Parkway (the "Parkway") boundary, and the extended 100-m buffer applied by the U.S. Geological Survey to produce the Parkway map.

5. Color-infrared imagery illustrating the misalignment between the road vector generated by the U.S. Geological Survey and the National Park Service's Natchez Trace Parkway boundary .....

6. Color-infrared imagery showing the width of the National Park Service's Natchez Trace Parkway plus a 100-m buffer with the overlay of the roadway vector created by the U.S. Geological Survey

7. Color-infrared images of the National Park Service's Natchez Trace Parkway plus a 100-m buffer extracted from the section 2 mosaic.

8. Color-infrared and mapped images showing variations of kudzu vine shrubland

9. Mapped images of landcover corresponding to the color-infrared image shown in figure 7.

10. Images demonstrating the process for classifying color-infrared digital orthophoto quarter quandrangles of different areas in the "2 south" mosaic. 
11. Color-infrared and mapped images showing examples of the spatial-

vegetation continuum (as indicated by spectral qualities).

12. Color-infrared images showing examples of white oak forest alliances mixed with different white oak associations

13. Color-infrared and mapped images showing an example of classification confusion resulting from spatial filtering...

14. Color-infrared and mapped images showing an example of forest types featuring different crown sizes and percentages of canopy closure.

15. Color-infrared images showing an example of field sites where landcover was classified by National Park Service personnel

16. Color-infrared and mapped images showing the process used to remove gaps and separately reintegrate them into mapped forest classes...

17. Color-infrared images showing examples of cutlines present in the different sections of the Natchez Trace Parkway mosaic

18. Color-infrared and mapped images showing results of the process to reduce mapping artifacts from the final map product.

19. Color-infrared images showing an example of two National Park Service forest sites mislocated outside the forested areas

20. Color-infrared and mapped images showing an example classification of the "scattered trees" class defined by U.S. Geological Survey scientists

21. Graph showing distribution of field points (total of 331) for which data were provided by National Park Service personnel.

22. Graph showing frequency of measurement ranges (in meters) indicating distance from tree line to field sites where classification data were collected by National Park Service personnel

23. Chart showing the graphic distribution of mapped classes within the Natchez Trace Parkway..

24. Color-infrared and mapped images showing an example of mapping landcover classification within an area of the Natchez Trace Parkway (the "Parkway")

\section{Tables}

1. Digital orthophoto quarter quadrangles covering the Natchez Trace Parkway

2. Initial landcover classification of field sites in the Natchez Trace Parkway that were mapped as "irregular" classes

3. Initial landcover classification of field sites in the Natchez Trace Parkway by National Park Service personnel in 2004.

4. Landcover classifications defined by National Park Service (NPS) personnel (2004 and 2005) as they were mapped by U.S. Geological Survey (USGS) scientists (including how the classes were grouped in the USGS classification).

5. Results from accuracy assessment of the landcover map of the Natchez Trace Parkway by U.S. Geological Survey scientists

6. Results from accuracy assessment of the landcover map of the Natchez Trace Parkway by U.S. Geological Survey scientists after merging the "sweetgum" and "sweetgum-oak" classes into a "sweetgum" class and the "pine" and "cedar" classes into a "pine-cedar" class 
7. Results from accuracy assessment of the landcover map of the Natchez Trace Parkway by U.S. Geological Survey scientists after merging the "sweetgum" and "sweetgum-oak" classes into a "sweetgum" class, the "pine" and "cedar" classes into a "pine-cedar" class, and the "white Oak" and "Oak" classes into an "Oak" class

8. Results from accuracy assessment of the landcover map of the Natchez Trace Parkway by U.S. Geological Survey scientists after the "white oak" class was retained as a separate class in the north and merged with the "oak" class in the south..

9. Total area of each class in the landcover map of the Natchez Trace Parkway produced by U.S. Geological Survey scientists.

10. Landcover classes mapped in the southern, middle, and northern sections of the Natchez Trace Parkway by U.S. Geological Survey scientists

11. Size of the largest area of continuous forest stands within each mapped section (southern, middle, and northern) of the Natchez Trace Parkway, as mapped by U.S. Geological Survey scientists

\section{Conversion Factors}

Inch/Pound to SI

\begin{tabular}{|c|c|c|}
\hline Multiply & By & To obtain \\
\hline \multicolumn{3}{|c|}{ Length } \\
\hline mile (mi) & 1.609 & kilometer (km) \\
\hline \multicolumn{3}{|c|}{ Area } \\
\hline acre & 4,047 & square meter $\left(\mathrm{m}^{2}\right)$ \\
\hline
\end{tabular}

SI to Inch/Pound

\begin{tabular}{lcl}
\hline \multicolumn{1}{c}{ Multiply } & By & \multicolumn{1}{c}{ To obtain } \\
\hline & Length & \\
\hline centimeter $(\mathrm{cm})$ & 0.3937 & inch (in.) \\
meter $(\mathrm{m})$ & 3.281 & foot $(\mathrm{ft})$ \\
meter $(\mathrm{m})$ & 1.094 & yard $(\mathrm{yd})$ \\
\hline & Area & \\
\hline square meter $\left(\mathrm{m}^{2}\right)$ & 0.0002471 & acre \\
square meter $\left(\mathrm{m}^{2}\right)$ & 10.76 & square foot $\left(\mathrm{ft}^{2}\right)$ \\
\hline
\end{tabular}

The map projection used for all products is the World Geodetic System of 1984 (WGS 84), Universal Transverse Mercator (UTM) Zones 15N and 16N (coordinates are in meters). 


\title{
Mapping the Natchez Trace Parkway
}

\author{
By Amina Rangoonwala, ${ }^{1}$ Terri Bannister, ${ }^{1}$ and Elijah Ramsey III
}

\section{Abstract}

Based on a National Park Service (NPS) landcover classification, a landcover map of the 715-km (444-mile) NPS Natchez Trace Parkway (hereafter referred to as the "Parkway") was created. The NPS landcover classification followed National Vegetation Classification (NVC) protocols. The landcover map, which extended the NPS field site-based landcover classification to the entire Parkway, was based on color-infrared (CIR) photography converted to $1-\mathrm{m}$ rasterbased digital orthophoto quarter quadrangles (DOQQs), according to U.S. Geological Survey (USGS) mapping standards. Mapping landcover within the Parkway was problematic because of the lack of NPS field sites (mode $=1$, and average $=4.5$ ) per NVC alliance.

Our goal was to include as many alliance classes as possible in the Parkway landcover map. To reach this goal while maintaining a consistent and quantifiable map product throughout the Parkway extent, a mapping strategy was implemented based on the migration of class-based spectraltexture signatures and the congruent progressive refinement of those class signatures along the Parkway. Progressive refinement provided consistent mapping by evaluating the spectral textural distinctiveness of the alliance-association classes, and where necessary, introducing new map classes along the Parkway. By following this mapping strategy, the use of raster-based image processing and geographic information system (GIS) analyses for the map production provided a quantitative and reproducible product.

Although field-site classification data were severely limited, the combination of spectral migration of class membership along the Parkway and the progressive classification strategy produced an organization of alliances that was internally highly consistent. The organization resulted from the natural patterns or alignments of spectral variance and the determination of those spectral patterns that were compositionally similar in the dominant species as NVC alliances. The final classes were (1) grasses, (2) oak (Quercus sp.) mix, (3) white oak (Quercus alba), (4) sweetgum (Liquidambar sp.), (5) pine (Pinus)-oak, and (6) pine. The overall mapping accuracy was 74 percent, and user and producer accuracies were above 58 percent. Nine additional map classes, including swamp forest, water, aquatic vegetation, plantation, invasive species, road and developed, scrub-shrub, scattered trees, and the "irregular" forest alliances were manually mapped (by using on-screen digitizing). The manually mapped alliances were seldom represented by more than one or two field observations. Manual classifications made up less than 8 percent of the mapped Parkway landcover.

Overall, the mapped landcovers represented the existent spectral textural patterns that defined and encompassed the complex variety of compositional alliances and associations of the Parkway. Based on that mapped representation, forests dominate the Parkway landscape, making up 66 percent of the $100-\mathrm{m}$ buffered Parkway landcovers. The forest makeup is 24 percent oak (includes white oak in the southern sections), 19 percent pine-cedar, 10 percent pine-oak, 9 percent sweetgum, and 4 percent white oak (as mapped in the northern sections). Grass is the second largest Parkway land cover at 22 percent, followed by scrub-shrub and shrubland classes (5 percent) and pine plantations ( 2 percent). The map provides a good representation of the landcover patterns and their changes over the extent of the Parkway, south to north.

\footnotetext{
${ }^{1}$ Five Rivers Services, LLC, for the U.S. Geological Survey.

${ }^{2}$ U.S. Geological Survey.
} 


\section{Introduction}

The U.S. Geological Survey (USGS) mapped the landscape of the Natchez Trace Parkway (hereafter referred to as the "Parkway"), which is managed by the National Park Service (NPS), from September 2004 to August 2010 (fig. 1). The USGS mapping extended the field site-based, National Vegetation Classification (NVC)-based landcover classification (text box) performed by the NPS. The complexities of the NVC system required expertise in defining associations (containing varied stand compositions in a complex vegetation landscape of species) that represented repeatable class units. As part of the same agreement with NPS, USGS scientists also mapped the landscape of the Vicksburg National Military Park, which was completed ahead of the Parkway mapping and for which a final report (and all other required products) was submitted to NPS in 2007. The scope of the current report is to describe mapping of the Parkway.

\section{Imagery Spatial Resolution}

The mapping of the Parkway included criteria that largely defined the mapping methods and, in large part, the ability to map the NVC classes located and classified by NPS through field sampling. The most critical mapping criterion was the spatial resolution of the source imagery to be used for the mapping. That resolution was set by the NPS request that small features (such as road markers) along the Parkway be visually identifiable. To obtain visual discrimination would have required submeter spatial resolutions, most likely less than 15-20 cm; however, mapping of natural resources such as grasslands is best performed at resolutions $1-5 \mathrm{~m}$ and forests at 5-30 $\mathrm{m}$ (Fassnacht and others, 2006). Although necessary for visual identification of fine features such as road markers, mapping at the 15-20-cm resolution would have severely impacted the performance of the resource mapping. The selected spatial resolution of the source imagery had to permit visual discernment of fine features on the images but not severely hamper the mapping classification of the mixed forest-to-grassland landcovers.

\section{Seasonal Timing of Imagery Collection}

A second critical mapping criterion was set because of the NPS request that mapping be conducted during green leaf-on conditions that occur from late spring to early fall. Because the project supported only a single date of data collection, a summerto-early fall (during full foliage) image collection was used. This timing posed a problem because in southern forests, spectral differences among major forest classes are often diminished during leaf-on conditions. The ubiquitous full green-leaf canopies combined with the inherent composition variability within any forest association class further increased complexities in the spectral discernment among identified NVC classes.
The NVC is hierarchical - the higher the level, the less numerous and more generalized. The highest level is the Division, followed by Order, five physiognomic levels that describe the structure and life form of the plant community, and two floristic levels that mainly describe the dominant species. The Division divides the earth into nonvegetated and vegetated levels, and the Order further divides the vegetated Division into tree, shrub, dwarf shrub, herbaceous, and nonvascular life forms. Physiognomic class defines the relative percent canopy cover of each Order at the peak of the growing season. Subclass describes the predominant leaf phenology of woody plants (evergreen, deciduous, mixed evergreen-deciduous) and the leaf type and periodicity of herbaceous plants. Group relates to a combination of climate, leaf morphology, and leaf phenologic factors. Subgroup divides the physiognomic group level into natural/ seminatural and planted/cultivated categories. The final physiognomic level, formation, divides the physiognomic subgroup into common environmental and additional physiognomic factors (for example, upland, seasonally flooded, pavement [sparsely vegetated]). The floristic levels, alliance and association, currently are not required as part of the NVC, but they are a required part of all NPS classifications. Alliance represents an aggregation of associations. Association, as the finest floristic level in the NVC, describes a diagnostic species that is shared by a physiognomically uniform group of vegetation stands that are generally found in similar habitat conditions. A complete overview and detailed explanation of the hierarchy is provided by the Federal Geographic Data Committee (2008). 


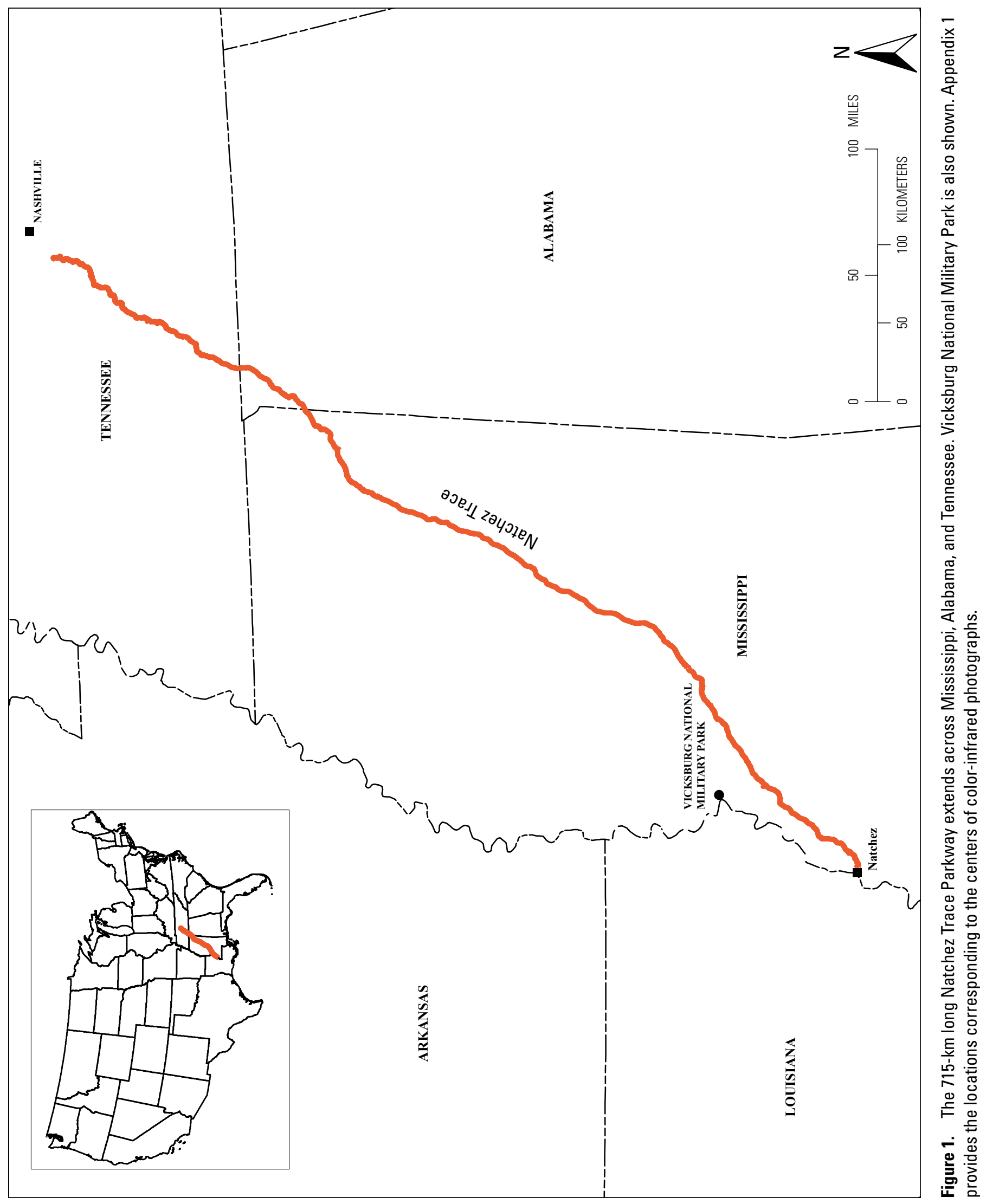




\section{Map Classification Accuracy Assessment}

A third mapping criterion involved the number of fieldsite observations per NVC alliance or association. In mapping a spatially extensive landscape based on classes containing composite mixtures, 30 field-site observations is the acceptable minimum (Congalton, 1991; Congalton and Green, 1999; Grenier and others, 2008). This minimum is acutely pertinent when mapping the $715-\mathrm{km}$ south to north extent of the Parkway. In mapping, a rule of thumb is to collect data at 30 reference sites for guiding the mapping classification and an additional 50 sites for assessing accuracy (Congalton, 1991; Congalton and Green, 1999).

\section{Map Classification Spatial Complexity}

A fourth critical mapping criterion was related to the desired spatial complexity of the map. NPS prescribed that relatively large, spatially contiguous mapped classes were more desirable than small, discrete classes. Based on the NPS response to a relatively discrete classification of Vicksburg Military Park (unpublished data), a more generalized map that would be more amenable to the NPS concept of forest association portrayal was sought by USGS. As an initial part of the USGS attempt to provide NPS with the desired spatial generalization, we applied a spatial filter matching the 2004 NPS field-site dimensions to the CIR bands. Aggregation of $\mathrm{NVC}$ classes and postprocessing procedures were also used to increase spatial uniformity and extents of mapped classes.

\section{Parkway Spectral Varibility Related to Mapping}

From a mapping perspective, and considering the south to north spatial extent, the Parkway landscape was spatially and spectrally complex. In reconnaissance performed by USGS scientists, it was found that the southern region of the Parkway was highly disturbed. In the more central sections of the Parkway, spatial complexity was high to moderately high because of the changing composite mixtures of most forest stands and the variability in forest stand canopy closures (changing top-of-canopy closure). This complexity persisted even though the forested regions for the most part occupied fairly flat and nondissected terrains (ravines and ridges were more common in the south and north). The southern and northern portions of the Parkway contained more topographic variability. When compositing and closure variability were accounted for, many forests were moderately uniform and spatially extensive; however, many forested regions were spatially complex even if considered to be in a single NVC class, and some were moderately to highly disturbed, with different mixtures of canopy and subcanopy trees, shrubs, and sometimes vines. Grasslands were mixed between groomed (mowed) and nongroomed.

\section{Mapping Classification Procedures}

Creating a mapping classification based on spectral features is a process by which all pixels in an image are automically categorized into landcover classes or themes. Typically, multispectral data (more than a single color band) are input, and the pixel spectral hue and intensity are used as the numerical bases for categorizing each pixel.

Categorizing pixels as a basis for mapping classifications can be accomplished with a variety of image processing methods. Two widely used methods apply supervised and unsupervised modes.

\section{Supervised Landcover Mapping}

In supervised landcover mapping, the analyst uses $a$ priori knowledge of the land covers and their locations in the landscape. The knowledge is used to define training sites (regions containing a single vegetation type or association). These training sites are then used to compile a numerical "interpretation" or "spectral key" that describes the spectral attributes of each landcover class of interest. Each pixel in the dateset is compared numerically with the interpretation key and labeled with the landcover class to which it is spectrally most similar.

\section{Unsupervised Landcover Mapping}

Unsupervised classification mapping does not require that the analyst select training sites. All class definitions and memberships are accomplished numerically and impartially (with little user bias) by aggregating the pixels into spectral groupings, or clusters, based solely on the spectral distribution present in the image. The analyst then determines the landcover identity of these spectral groups by associating the classified image data with ground reference data. We used unsupervised classification for our data and applied an iterative self-organizing data analysis technique. An unsupervised technique was used because we had limited a priori knowledge of the Parkway and a severely limited number of field-site observations per alliance.

\section{Site Composition and Mapping Classification Confusion}

Most of the field-site data were collected in forested areas. The relative percent occurrence of different species as well as the composition of species varied within an alliance. To more correctly map these classification mixtures, the mean photographic response (hue, intensity, and saturation) and spectral variance per alliance must be well estimated. The more field sites collected per alliance, the better the photographic response can be defined. Increased definition of the photographic responses improves the classification detail 
(types of alliances separable) and accuracy; however, better definition can result in a lower spectral separation between alliances defined through field-site observations. For example, forest alliances differing by dominant substory species often would not be spectrally separable. Similarly, variable composition mixtures within a class decrease mapping performance. For another example, herbaceous alliances (mixtures of different grasses, ferns, and weeds) are often inseparable unless associated with highly different biomass contents (portending highly different near-infrared responses).

\section{Methods}

\section{Photographic Image Data Collection}

The CIR aerial data were collected during leaf-on conditions with no visible senescence onset, as was required by NPS to accomplish their ground-based vegetation classification (which followed NVC protocols). The CIR aerial data was collected at a 1:24,000 photographic scale to obtain a ground resolution of $1 \mathrm{~m}$ or better. The 1-m spatial resolution provided a compromise between the exceedingly high resolution needed to visually discern road markers on the CIR photography and the need to moderate the spectral variability for the mapping classification. A total of 388 photographic frames, including 9 frames over the Vicksburg National Military Park, were collected September 29-30 and October 6-15, 2004 (see app. 1 for CIR photography centers). The aerial photographic frames were scanned, and DOQQs were produced (a detailed description of the collection and processing of the photographic data is in app. 2). The orthophotographic production created precise terrain-corrected images that were projected to a World Geodetic System of 1984 (WGS 84), Universal Transverse Mercator (UTM) coordinate system. The images were cut to match existent DOQQs (table 1, fig. 2). The DOQQs are compliant with the DOQQ standards defined by the USGS Rocky Mountain Mapping Center (2000). The 235 DOQQs created from the 388 aerial frames were mosaiced to create full coverage of the Parkway graphic (fig. 3). Ground resolution of the DOQQs was 1 by $1 \mathrm{~m}$.

Table 1. Digital orthophoto quarter quadrangles covering the Natchez Trace Parkway. See figure 3 for mosaic locations.

[UTM, Universal Transverse Mercator; NW, northwest; SE, southeast; NE, northeast]

\begin{tabular}{|c|c|c|c|c|c|c|c|c|c|}
\hline \multirow{2}{*}{\multicolumn{2}{|c|}{$\begin{array}{c}\text { UTM Zone } 15 \\
\text { Mississippi }\end{array}$}} & \multicolumn{8}{|c|}{ UTM Zone 16} \\
\hline & & \multicolumn{4}{|c|}{ Mississippi } & \multirow{2}{*}{$\begin{array}{c}\text { Alabama } \\
\text { Mosaic } 5 \\
\text { south }\end{array}$} & \multicolumn{3}{|c|}{ Tennessee } \\
\hline Mosaic 1 & Mosaic 2 & $\begin{array}{c}\text { Mosaic } 3 \\
\text { south }\end{array}$ & $\begin{array}{c}\text { Mosaic } 3 \\
\text { north }\end{array}$ & $\begin{array}{c}\text { Mosaic } 4 \\
\text { south }\end{array}$ & $\begin{array}{c}\text { Mosaic } 4 \\
\text { north }\end{array}$ & & $\begin{array}{c}\text { Mosaic } 5 \\
\text { north }\end{array}$ & Mosaic 6 & Mosaic 7 \\
\hline Natchez & Carlisle & $\begin{array}{l}\text { Goshen } \\
\text { Springs }\end{array}$ & $\begin{array}{l}\text { French } \\
\text { Camp }\end{array}$ & $\begin{array}{c}\text { Houston } \\
\text { East }\end{array}$ & Tupelo & Bishop & Cypress Inn & Riverside & $\begin{array}{l}\text { Primm } \\
\text { Springs }\end{array}$ \\
\hline Washington & Utica West & Shoccoe & Weir & Troy & Guntown & Margerum & Westpoint & Henryville & Theta \\
\hline Pine Ridge & Big Black & Sharon SE & Tomnolen & Troy SE & Ratliff & Barton & Whitten & Gordonsburg & Fairview \\
\hline Cranfield & Cayuga & Farmhaven & Reform & Bissell & Kirkville & Cherokee & $\begin{array}{l}\text { Three } \\
\text { Churches }\end{array}$ & Sunrise & $\begin{array}{c}\text { Leipers } \\
\text { Fork }\end{array}$ \\
\hline Church Hill & Learned & Ofahoma & Sapa & Verona & Marietta & Wright & Collinwood & Mount Joy & $\begin{array}{l}\text { Kingston } \\
\text { Springs }\end{array}$ \\
\hline Rodney & Edwards & Thomastown & Maben & Sherman & Fulton NE & $\begin{array}{l}\text { Sinking } \\
\text { Creek }\end{array}$ & $\begin{array}{l}\text { Waynesboro } \\
\text { East }\end{array}$ & $\begin{array}{l}\text { Greensfield } \\
\text { Bend }\end{array}$ & Bellevue \\
\hline Lorman & Terry NW & Conway & Mantee & Tupleo & Paden SE & Threet & Ovilla & Williamsport & \\
\hline Red Lick & Raymond & Joseph & Montpelier & & Belmont & $\begin{array}{l}\text { Pleasant } \\
\text { Site }\end{array}$ & & & \\
\hline Widows Creek & Clinton & Singleton & Woodland & & Tishomingo & & & & \\
\hline Port Gibson & Pocahontas & Kosciusko & Sparta & & & & & & \\
\hline Willows & Jackson & McAdams & & & & & & & \\
\hline \multirow[t]{3}{*}{ Hermanville } & Ridgeland & Ethel South & & & & & & & \\
\hline & Madison & Kosciusko NE & & & & & & & \\
\hline & Canton & & & & & & & & \\
\hline
\end{tabular}




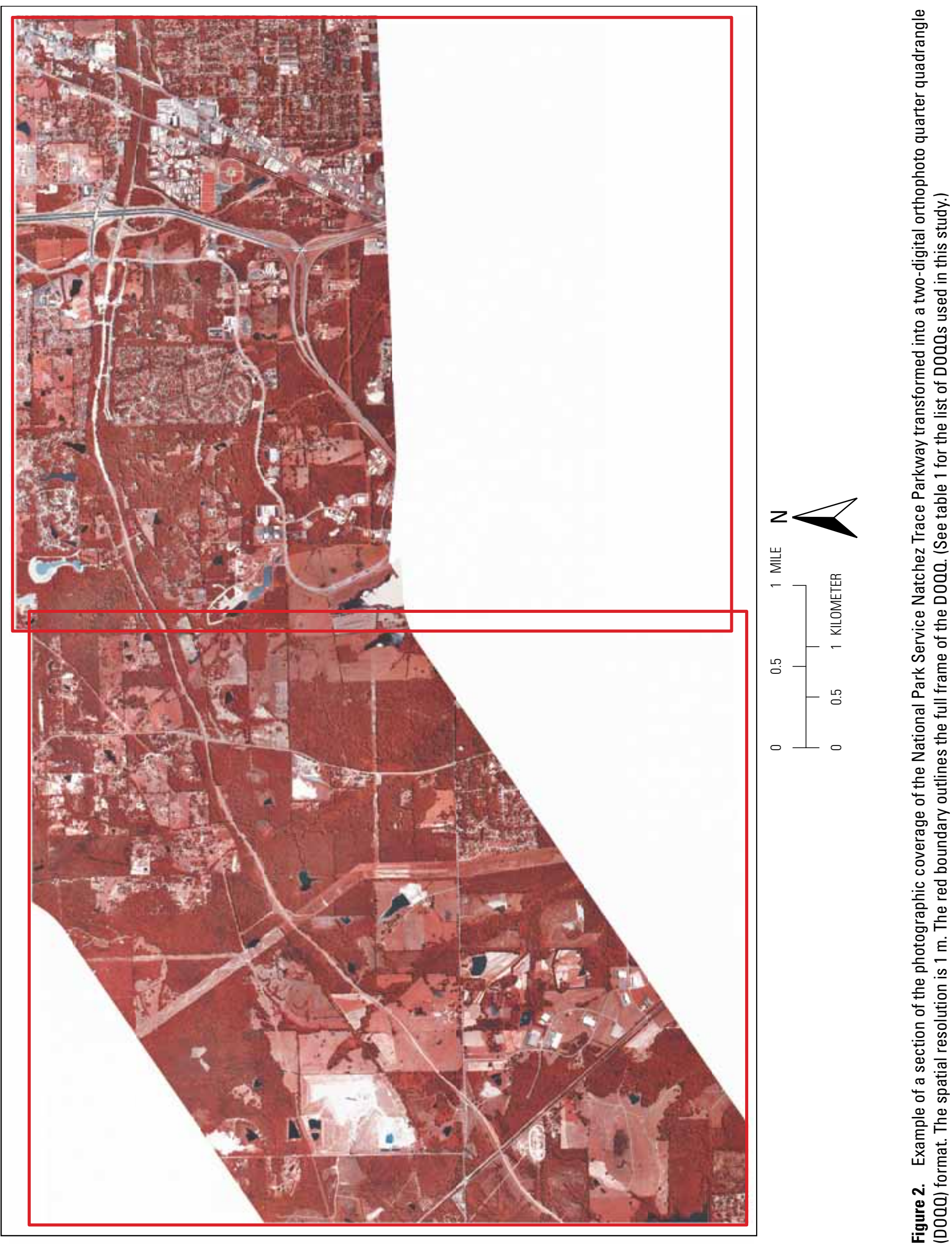




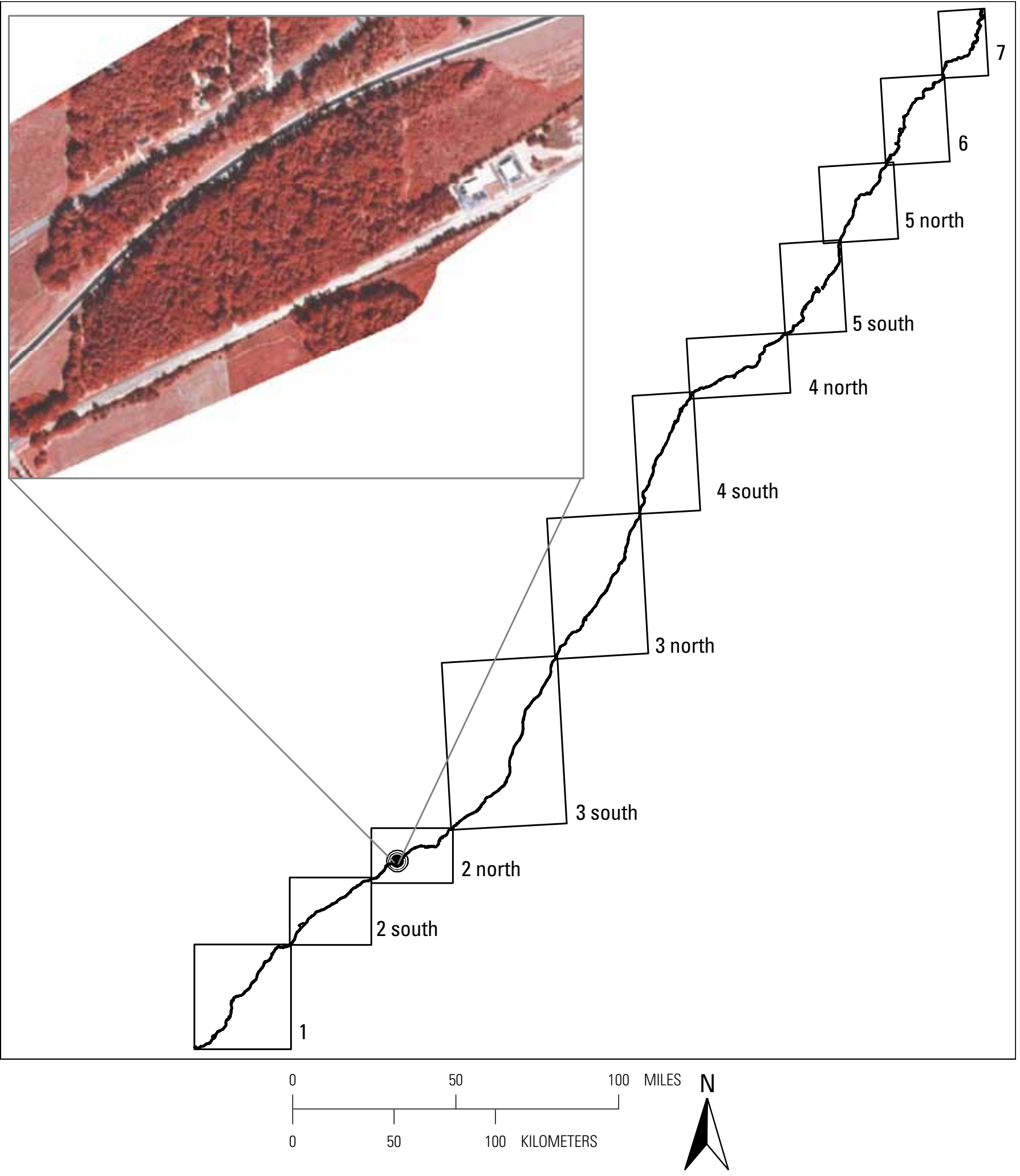

Figure 3. Graphic overview of the National Park Service Natchez Trace Parkway (the "Parkway"). Photography of the Parkway was divided into 11 mosaic tiles (sections 1 to 7 ) for processing. The location and extent of the 11 mosaic tiles are illustrated. The inset shows a small section from mosaic "2 north." 


\section{Creation of the Roadway Vector for the Natchez Trace Parkway}

A vector representation of the Parkway roadway was constructed before the CIR photographic data collections (details are in app. 3). Although created to locate the centers of aerial photographic frames along the Parkway, the most important outcome of creating the roadway vector was associated with the Parkway boundary file received from NPS. Overlay of the newly created roadway vector on the Parkway boundary uncovered a substantial misalignment. The misalignment was due to an incorrectly projected Parkway boundary. A corrected Parkway boundary polygon was subsequently supplied by NPS.

\section{Parkway Coverage Extracted from the CIR D000 Mosaic}

For backup and analysis to be practical, the Parkway was divided into 11 DOQQ mosaic sections (fig. 3). In addition, a spatial buffer was added to the park boundary in order to provide mapping continuity of the Parkway landcover to the adjacent landscape.

The final park boundary polygon provided by NPS was extended by $100 \mathrm{~m}$, and the extended polygon was used as a mask to extract the area of the DOQQ mosaic that would be mapped on the basis of the site-specific NVC landcover classification (fig. 4). Even with the 100-m extension, there are some places where the extracted polygon barely includes the Parkway roadway vector (fig. 5). These misalignments are probably due to persistent inconsistencies in the Parkway boundary polygon provided by NPS. In these instances, USGS scientists adjusted coverage by further increasing the Parkway boundary buffer. As seen in figure 4, the DOQQ mosaics (centered on the Parkway roadway) are about 4,500-m wide, whereas the Parkway boundary is only about $480-\mathrm{m}$ wide. Depictions of the different mosaic sections of the extracted Parkway mosaic are shown in figures 5, 6 and 7.

\section{A CIR Rendition Appropriate for Mapping Forest Stands}

The 1-m spatial resolution CIR-based DOQQs provided good spectral discrimination of boundaries, such as between forest and grassland and between grassland and road, and the 1-m resolution was appropriate for mapping most features, including grasslands, developments (for example, buildings and roads) and agriculture on the Parkway and the Vicksburg National Military Park (unpublished data). The 1-m resolution, however, was too fine for mapping the forests because it resulted in direct mapping of the highly illuminated side and the shadowed side of each tree crown, thus diminishing the ability to discriminate differences at the forest stand level. To alleviate this over sampling, we applied a premapping averaging filter to the image data. Different preclassification transforms were tested on a section of the Parkway imagery to discover the best method to relate the 1- by 1-m DOQQ to the ground-based observations from the 20 - by 50 -m ground plots used by NPS in the 2004 field reconnaissance. The testing involved application of spatial filters of different sizes.

Spatial filtering is a "local" operation in which the picture element (pixel) values (digital numbers [DN]) in the original image are modified on the basis of the intensity levels of the neighboring pixels. For example a 9- by 9-m pixel filter (window) may be implemented by passing a moving window throughout an original image and creating a second image where the DN at each central pixel corresponds to the local average within the moving window at each of its positions in the original image. In preparing the CIR-based DOQQs of the Parkway for the mapping classification, the filter size and dimensions were selected to accommodate both the need to reduce the spatial variability of the forest CIR spectral rendition and the size and dimension of the 2004 NPS field landcover classifications.

During a coordinated USGS-NPS field trip during September 8-11, 2004, NPS field-site classifications in the forested areas were based on 20 - by $50-\mathrm{m}$ plots. To enhance compatibility with the NPS field-site plots and improve forest mapping effectiveness, USGS simulated the 20 - by $50-\mathrm{m}$ plots by using spatial filters. In our analyses, the best results were obtained by using an average 11- by 25-pixel (or 11- by 25-m) spatial filter. The 11 - by $25-\mathrm{m}$ filter dimension produced a scale comparable to the 20 - by $50-\mathrm{m}$ ground-plot size used by NPS and was, thus, applied to each of the 11 mosaic sections of the Parkway imagery (comparison of fig. $7 A$ [nonaveraged] and fig. $7 B$ [averaged]).

\section{Mapping "Irregular" Classes}

In the field-site classifications received from NPS, we grouped 30 of the 331 total field sites into an "irregular occurrence" class. Twelve of the 15 alliances included in this group were observed at one to a few sites along the entire Parkway and were often of limited spatial extent. From a mapping perspective, it was highly unlikely these sites would be identified by using the unsupervised classification strategy. For these isolated and comparatively rarely occurring alliances, we formed a spectral key for each and subsequently used a supervised classification strategy to locate other occurrences of that alliance throughout the Parkway. These targeted, supervised classifications were not successful. No spectral key created for these individual alliances provided a unique signature, which is necessary for successful mapping. The high spectral variability and common features of these alliances on CIR image data prevented determination of unique spectral keys. Although these alliances could not be mapped throughout the Parkway, they were manually classified (visual detection and "heads-up" digitization) wherever the alliance extent could be spectrally discerned at the NPS field sites (table 2). 

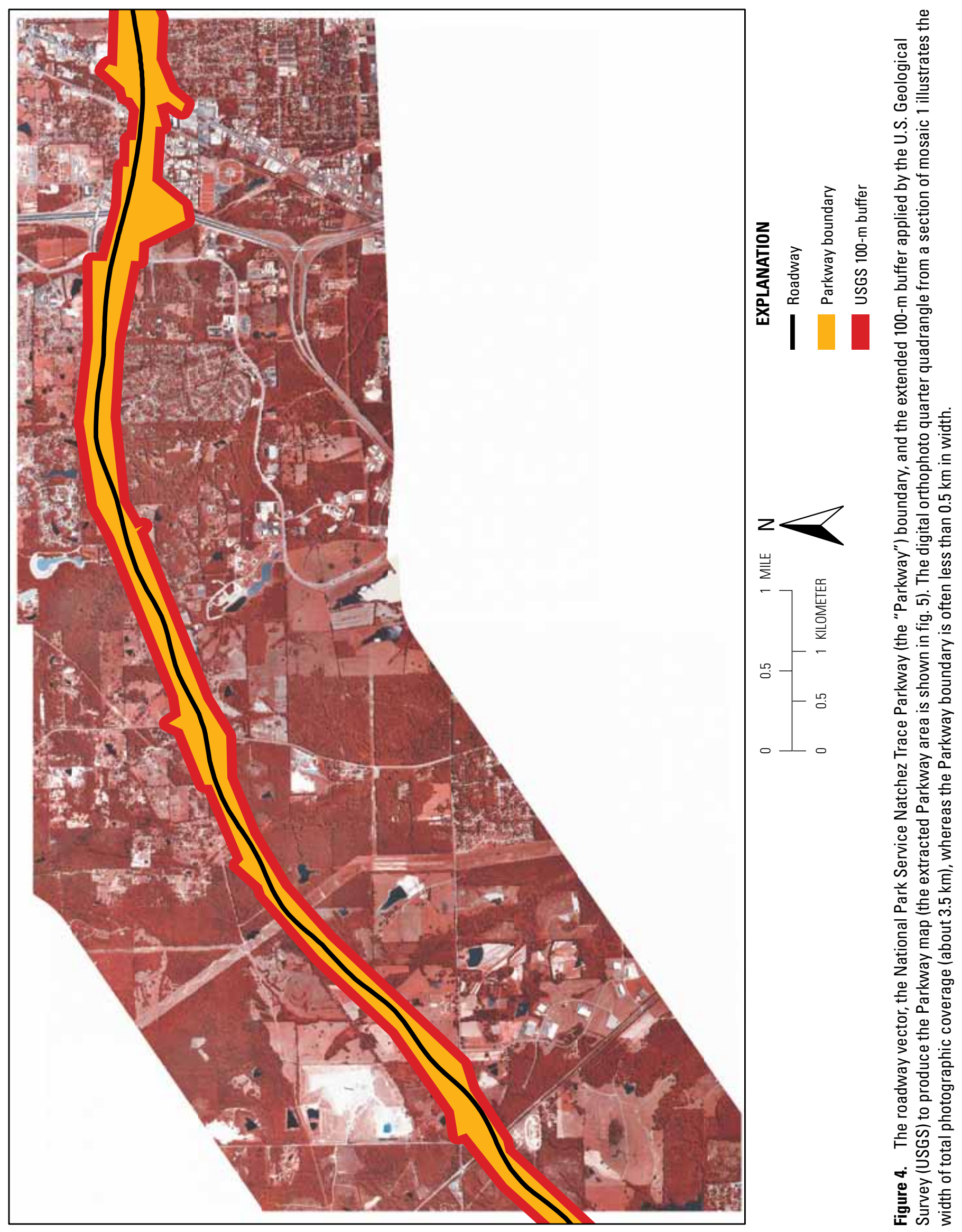


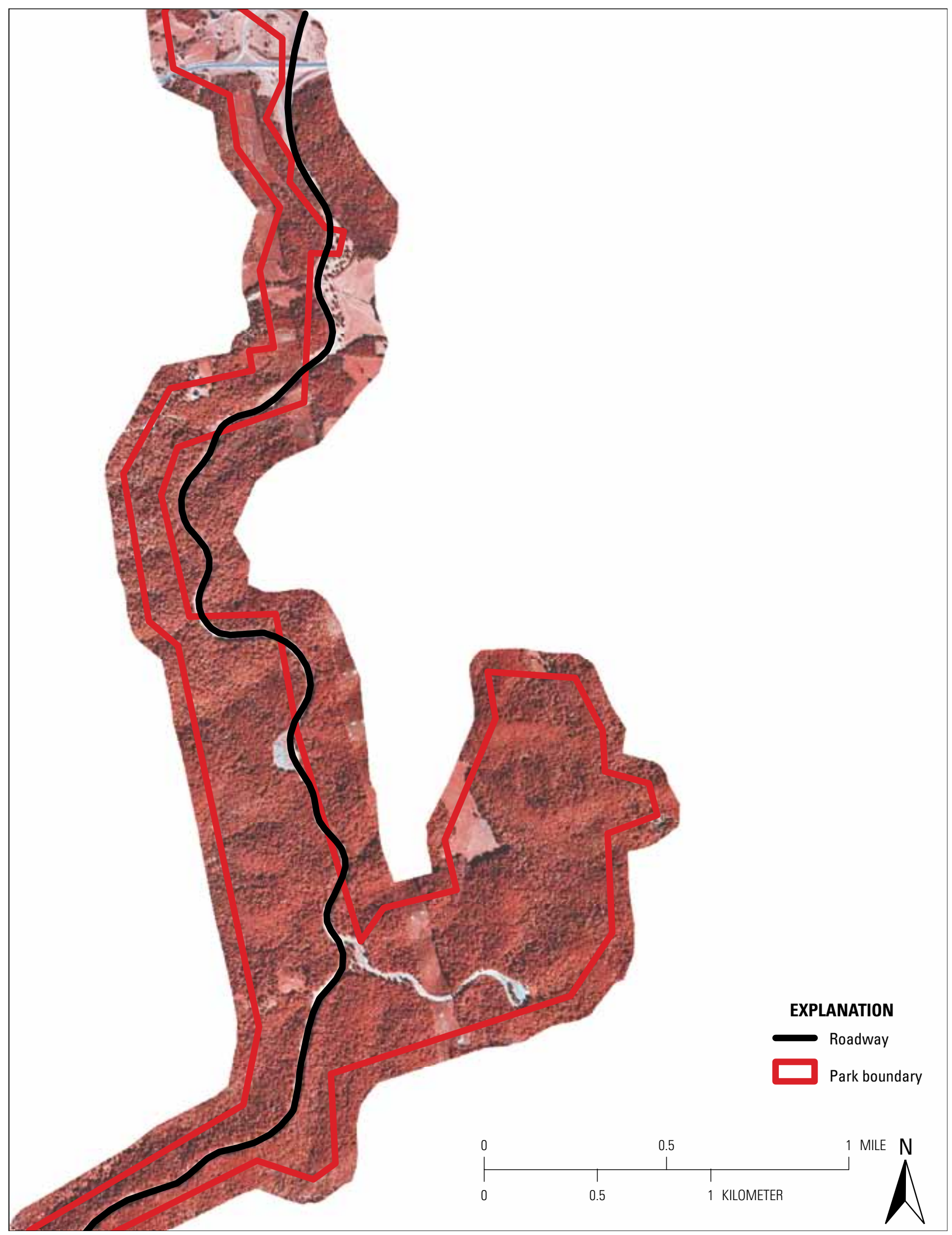

Figure 5. This color infrared (CIR) image illustrates the misalignment between the road vector generated by the U.S. Geological Survey (USGS) and the National Park Service Natchez Trace Parkway boundary. These anomalies were rectified by the $100-\mathrm{m}$ buffer applied by USGS, as shown on the extracted CIR digital orthophoto quarter quadrangle mosaic. 

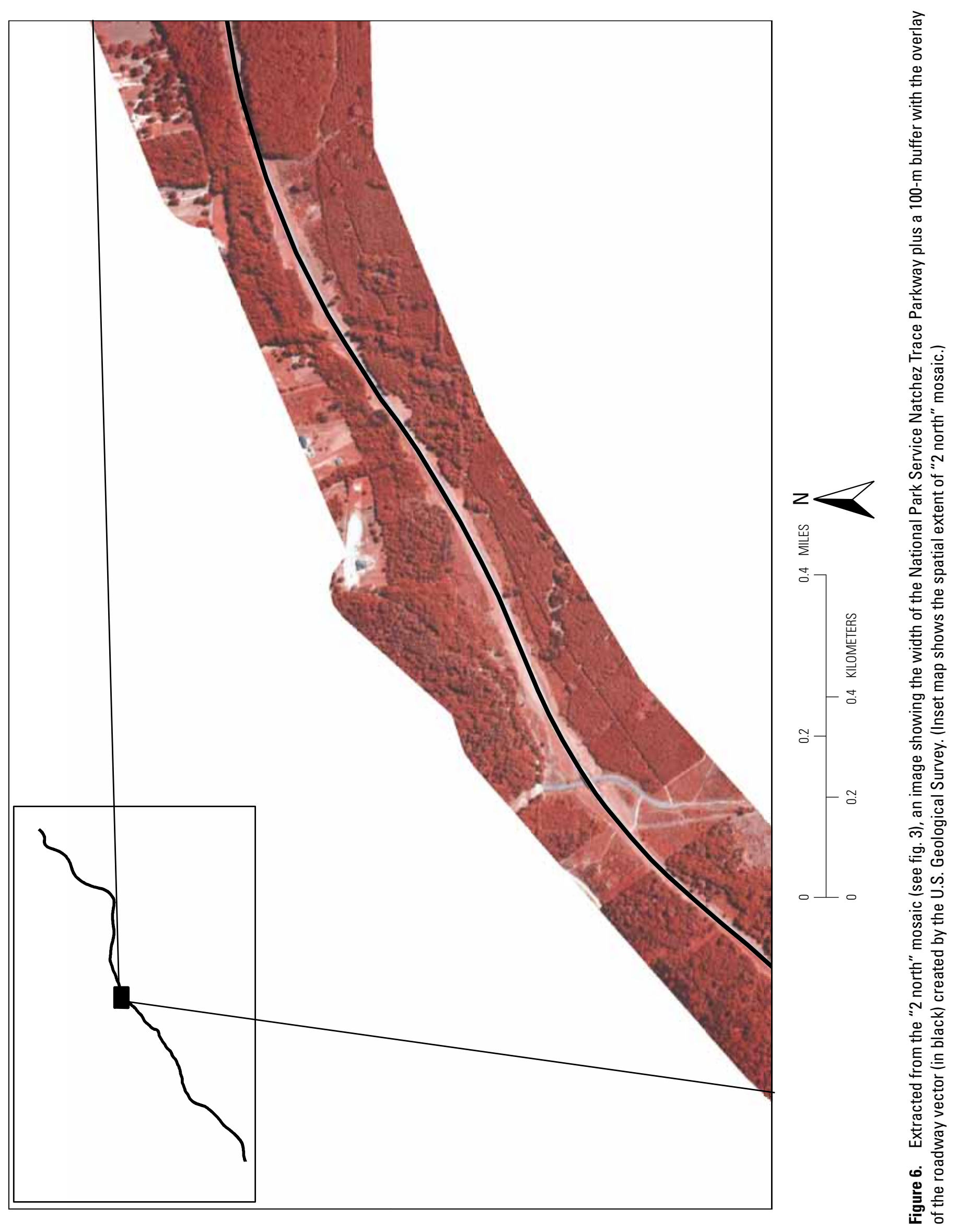


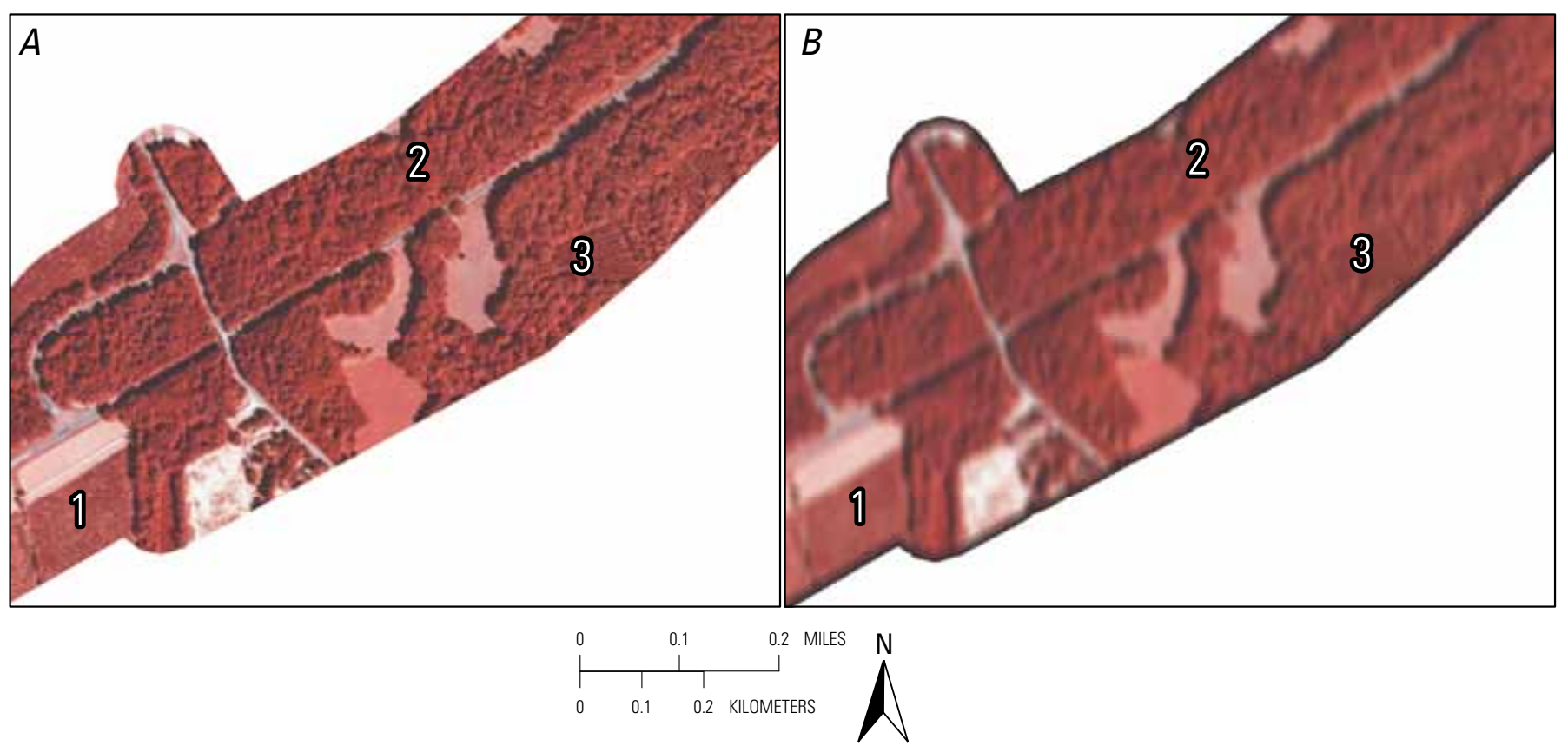

Figure 7. Images of the National Park Service Natchez Trace Parkway plus a 100-m buffer extracted from the section 2 mosaic (see fig. 3). Images include three classes of vegetation cover, including (1) scrub-shrub and shrubland, (2) mature forest, and (3) tree plantation sites. Note the differences in color infrared tone (hue, intensity, and saturation) and texture among the three different vegetation covers. $A$, Image before application of the 11 - by $25-\mathrm{m}$ average filter. $B$, Image after application of the 11 - by $25-\mathrm{m}$ average filter.

Table 2. Initial landcover classification of field sites in the Natchez Trace Parkway that were mapped as "irregular" classes. The initial classification was produced by National Park Service personnel in 2004. Classification codes are from the National Vegetation Classification. Frequency of observations per landcover class is provided.

[NVC, National Vegetation Classification; No., number]

NVC alliance code

A. 214

A. 227

A. 227

A. 232

A. 236

A. 236

A. 278

A. 279

A. 280

A. 284

A. 286

A. 288

A. 288

A.316

A.369
NVC association

No. of field-site observations
Upper East Gulf Calcareous Bluff Forest 1

Beech - Maple Unglaciated Forest $\quad 8$

Southern Mesic Beech - Tuliptree Slopes $\quad 1$

Interior Low Plateau Sugarberry, Northern Hackberry Successional Forest 2

Mid- to Late-Successional Tuliptree - Hardwood Upland Forest (Acid Type) 1

Successional Tuliptree Forest (Circumneutral Type) 2

Box-elder Floodplain Forest $\quad 2$

Silver Maple-Sugarberry-Pecan Floodplain Forest $\quad 1$

River Birch Levee Forest $\quad 2$

East Gulf Coastal Plain Beech Floodplain Forest $\quad 2$

Southern Green Ash - Elm - Sugarberry Forest 3

Gulf Coastal Plain Sycamore - Sweetgum Floodplain Forest 2

Sycamore - Silver Maple Calcareous Floodplain Forest 1

Red Maple - Green Ash Seasonally Flooded Swamp 1

East Gulf Coastal Plain Calcareous Bluff Beech - Magnolia Forest $\quad 1$ 


\section{Mapping Kudzu (Pueraria) Vine}

The one kudzu (Pueraria) site identified by NPS in the southern Parkway was located under edge shadows in the CIR photography. The occurrence of only a single kudzu site and the associated shadows prevented the ability to create a kudzu spectral key from the CIR photographic data.

In 2009, NPS requested USGS to provide as much information as possible concerning the distribution of kudzu in the Parkway. Even though we could not map kudzu in the Parkway based on a single occurrence, we used experience gained in mapping the various forms of kudzu in Vicksburg Military Park (unpublished data) to manually map likely occurrences in the Parkway. The visual detection was based solely on recognized hue and texture patterns on the CIR photography that suggested the occurrence of kudzu.

During mapping of kudzu in the Vicksburg National Military Park (unpublished data), USGS scientists found that kudzu was visible in a variety of hues and spectral textures on the CIR photography. The various spectral textural differences were associated broadly with two landcover subclasses of kudzu. The first subclass was associated with lush, greenvine ground covers (fig. $8 A, C$ ). A second subclass was often located adjacent to the ground kudzu but occurred as a high-to-moderate cover of scattered canopy trees, shrubs, and ground cover. By the time of kudzu mapping in the military park, much of the kudzu had been treated with herbicides as part of an invasive species eradication campaign (figs. 8A, C). Depending on the elapsed time since herbicide treatment and the collection of CIR photography, kudzu in the Vicksburg National Military Park (unpublished data) exhibited a range of CIR hues from bright red (healthy) to slightly brown to gray. Also based on field reconnaissance in the military park, USGS scientists found that although grapevines were visually distinguishable from kudzu vines, the two canopy-type vines were not distinguishable in the CIR photography.

Transference of knowledge learned from mapping kudzu in the Vicksburg National Military Park (unpublished data) allowed qualitative mapping of occurrences in the Parkway. Because of the lack of kudzu field sites and the highly variable spectral character of kudzu, mapping was accomplished by manual classification (example shown in fig. $8 B, D$ ). Accuracy assessment of the manual mapping of kudzu could not be performed because of the lack of kudzu field sites visited by NPS personnel.

\section{Field-based Reconnaissance and Mapping Classification}

In September 2004, USGS scientists accompanied by NPS personnel visited 30 field sites within the Parkway. The purpose of having USGS scientists accompany NPS personnel was to document environmental features important to the image-based mapping classification that may have been missed by NPS personnel unfamiliar with image processing.
The number of field-site observations per alliance initially received by USGS scientists in 2004 (table 3) was less than that requested. Of the 83 field sites located along the entire Parkway, the maximum number of field-site observations for any given alliance or association was 12 , representing the white oak (Quercus alba) alliance. Twelve alliances represented by 14 total field-site observations were associated with the herbaceous class, and 3 alliances of the shrubland physiognomic class were represented by 4 total field-site observations. Of the other 19 forest alliances, most were supported by 1 or 2 field-site observations, except for 2 alliances that were observed at 7 and 9 sites, respectively, and 4 alliances that were observed at 4 or 5 sites. The number of field-site observations per alliance was far less than statistically required (for instance with a Chi Square criteria) (for example, Grenier and others, 2008).

\section{Formation of Spectrally Distinct Mapping Classes}

The number and types of field sites for which USGS scientists received data from NPS in 2004 were not sufficient to generate spectral attributes (spectral key based on the class means and variance) for the landcover classes of interest in order to apply a supervised classification strategy. To overcome the lack of sufficient field-site observations, an unsupervised classification strategy was initially applied. Inputs into the unsupervised method were the three green, red, and near-infrared image planes making up mosaic sections created by mosaicing individual DOQQ frames.

In unsupervised classification, we used a minimum spectral distance formula to form clusters that were subsequently assigned class memberships. The algorithm began with arbitrary spectral means. For each iteration, the cluster centroid position was recalculated to reflect changes in the cluster-class memberships. The new cluster means were then applied in the subsequent iteration. Iteration continued until either the maximum iteration number defined by the user was reached or a maximum percentage of unchanged pixels remained below a user-specified threshold between two sequential iterations.

The unsupervised mapping algorithm was applied separately to each of the 11 mosaics (see fig. 3 for mosaic graphics). The unsupervised classifications included 100 initial arbitrary clusters. By using image analysis software, the classified image was visually compared with the original CIR image. On the basis of communality in spectral color, tone, and texture the 100 clusters were merged into 10 to 12 clusters and each merged cluster assigned a class value based on its physical association with a NVC class from the 2004 NPS landcover classification. Examples of the initial unsupervised classification produced in anticipation of the field reconnaissance during September 20-25, 2005, are shown in figures $9 A$ and $10 C, D$. 

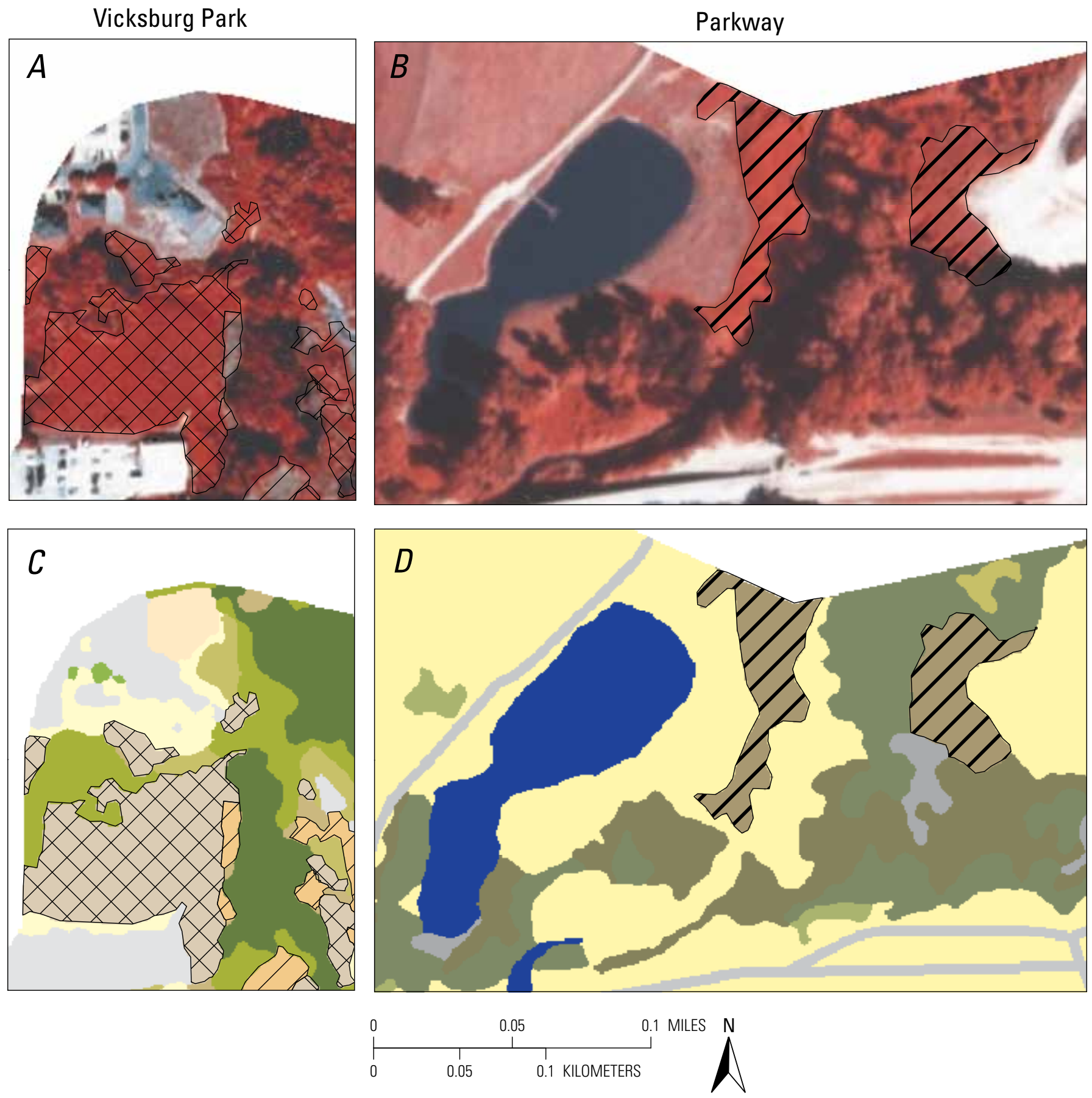

\section{EXPLANATION}

$\square$ Herbicide-treated kudzu

$\triangle$ Spectrally detected kudzu

$\square$ Manually classified kudzu

Figure 8. Variations of kudzu vine shrubland. $A, C$, Examples from the Vicksburg National Military Park ("Vicksburg Park"; unpublished data). $B, D$, Examples from the Natchez Trace Parkway (the "Parkway"). Kudzu vine was distinctly visible by its tone and texture on the color-infrared images (parts $A$ and $B$ ), and parts $C$ and $D$ show the vegetation as mapped by U.S. Geological Survey scientists. Both examples show "ground" kudzu vine. Also shown in part $C$ (example from the Vicksburg Park) is a small area of herbicide-treated kudzu. 
Table 3. Initial landcover classification of field sites in the Natchez Trace Parkway by National Park Service personnel in 2004. Classification codes are from the National Vegetation Classification. Frequency of observations per landcover class is provided.

[NVC, National Vegetation Classification; No., number]

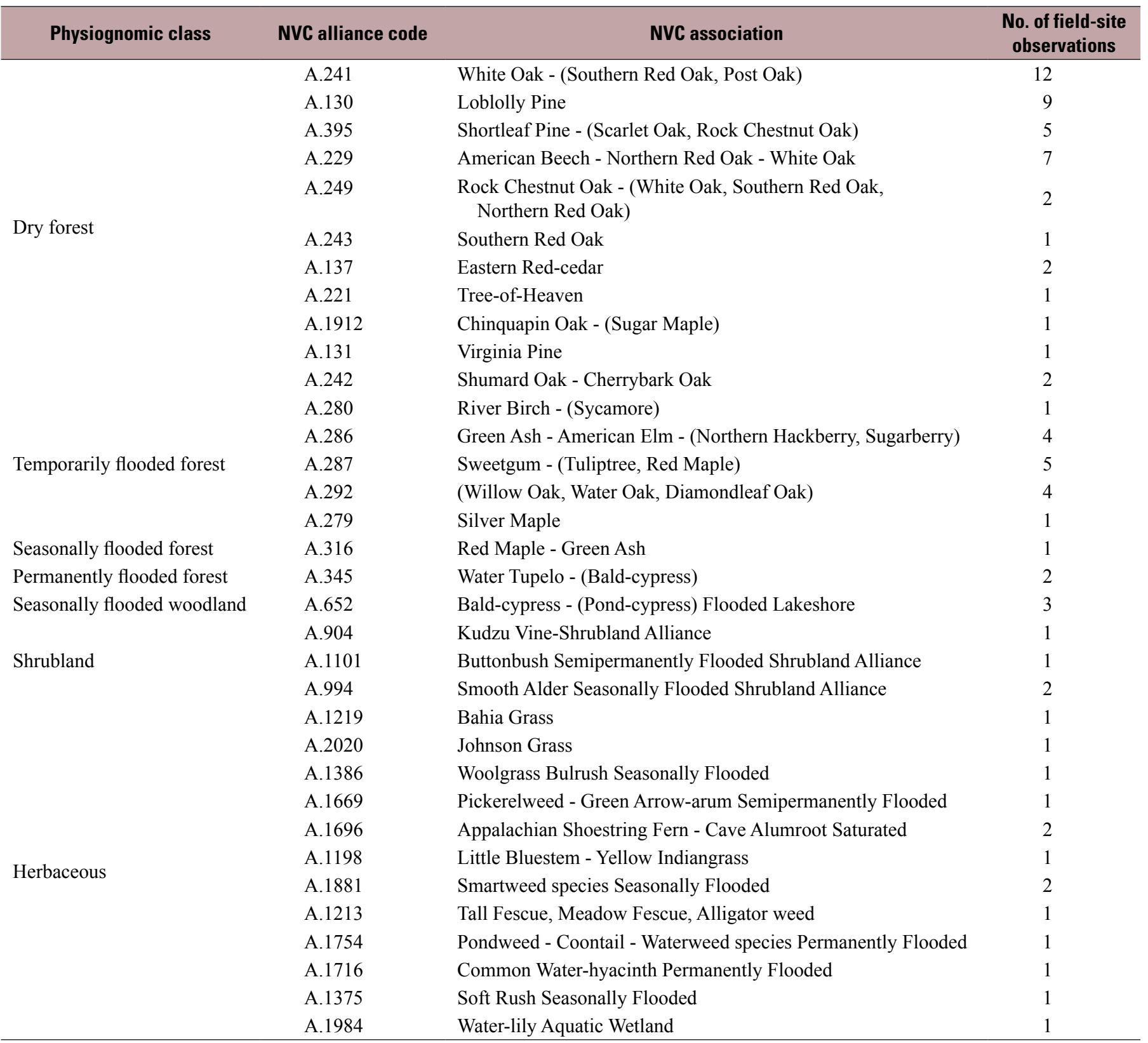



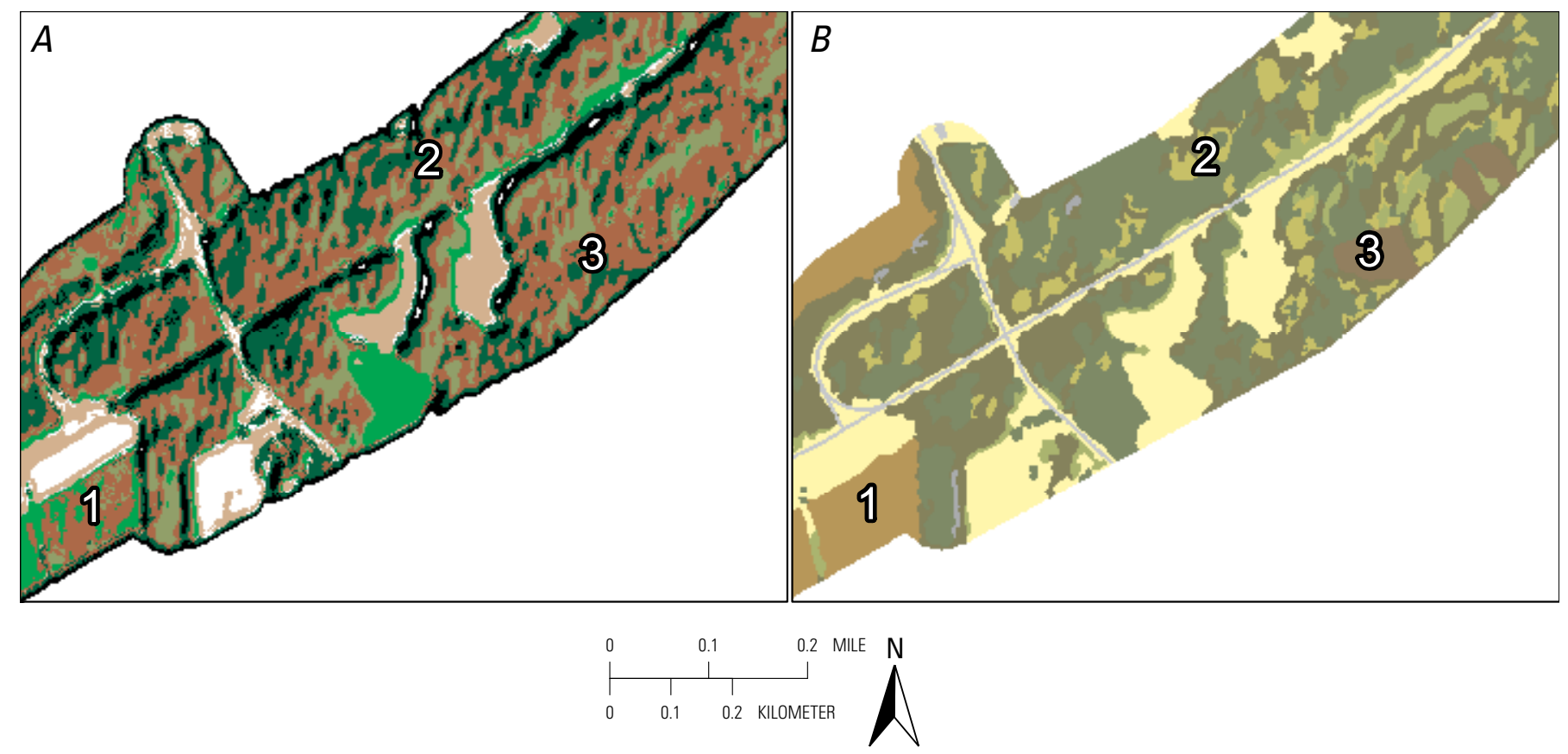

Figure 9. Mapped landcover corresponding to the color-infrared image shown in figure 7. $A$, The initial unsupervised classification wherein scrub-shrub, shrubland (area A1), some mature forest stands (area A2), and plantations (area A3) were being represented by the same spectral signature. $B$, The final mapped classification of the area after applying different image processing techniques as discussed in the "Final Mapping Classification" section of the current report (areas B1-3 correspond to areas A1-3 in part A).

In the initial unsupervised classifications, it became apparent that the mapping classification of each mosaic was dependent to some extent on the interpretation of the analyst. In other words, consistency among analysts from mosaic to mosaic was not assured. At times, this variability resulted in inconsistent class mapping across mosaics. To diminish analyst-dependent variability and help maintain classification consistency, we applied the migration of signatures procedure (class centroid migration) from one mosaic to the next. The classes delineated in one mosaic were used as the cluster seeds (or a priori knowledge) for mapping of the next mosaic. At this point, the mapping became a supervised classification. Migration of cluster means from one mosaic to an adjacent mosaic relied on a majority of the landcover classes remaining spectrally similar from mosaic to adjacent mosaic. Minor spectral changes among the same landcover classes could exist, however, and a small number of new classes could appear in a newly classified mosaic. In the latter case, any signature that was not spectrally close to spectral classes of any of the previous mosaics was assigned to a new class. Before implementation of the migration of the means, testing indicated that the technique produced reasonable results.

\section{Second NPS Field Classification}

During September 22-30, 2005, a second field trip was conducted to add additional field-site observations for the initial NPS landcover classification of the Parkway. The USGS team accompanied classification representatives on one of the three NPS teams.

\section{NPS Field-Site Sampling Strategy}

At the request of USGS, the number of field sites was increased in a coordinated USGS and NPS field exercise that occurred about 1 year after the CIR image data collection. In this second USGS-NPS coordinated field trip during September 22-30, 2005, the 20- by 50-m plot size that was used in the first field classification was changed. These new "quick plots" were limited to a boundary defined by an $11.3-\mathrm{m}$ radius $\left(400 \mathrm{~m}^{2}\right)$, and the minimum separation distance among the field plots was set at $50 \mathrm{~m}$. This change in plot size created a discrepancy with the image classification method already established by USGS scientists, which was generated 

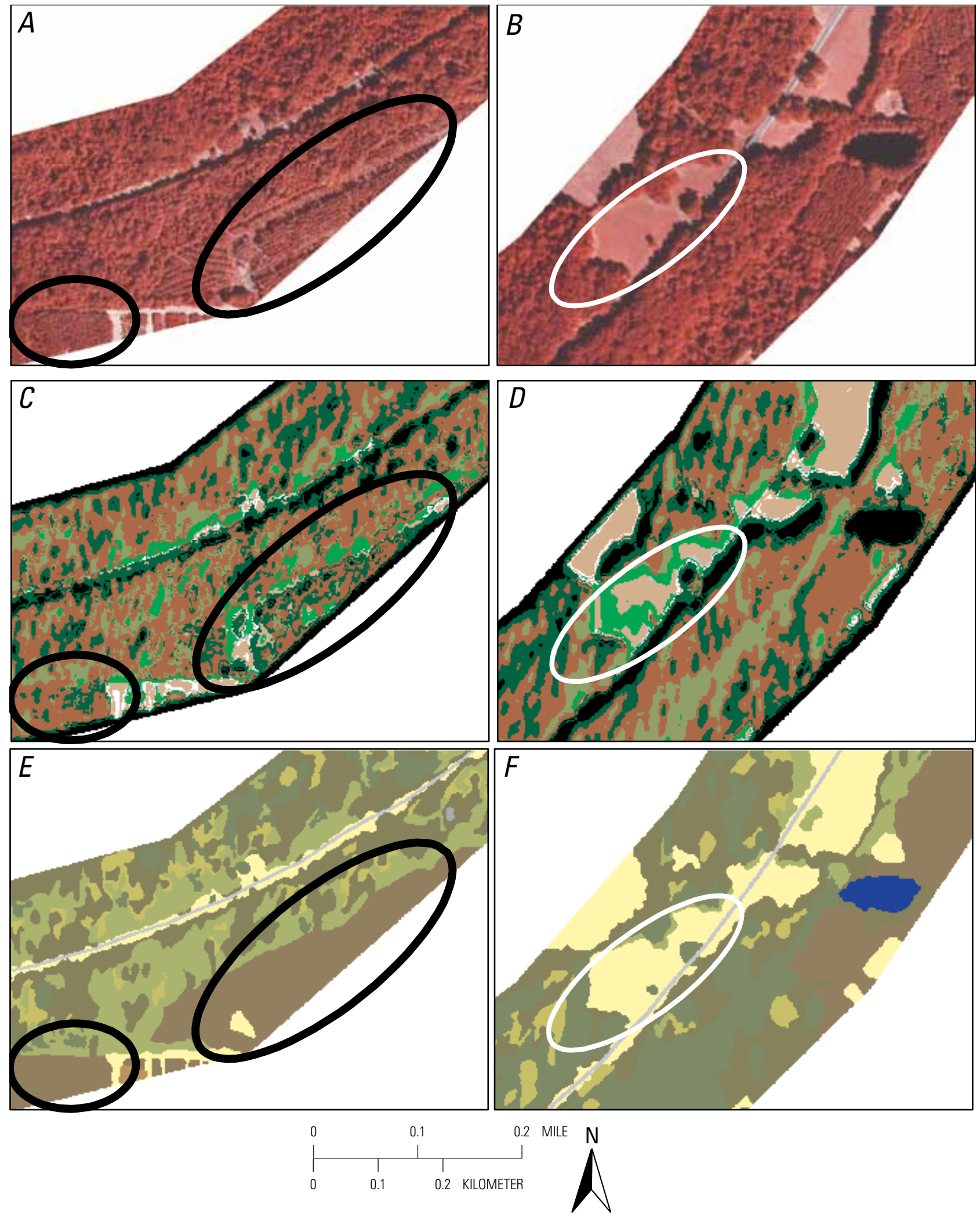

Figure 10. Process for classifying color-infrared (CIR) digital orthophoto quarter quandrangles (D000s) of different areas in the "2 south" mosaic (see fig. 3). $A, B$, Source D000s. $C, D$, The initial unsupervised classification wherein confusion exists between forests and planted forests (shown within black ovals in parts $A, C$, and $E$ ) and between grasslands and edge trees (depicted within white ovals in parts $B, D$, and $F$. $E$, $F$, Final landcover maps created after applying a number of image processing and geographic information system $(G I S)$ techniques and manually mapping the planted forests. 
to best reproduce the initial 20- by 50-m plot dimension. Although decreasing the plot size for expediency did decrease the amount of time spent per plot, it also spatially limited plot sampling, thus limiting information concerning the spatial extensiveness of any given landcover class identified within the circle or surrounding the circle. Where spatially extensive, homogeneous compositions existed, the quick-plot sampling method was appropriate; however, where more heterogeneous patterns existed, this sampling method did not sufficiently indicate landcover composition outside the spatially restricted observations. This lack of information was pertinent to assessing mapping accuracy.

\section{Field-Site Selection for the Second NPS Landcover Classification}

For the 2005 NPS-field reconnaissance, about 60 field sites (located by UTM coordinates) exhibiting sets of unique CIR hues and spatial textures were selected by USGS scientists from areas within each of the 11 mosaics (mosaics 1 to 11 , fig. 3) as candidates of ground-based landcover classification by NPS personnel. In mosaics 1 to 5 , a minimum of five or six field-site locations were selected from each of the 11 to 12 spectral classes delineated in the initial USGS mapping effort (table 3). Field sites selected from mosaics 6 and 7 were based on the nonclassified CIR photography. The UTM coordinates for all selected field sites were transferred to NPS teams for field-site landcover classifications, and then NPS teams selected the field sites that were visited. Most USGS field sites were not visited by NPS classification specialists and therefore were not used in the USGS mapping of the Parkway; however, numerous USGS selected field sites used and classified by NPS classification specialists were discovered to contain landcover alliances (as defined in the NVC) that had not been identified in the previous 2004 field reconnaissance.

During the second field reconnaissance, the number of field sites was increased by 263 , and 27 new NVC alliances were added to the 2004 catalogue. Out of the total 346 field sites, 6 had no classified NVC alliances or associations, 7 were outside the Parkway boundary, and the coordinates of 2 forest sites were mislocated in the roadway. These 15 sites were not included in the final mapping effort. In total, the final landcover classification reference sites included 61 alliances across 331 field sites. Although increased field landcover classifications were advantageous, the alliances were still significantly under-represented by field landcover classification data. Even excluding the "irregular" class (discussed in the "Mapping 'Irregular' Classes" section), only one NVC alliance was represented by an adequate number of field-site observations.

\section{Mapping Limitations}

\section{Composition Gradients}

A source of confusion concerning the mapping classification was related to assigning distinct class values along a continuum of spatial-vegetation gradient. This confusion occurred where one landcover class (for example, an alliance comprising a variable mixture of vegetation types) grades into another class over some distance. The necessity to assign each pixel along the gradient to a single class creates an unwanted but unavoidable level of classification confusion within the gradient (fig. 11). This problem is further complicated when compositions defining a class vary, as well as when many compositions of vegetation are shared among differently assigned classes.

\section{Varying Class Compositions}

Where landcover classes are spatially variable, as observed in the Parkway, spatial-vegetation continuums and mixed-variable compositions increase spectral confusion and tend to lower the expected mapping detail (number of identifiable landcover classes) and lower the mapping accuracy per class. In the case of mixed-variable compositions, increased field-site observations per landcover class increase the ability to determine whether or not assigned classes can be spectrally separated with the photographic data. For example, field sites classified in the white oak alliance were dominated by white oak at some percentage level; however, a variety of species co-occurred with white oak, including hickory (Carya sp.), southern red oak (Quercus falcata), tuliptree (Liriodendron tulipifera), water oak (Quercus nigra), and diamond leaf oak (Quercus laurifolia). One field site containing white oak might also include northern red oak and hickory, whereas another might only include water oak as the co-occurring species. Conversely, alliances dominated by other tree species could include white oak and other co-occurring species; for example, a pine alliance that included white oak, southern red oak, post oak, and oak. In figure 12, six different white oak alliance field landcover classification sites are shown as they appear on the CIR photography including four that are the same alliance and same association but exhibit highly different spectral hues and tones.

In addition to variable compositions within classes, the percent occurrences and dominant substory species could vary within an alliance. Where substory species are detected within the photographic response, they would influence the photographic hue (color), intensity, and saturation (color purity) and thereby would influence the mapping classification. 


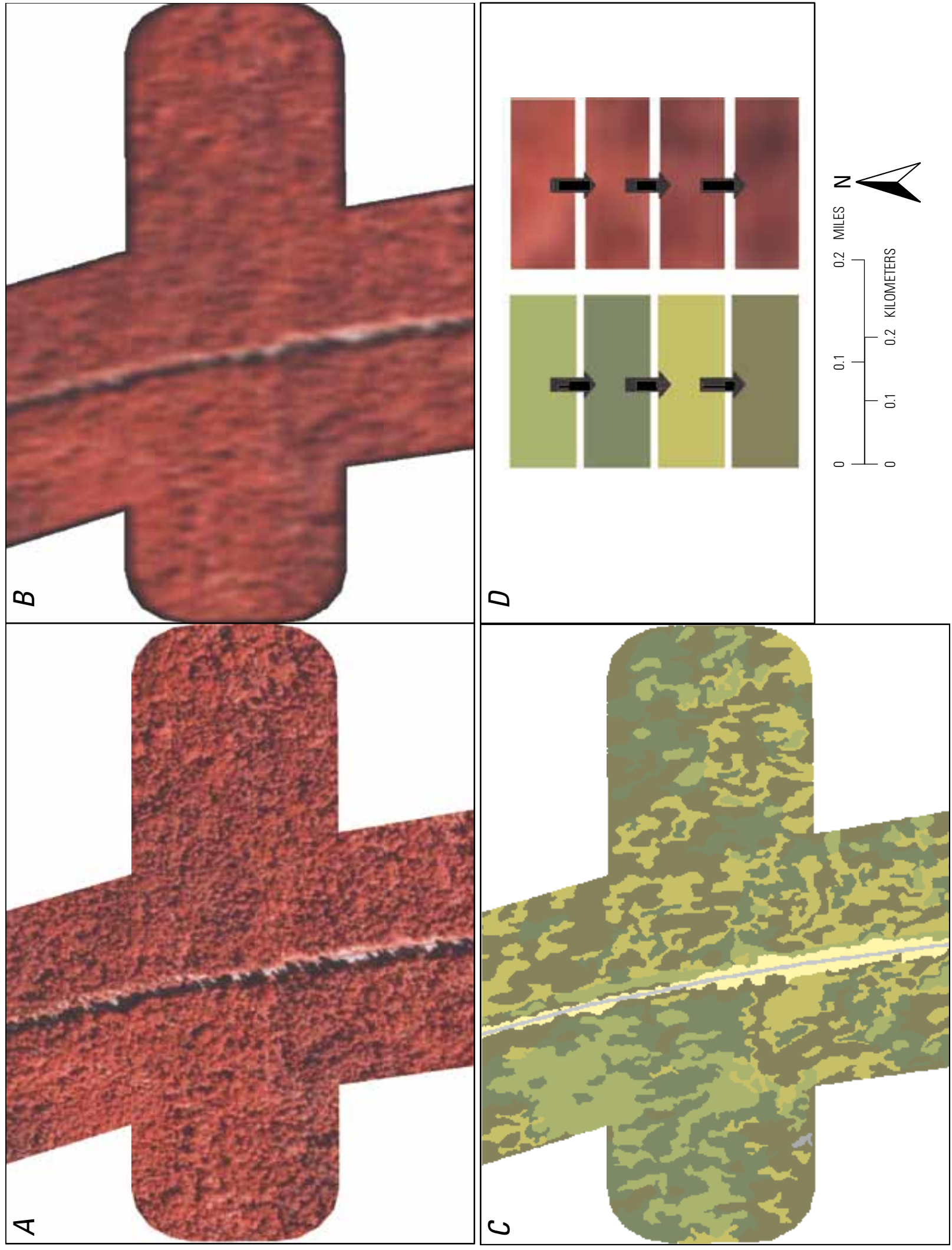

$+\stackrel{0}{*}$

$\stackrel{0}{ \pm}$

흥추을

\%

흘

뜬

๘.

금

ষᄒ

券

듬흠

훙

등. 잉 응

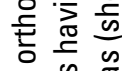

ㅍ.

흫 응 히



능 은

递

密 혼

产

흥 홍

它

$\leftarrow \overline{0}$

诺

崖

可

중 0 잉

당

远京

is

文产.

Ф્ّ

.으므.

홍

s 응 흥

昲部

心

.

总要

0 웡

들

要志

ब्ञ

要贾

要 की

的政

的

表夜

i 용

응

产

这.

: $\stackrel{\text { : }}{\mathrm{E}}$

잉

言至吉 

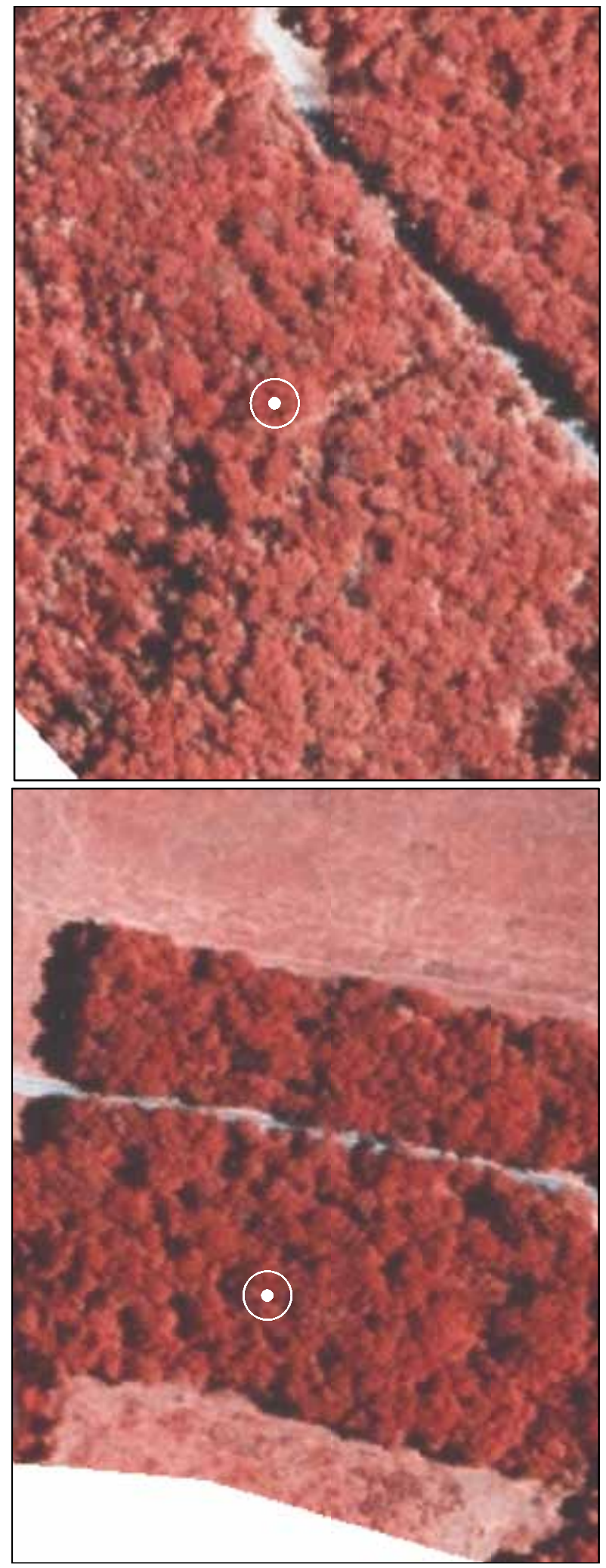

$\checkmark$
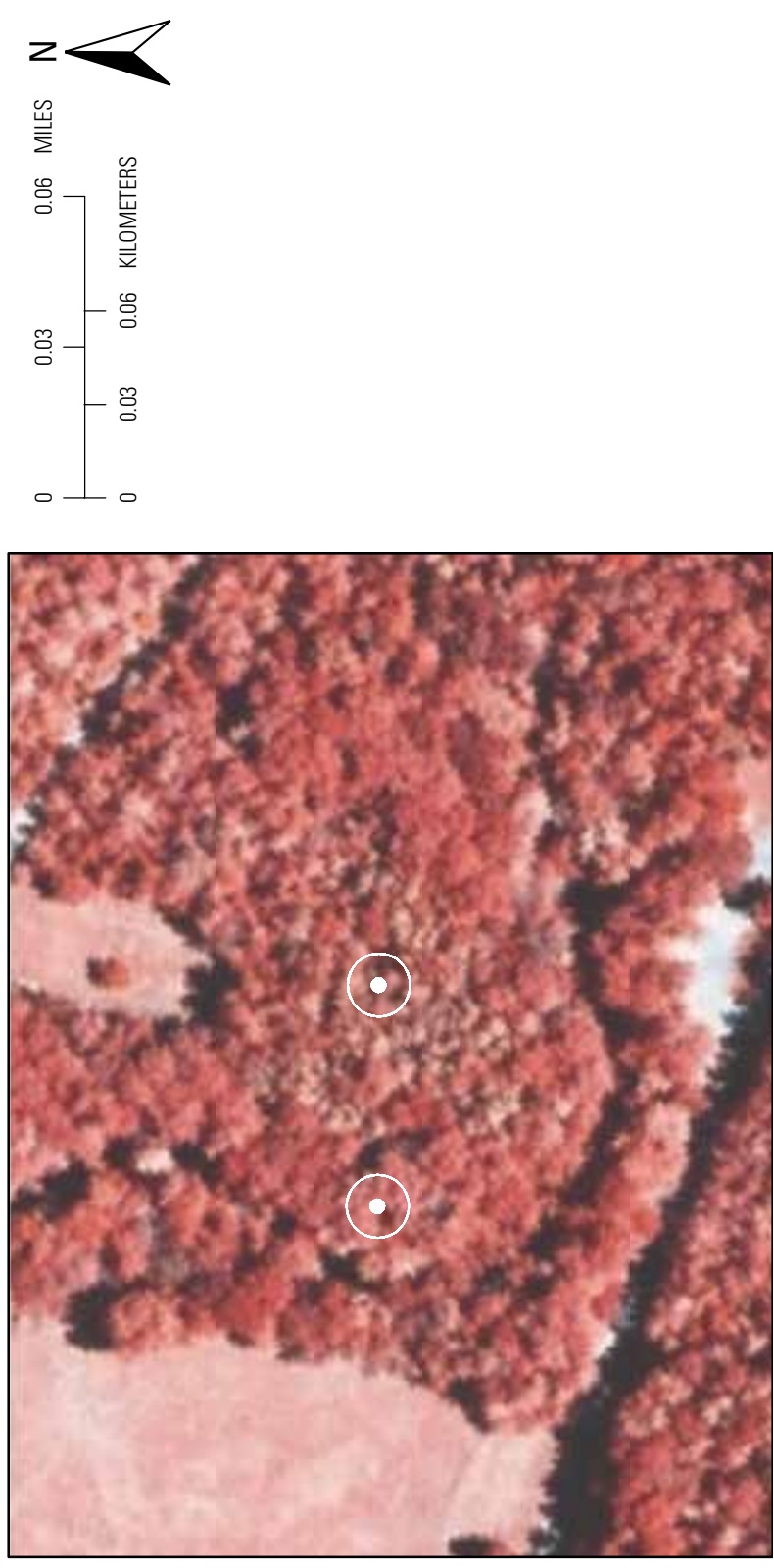

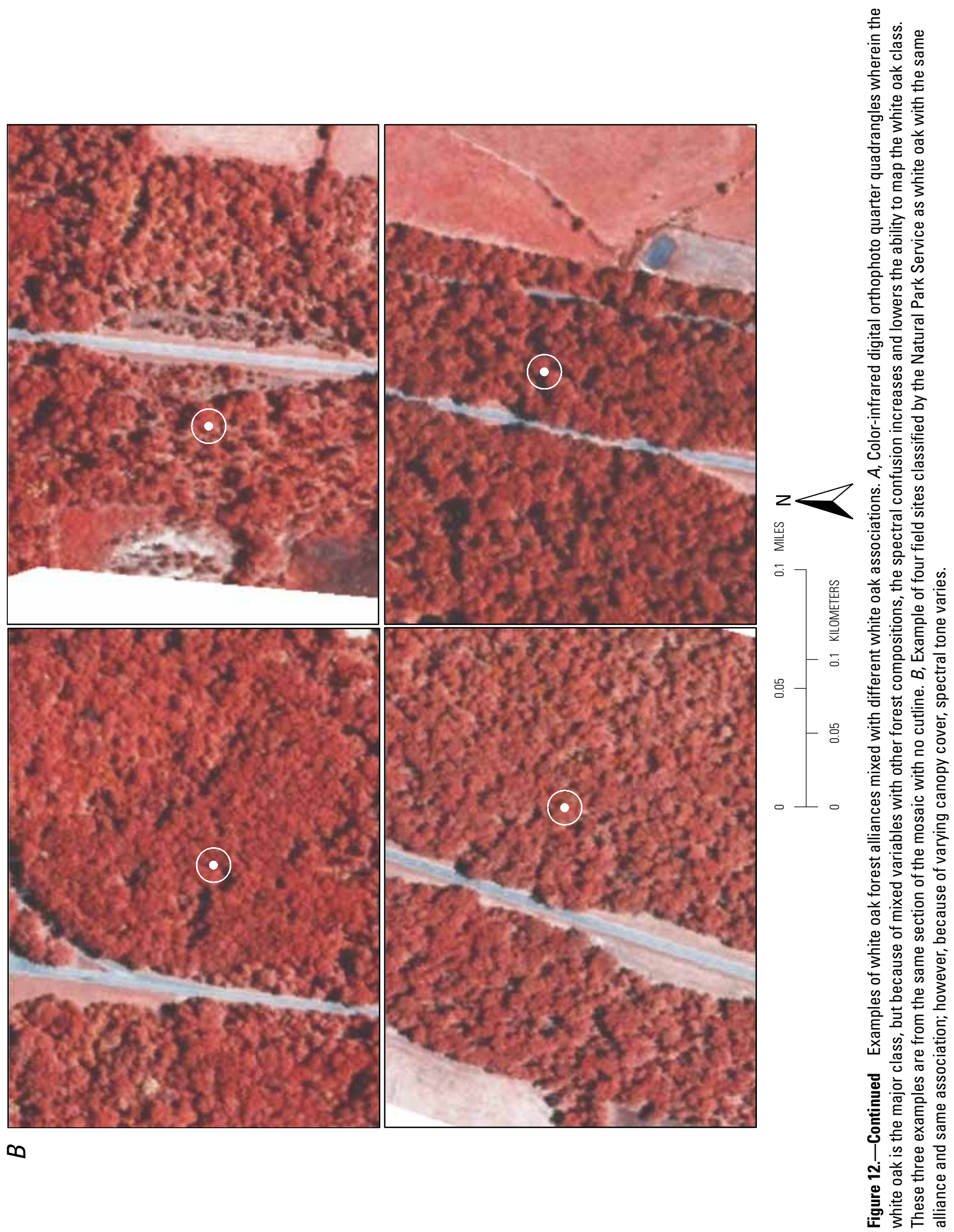
In the case of the spatial-vegetation continuums, postprocessing procedures were used to minimize many ribbon type features in the mapping classification that resulted from a discrete classifier (one class per pixel) placed on a spatial continuum. Although minimized, these features were not totally eliminated from the mapping classification.

\section{Spatial Filtering and Mapping Classification}

Application of the spatial filter (discussed in the "A CIR Rendition Appropriate for Mapping Forest Stands" section) conformed to the 20 - by $50-\mathrm{m}$ field landcover classification sites while minimizing unwanted canopy variability (irregularly illuminated tree crowns and canopy gaps and associated shadowing) and maximizing forest-stand identification. The drawback was the loss of spectral detail and blurring of edges resulting in loss of definition of individual trees (for example, fig. 13). The image smoothing at onequarter of the field site extent provided a spatially enhanced forest mapping classification and accounted for and minimized canopy variability and maximized canopy-stand texture within a landcover class.

\section{Canopy Structure}

An often overlooked variance in mapping classification is associated with canopy structure. The greatest influences on photographic classifications (manual and image processing) are crown type and canopy closure or openness. At times, canopy structure can help identify different species compositions. At other times, canopy structure variability masks spectral differences that define two or more alliances, thus increasing misclassifications among alliances. Smoothing filters and contextual filters (texture) were used to help alleviate some canopy-structure variability while enhancing selected canopy structure patterns to improve mapping classification performance (fig. 14).

\section{Final Mapping Classification}

In the final mapping strategy, the first expectation was that the initial USGS mapping effort had identified all the major spectral classes in the Parkway. The second expectation was that unsupervised mapping would not produce an acceptable classification because of (1) the ubiquitous edge and gap shadows in the DOQQ image data and (2) other noted complexities, such as site-location error, limited site extent, and mosaiced DOQQ cutlines (changing spectral renditions of the landscape), (3) varying compositions and varying canopy structures within the alliances (and thus the lack of a consistent spectral key) (figs. 12 and 15), and (4) inadequate number of field-site classifications per NVC alliance throughout the Parkway.

To determine spectral distinctiveness in the combined 2004 and 2005 landcover classification, the initial mapping based on the 2004 classification had to be refined. The final mapping of the entire Parkway per the NPS landcover classification included the following steps:

- The isolation and replacement of edge shadows (primarily along the roadway) and gap shadows (under a selected size) in forest areas,

- The detection and isolation of cutlines in the DOQQ mosaic in preparation for segmentation of mapping from cutline to cutline,

- Determination and formation of spectrally distinct classes, including the reiteration and refinement of class mapping in cases where there was significant confusion within one or more classes,

- Postclassification procedures that were carried out to minimize ribbons and maximize contiguous spatial coverages of the mapped classes, and

- An assessment of mapping accuracy.

\section{Removal and Replacement of Edge and Gap Shadows}

Canopy shadows are a considerable hindrance to producing accurate mapping classifications. Some problems were eliminated with the averaging filters. In these cases, the shadows were considered part of the forest structure and included in the progressive classification. In the case of extensive edge shadows and shadows within the forest associated with large canopy gaps, the shadows had to be classified independent from the progressive classification.

For the most part, edge shadows were limited to the area adjacent to the Parkway; however, edge shadows also occurred at any abrupt changes in vegetation. Multiple combinations of image processing techniques were applied to isolate the edge shadows. These combinations primarily included spectral texture and hue combinations, adjacency (to a roadway or forest cut for instance), and in some cases, spectral thresholds. Once edge shadows were isolated, replacement of the shadowed area by an appropriate landcover class was undertaken. Replacement again involved multiple image processing techniques. Many replacements combined some intelligence through GIS applications, for instance the distance to known features and class adjacency and distance, to decide which class would be used to replace the shadowed area. Consistency of the assigned landcover class with the surrounding vegetation was verified by visual comparison to the CIR photography.

The image processing steps taken to isolate the edge shadows also included forest gaps by their associated shadows. As stated previously, the average filter had integrated many forest canopy gaps into the mapping classification; however, in some cases the integration of the forest gaps reduced mapping effectiveness. In these cases, 


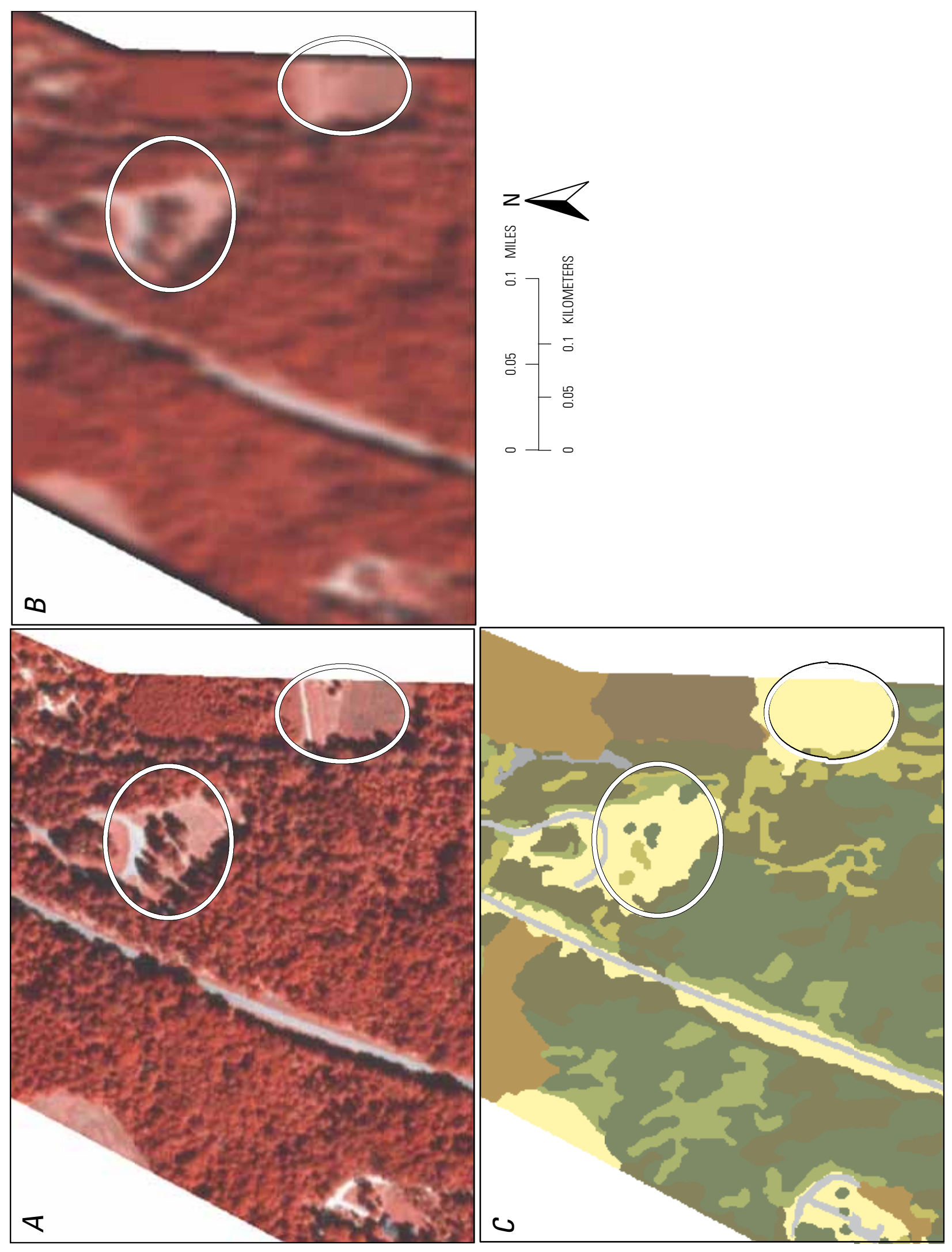

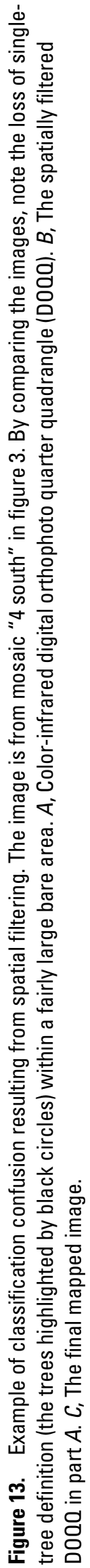




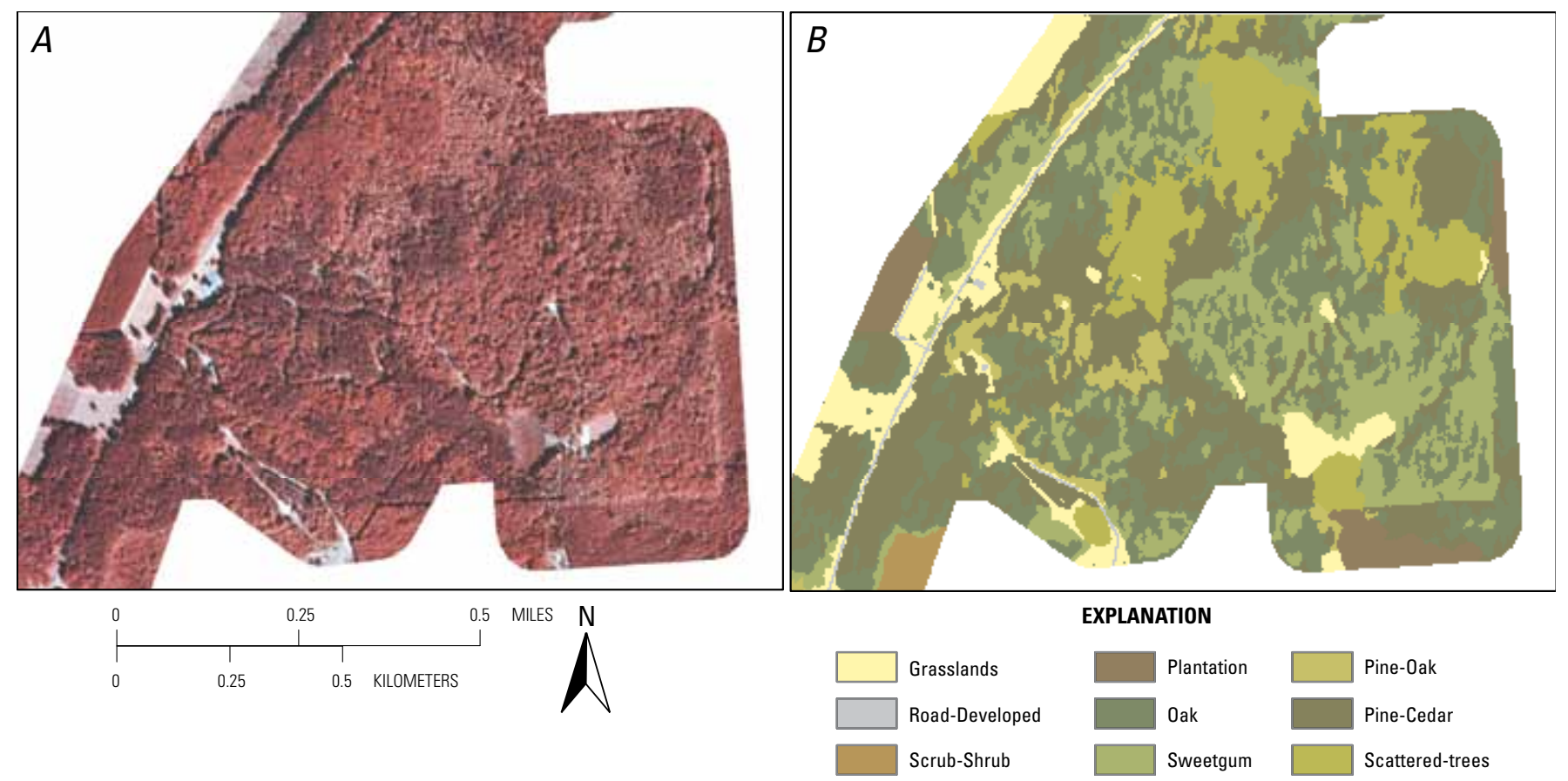

Figure 14. An example of forest types featuring different crown sizes and percentages of canopy closure. $A$, Color-infrared digital orthophoto quarter quandrangle (D000). $B$, Mapped area after applying smoothing and contextual filters to the D000.
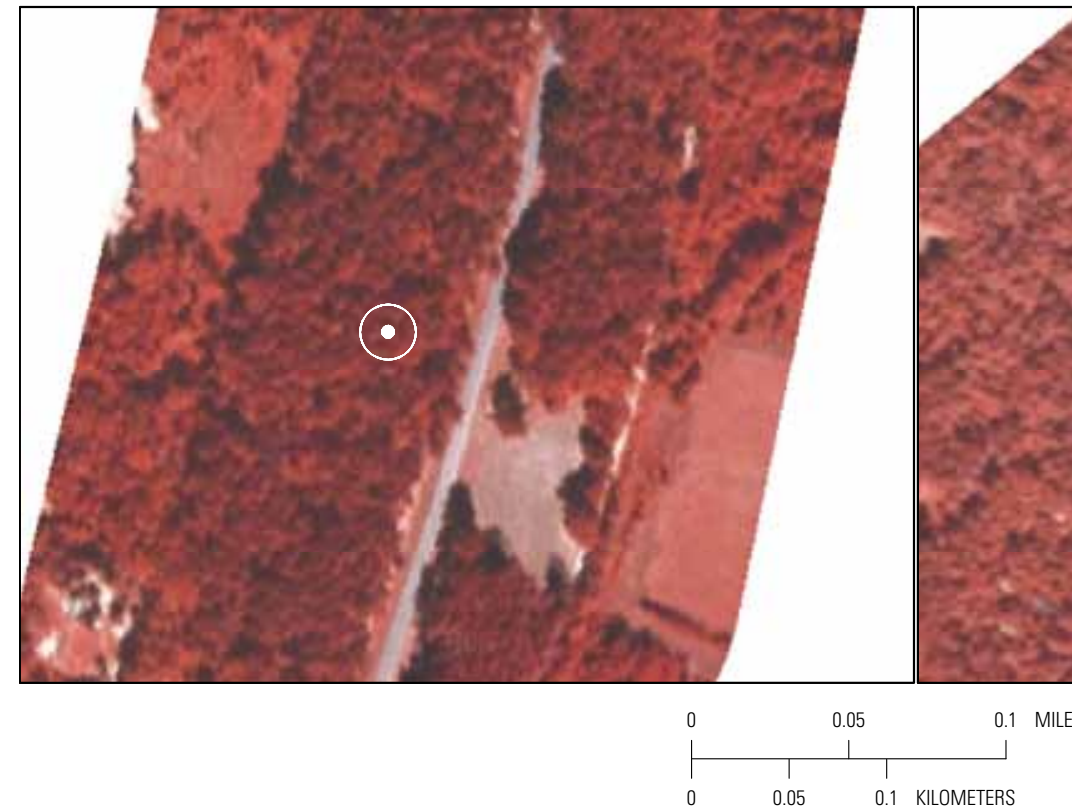

Figure 15. An example of field sites where landcover was classified by National Park Service personnel. The data points are located in an area of mosaic "3 south" (see fig. 3) and both correspond to pine-oak forest (as defined in the National Vegetation Classification). In this case, both sites are classified within the same alliance and association. The variation of spectral tone is very distinct. No cutline occurs between these two examples. 
gaps were removed and separately reintegrated into mapped forest classes. The integration was performed by using GIS functions to effectively partition the gap into the surrounding forest classes. Correctness of the gap reassignment into a landcover class was ascertained by visual examination, and the results were incorporated within the overall class accuracy assessment with respect to class continuity and field assessments (fig. 16). In addition, even though smaller gaps could be considered integral components of the forest class structure, gaps of considerable spatial extent in the forest landscapes may provide an important function that is important for forest management. For that purpose, forest gaps of less than or equal to $200 \mathrm{~m}^{2}$ were integrated into the surrounding forest classes during one of the postmapping GIS procedures while larger gaps were retained.

\section{Detection and Isolation of the Mosaiced D000 Cutlines}

Orthophoto cutlines are a direct impediment to producing continuous and consistent classes extending throughout the spatially extensive Parkway. As discussed, the mapping procedure of using the migration of spectral means allowed for the incorporation of changes in landcover class dominance throughout the southern to northern extent of the Parkway. This mapping technique is appropriate and advantageous when spectral consistency is maintained or changes progressively or when there are a limited number of abrupt changes related to the introduction of new classes. Cutlines in the orthophoto image, however, can introduce abrupt spectral changes in all classes, at times exceeding the ability of the progressive mapping strategy to maintain spectral-class consistency (fig. 17).

Although cutlines were anticipated at the project onset, the high number of cutlines in the orthophoto mosaic intensified the complexity of the progressive mapping procedure. In addition, although the sensitivity was not apparent in the initial mapping effort, the application of the progressive mapping strategy to detect fairly subtle spectral changes led to an unexpectedly high sensitivity of the mapping procedure to the occurrence of cutlines. In most cases, cutline influences were circumvented by adding visually determined cutline regions to produce a consistent map product.

\section{Landscape Mapping Classification Logistics}

To compensate for some of the mapping challenges, USGS scientists applied a widely used spectral classification technique based on progressive narrowing of the spectral variance per mapped class (for example, Ramsey and Laine, 1997). The 2004 landcover mapping contained excessive areas of confusion; however, the initial spectral grouping provided an effective starting point for implementation of a refined mapping methodology (for example, Ramsey and Laine, 1997), excluding the manually classified categories. The refined classification procedure was operated on each of the classes initially mapped in the unsupervised classification. USGS scientists used this technique and attempted to map all classes identified in the NPS landcover classification of the Parkway whether or not the class was properly represented with an adequate number of field-site observations (table 4). Inputs into the modified unsupervised mapping procedure were the three green, red, and near-infrared image planes making up mosaic sections, and in addition, the 2004 initial mapping classification.

The refinement of the initial unsupervised mapping classification still applied the unsupervised K-means clustering algorithm but within a progressive clustering technique (PCI Geomatics, 1998; Ramsey and others, 1998; Ramsey and others, 2001a and b; Ramsey and others, 2002). In the progressive classifications, the spectral values associated with each image element (pixel) are combined into spectrally similar clusters and each cluster then associated with identifiable landscape features (for example, NVC-defined alliances or associations). Clusters that exhibited mixed combinations of landcovers (alliances or associations) were separated and grouped with other clusters that also exhibited mixed identities. The progressive clustering technique was reiterated until no clusters exhibited mixed identities or until the composition of the remaining mixed clusters became constant. This regrouping and reassignment of image values progressively narrowed the spectral variance until it represented undefined noise. The final set of clusters identified the spectrally separable and inseparable classes (alliances and associations). Figure 9 and figures $10 C-F$ illustrate the transformation from the initial mapping based solely on K-Means clustering and the K-Means clustering results modified by the progressive mapping classification strategy.

The final set of classes were then migrated to the next adjacent mosaic section. When cutlines were present within mosaic sections, the signature migration was from one cutline section to the adjacent cutline section. A single signature migration was not applied from one end of the Parkway to the other; however, a mixture of progressive mapping classifications and signature migrations were applied throughout the Parkway. Restarting the signature migration by initiating a new progression of mapping classification was at times beneficial in mapping the southern to northern extent of the Parkway.

\section{Reduction of Mapping Artifacts after Mapping}

In a continued effort to generate a map product conforming to requests by NPS personnel, filters and sieves were applied to the mapping output in order to reduce mapping artifacts. Many times these mapping artifacts result from application of a discrete class structure on a spectrally and physically continuous landscape. Most of these artifacts were manifest as (1) isolated single-to-multiple pixel groups that are widely distributed spatially and throughout all classes and (2) ribbons that result from mapping discrete classes on a spatially continuous landscape (fig. 18A-D). 


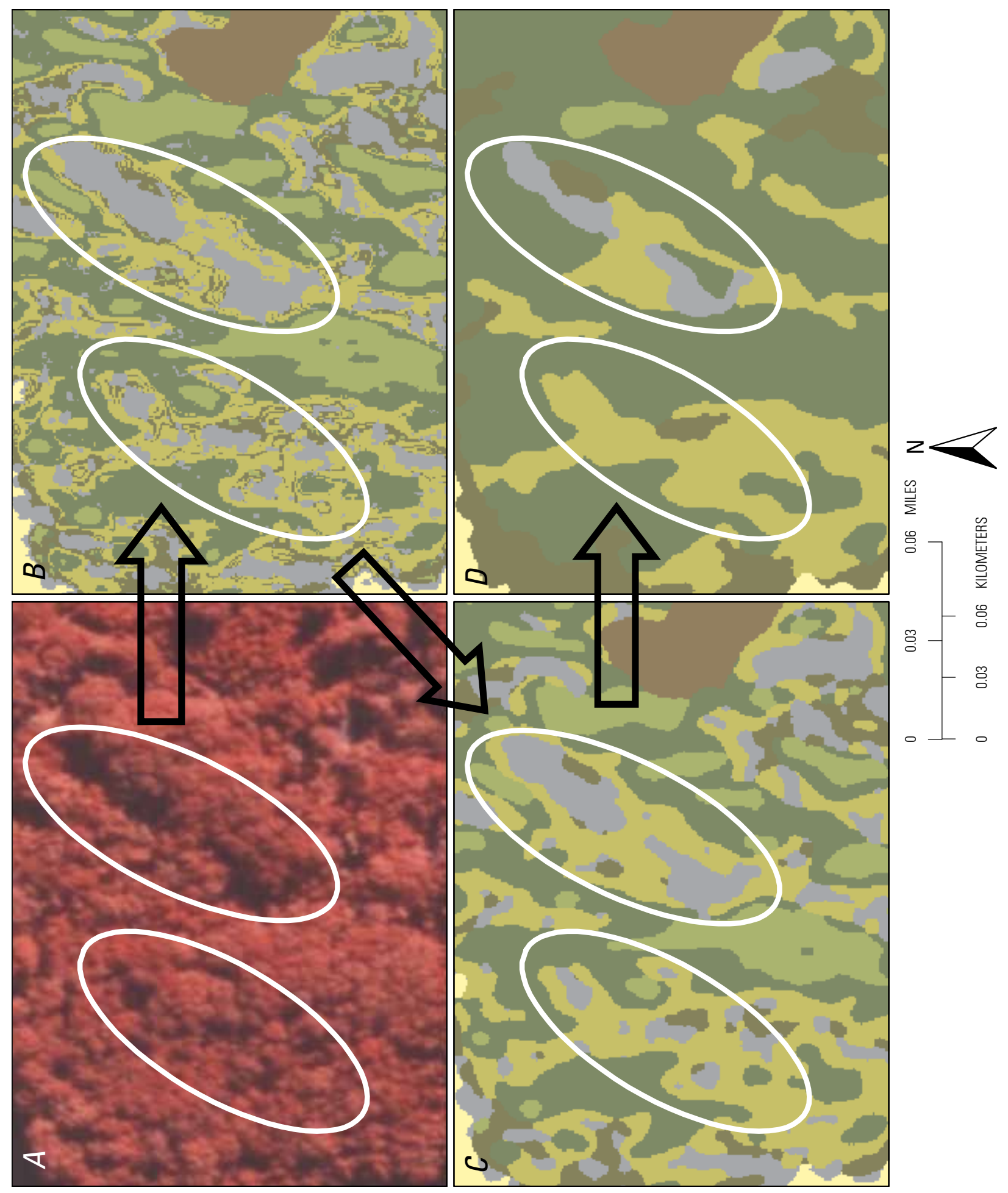

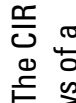

$\stackrel{5}{\infty}$

$\frac{0}{\frac{0}{2}} \frac{\pi}{\frac{\pi}{5}}$

뜬 듬

迹

금

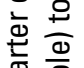

음 을 능

으 홍

은 응

흥 흥 증

능 응

즐 흫

흥

定空

足

늘

d

䨔

눙

흥 을 흥

ऽ 인

중 흉

o

要

인

语

\& 흠 ⿹ㅡㄹ

훙 후

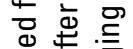

응

ॠ 흘

은 등 응

을

틍 흥.

$\stackrel{\Phi}{\stackrel{\Phi}{\omega}}$

送

蒠昰

心元

壾市 윻

$\geq$ 흥

훈 을

증

边

寒亮点

里

票紫的

$\$ \frac{\pi}{0} \frac{\pi}{0}$

웜

@

오원운

菏

की

๑

\&

한

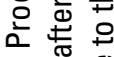

응 용

응

온은 

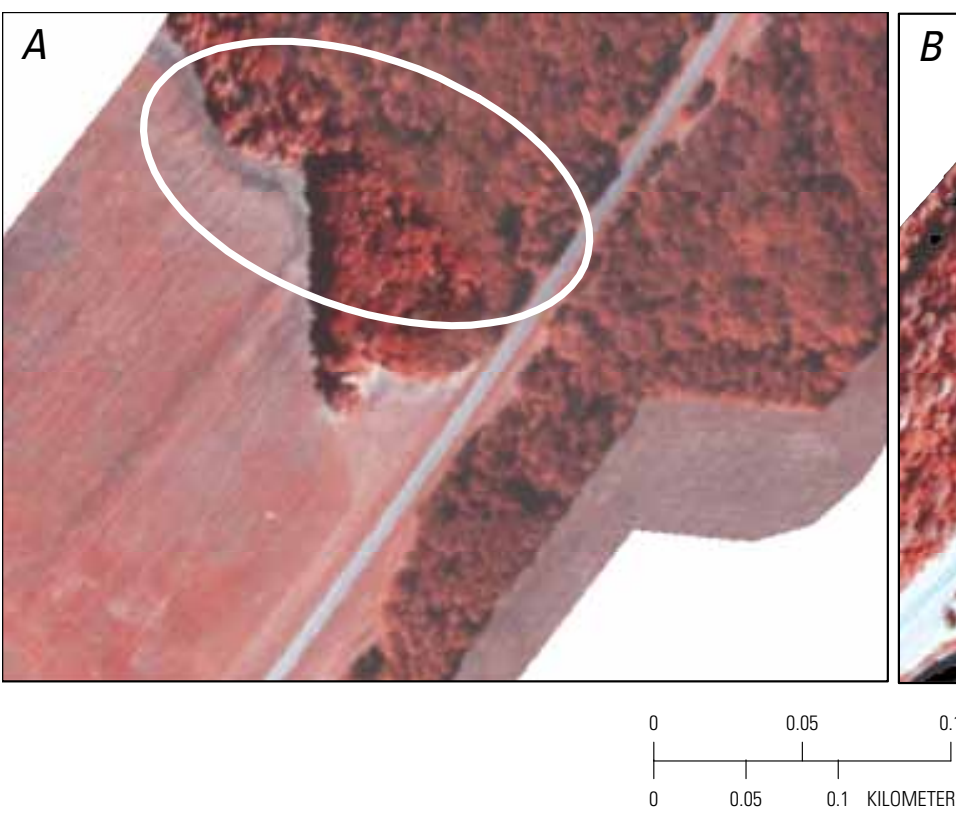

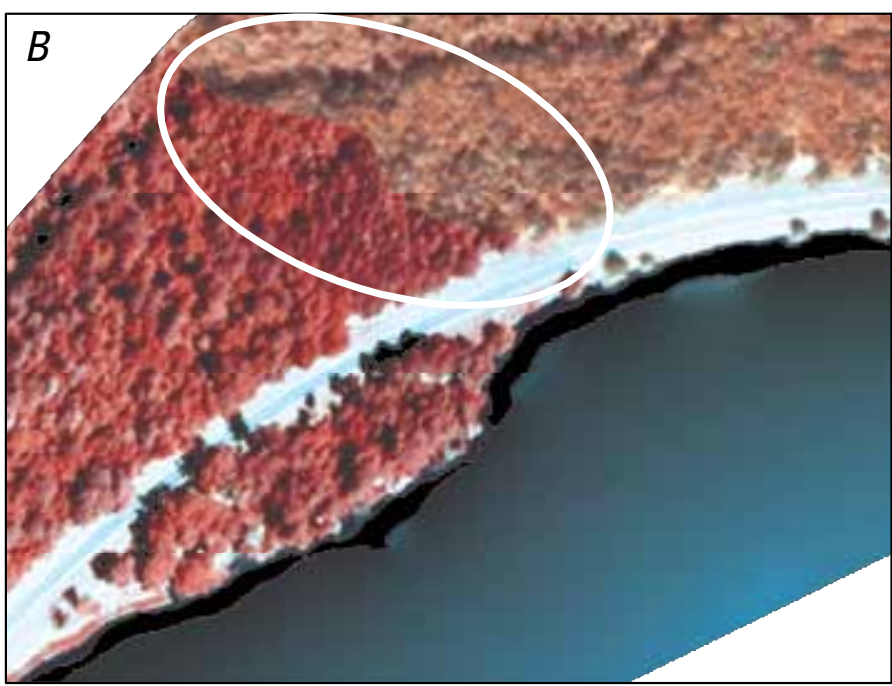

0.1 MILES $N$

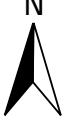

Figure 17. Examples of cutlines present in the different sections of the Natchez Trace Parkway mosaic. These cutlines were taken into account by creating masks and applying classification algorithms only under the masks. $A$, Cutline present on mosaic " 3 north" (see fig. 3). $B$, Cutline present on mosaic "3 south" (see fig. 3).

Table 4. Landcover classifications defined by National Park Service (NPS) personnel (2004 and 2005) as they were mapped by U.S. Geological Survey (USGS) scientists (including how the classes were grouped in the USGS classification). Classification codes are from the National Vegetation Classification. Frequency of field-site observations per class by NPS personnel is provided.

[NVC, National Vegetation Classification; No., number; USGS, U.S. Geological Survey]

\begin{tabular}{|c|c|c|c|c|}
\hline Physiognomic class & $\begin{array}{l}\text { NVC alliance } \\
\text { code }\end{array}$ & NVC association & $\begin{array}{l}\text { No. of field-site } \\
\text { observations }\end{array}$ & USGS classification \\
\hline \multirow{10}{*}{ Herbaceous } & A. 1191 & Highland Rim Wet-Mesic Prairie & 1 & \multirow{4}{*}{ Grasslands } \\
\hline & A. 1208 & Successional Broomsedge Vegetation & 2 & \\
\hline & A.1213 & Cultivated Meadow & 1 & \\
\hline & A. 2020 & Johnson grass vegetation & 2 & \\
\hline & A. 1657 & Water-willow Rocky Bar and Shore & 1 & \multirow{5}{*}{ Aquatic vegetation } \\
\hline & A. 1375 & Rush Marsh & 1 & \\
\hline & A. 1881 & Smartweed - Water-pepper Pond & 1 & \\
\hline & A. 1881 & $\begin{array}{l}\text { smartweed species - Savanna Panicgrass Seasonally } \\
\text { Flooded Herbaceous Vegetation }\end{array}$ & 1 & \\
\hline & A.1984 & Water-lily Aquatic Wetland & 1 & \\
\hline & A. 1716 & Water-hyacinth Aquatic Vegetation & 2 & Invasive species \\
\hline
\end{tabular}


Table 4. Landcover classifications defined by National Park Service (NPS) personnel (2004 and 2005) as they were mapped by U.S. Geological Survey (USGS) scientists (including how the classes were grouped in the USGS classification). Classification codes are from the National Vegetation Classification. Frequency of field-site observations per class by NPS personnel is provided.-Continued

[NVC, National Vegetation Classification; No., number; USGS, U.S. Geological Survey]

\begin{tabular}{|c|c|c|c|c|}
\hline Physiognomic class & $\begin{array}{l}\text { NVC alliance } \\
\text { code }\end{array}$ & NVC association & $\begin{array}{l}\text { No. of field-site } \\
\text { observations }\end{array}$ & USGS classification \\
\hline \multirow{3}{*}{ Shrubland } & A.1011 & Southern Buttonbush Pond & 1 & \multirow{3}{*}{ Shrubland } \\
\hline & A.993 & Grapevine - Peppervine - Trumpetvine Thicket & 1 & \\
\hline & A.994 & Southeastern Smooth Alder Swamp & 5 & \\
\hline Planted Forest & A.99 & Loblolly Pine Plantation & 6 & Plantation \\
\hline \multirow{11}{*}{ Upland Deciduous Forests } & A.221 & Successional Tree-of-Heaven Forest & 2 & Invasive species \\
\hline & A.229 & Central Interior Beech - White Oak Forest & 3 & \multirow{4}{*}{ White oak } \\
\hline & A.239 & $\begin{array}{l}\text { Highland Rim White Oak - Tuliptree Mesic Lower } \\
\text { Slope Forest }\end{array}$ & 4 & \\
\hline & A.239 & White Oak - Red Oak Dry-Mesic Acid Forest & 6 & \\
\hline & A. 241 & Southern Red Oak - White Oak Mixed Oak Forest & 22 & \\
\hline & A.1912 & $\begin{array}{l}\text { Interior Plateau Chinquapin Oak - } \\
\text { Shumard Oak Forest }\end{array}$ & 2 & \multirow{6}{*}{ Oak } \\
\hline & A. 238 & Basic Mesic Coastal Plain Oak-Hickory Forest & 2 & \\
\hline & A. 243 & Dry Acid Eastern Coastal Plain Oak - Hickory Forest & 17 & \\
\hline & A. 243 & Southern Red Oak Flatwoods Forest & 3 & \\
\hline & A. 247 & Successional Water Oak Forest & 2 & \\
\hline & A.249 & $\begin{array}{l}\text { Interior Low Plateau Chestnut Oak - } \\
\text { Mixed Oak Forest }\end{array}$ & 7 & \\
\hline \multirow{10}{*}{ Upland Evergreen Forests } & A. 625 & Western Highland Rim Escarpment Post Oak Barrens & 2 & \\
\hline & A. 234 & $\begin{array}{l}\text { Interior Mid- to Late-Successional Sweetgum - } \\
\text { Oak Forest }\end{array}$ & 2 & \multirow{3}{*}{ Sweetgum } \\
\hline & A. 234 & Loess Bluff Sweetgum - Pecan - Water Oak Forest & 3 & \\
\hline & A.234 & Successional Sweetgum Forest & 4 & \\
\hline & A. 287 & Successional Sweetgum Floodplain Forest & 22 & \multirow{6}{*}{ Sweetgum } \\
\hline & A.291 & $\begin{array}{l}\text { East Gulf Coastal Plain Calcareous Brownwater } \\
\text { Terrace Forest }\end{array}$ & 1 & \\
\hline & A.291 & $\begin{array}{l}\text { East Gulf Coastal Plain Small Oak } \\
\text { Bottomland Forest }\end{array}$ & 2 & \\
\hline & A.291 & $\begin{array}{l}\text { Swamp Chestnut Oak - Sweetgum Mesic } \\
\text { Floodplain Forest }\end{array}$ & 1 & \\
\hline & A.291 & Sweetgum - Cherrybark Oak Floodplain Forest & 8 & \\
\hline & A. 292 & $\begin{array}{l}\text { East Gulf Coastal Plain Oak-Sweetgum Small Stream } \\
\text { Floodplain Forest }\end{array}$ & 12 & \\
\hline
\end{tabular}


Table 4. Landcover classifications defined by National Park Service (NPS) personnel (2004 and 2005) as they were mapped by U.S. Geological Survey (USGS) scientists (including how the classes were grouped in the USGS classification). Classification codes are from the National Vegetation Classification. Frequency of field-site observations per class by NPS personnel is provided.-Continued

[NVC, National Vegetation Classification; No., number; USGS, U.S. Geological Survey]

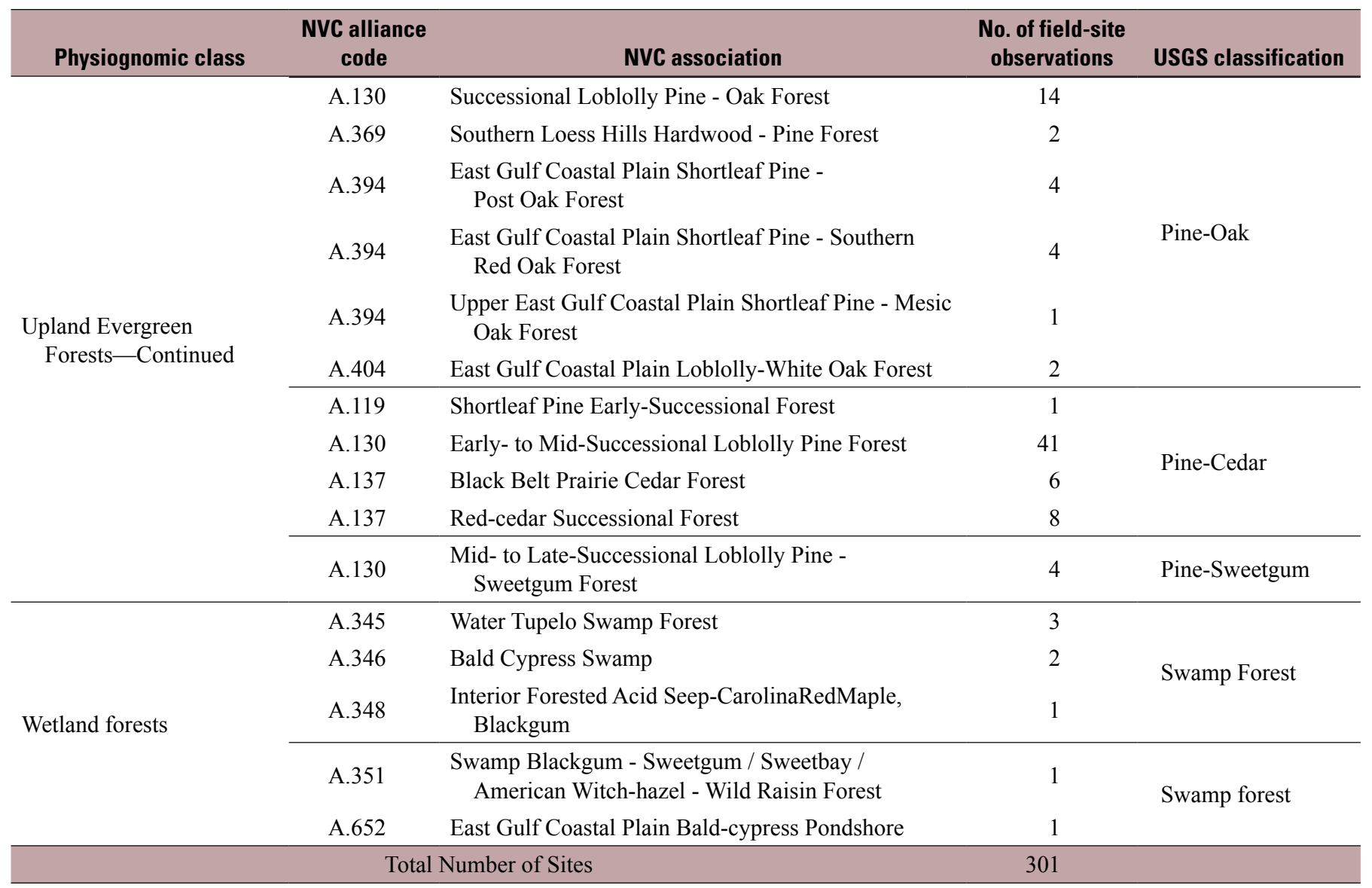




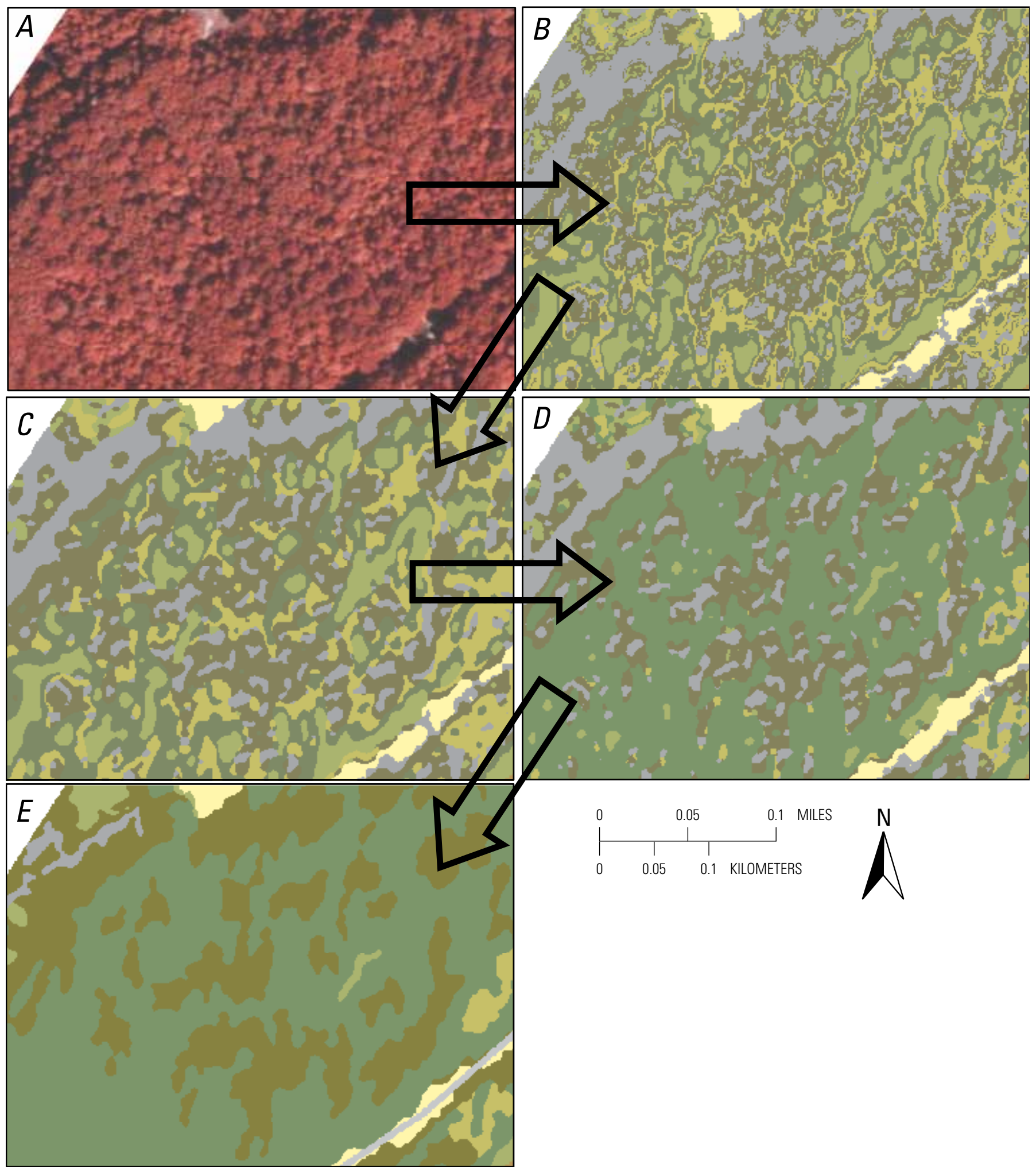

Figure 18. Results of the process to reduce mapping artifacts from the final map product. $A$, Color-infrared digital orthophoto quarter quadrangle (D00Q). $B$, Initial unsupervised classification of the D000, which produced a lot of artifacts (as expected). $C$, Application of spatial mode filters. $D$, Merging of forest clusters within a defined threshold. $E$, Result of geographic information system (GIS) techniques to remove shadows and further image processing to merge small islands into the major forest classes. 


\section{Field-Site Location and Accuracy Assessment of Mapped Classes}

During the 2005 field reconnaissance, the USGS team noted that in some instances field-site locations defined by GPS coordinates were not co-located with corresponding locations on the CIR photographic or mapped image (fig. 19). Partial alleviation of this discrepancy was provided by using the average of all satellite signals accumulated over the time taken to visit the field plot instead of using the initial GPS coordinate reading. Even with averaging the satellite signals, location errors associated with GPS units used in the 2005 (and most likely in the 2004) landcover classification were significant. Verbyla and Hammond (1995) showed that positional errors alone can lower mapping accuracy assessments by more than 50 percent.

Location errors associated with hand-held GPS units, the primary tool for specifying field-site locations, can vary dramatically under forest canopies, primarily in response to the varying canopy densities (Barette, 2000; Karsky and others, 2000; Mancebo and Chamberlain, 2000; Chamberlain, 2002a, b). Reported location errors between 5 and $30 \mathrm{~m}$ associated with time-averaged GPS recordings were typical of field reconnaissance. In response to the varying position error, the areal nature of the vegetation canopies (especially the forest canopies), and the spatially complex landscape, a 15-m positional tolerance buffer was attached to each GPS location received from NPS personnel by USGS scientists. If spatial concurrence between the NPS field landcover class location and the mapped location was within $15 \mathrm{~m}$, correspondence was certified.

Mapping accuracy assessments are reported within contingency table formats (Congalton, 1991). The table matrix format lists the field-site classes observed by NPS personnel in the first column and the same classes as they were mapped by USGS scientists in the first row (tables 5-8). The entries within the table describe the correspondence between the field-based classification of sites and mapped classes. Entries along the matrix trace contain the number of correctly mapped field sites while entries off the trace denote misclassifications. Misclassifications are of two types - misclassifications along the column of any particular target class depict commission errors or user accuracy. These misclassifications define the number of times another class is incorrectly mapped as the target class; the target class has been incorrectly expanded into other observed classes. Misclassifications along the row of any target class define omission errors or producer accuracy. These misclassifications signify the number of times the target class has been incorrectly mapped as another class; the target class has been incorrectly decreased.
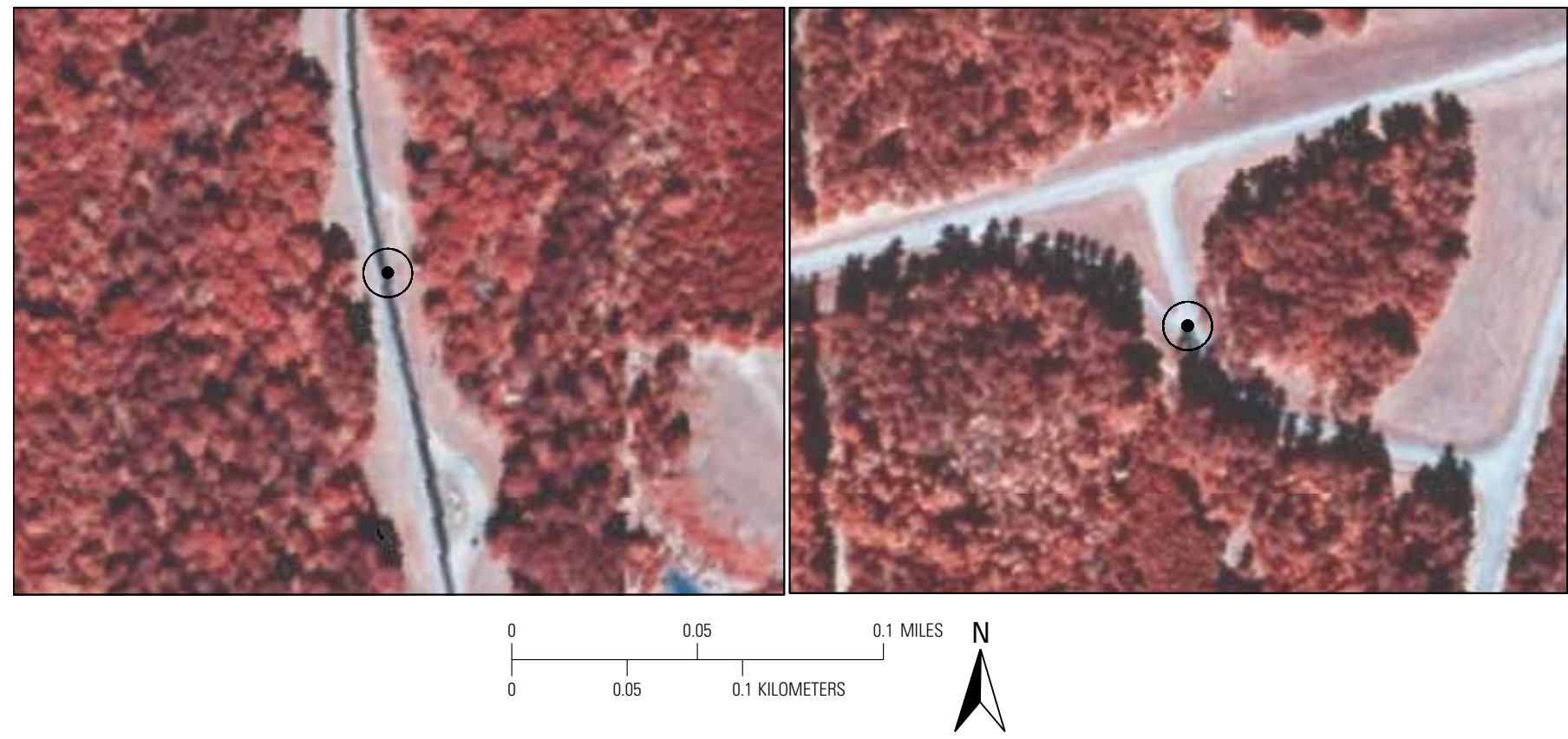

Figure 19. Example of two National Park Service forest sites mislocated outside the forested areas. 
Table 5. Results from accuracy assessment of the landcover map of the Natchez Trace Parkway by U.S. Geological Survey scientists. The map was based upon a landcover classification provided by National Park Service (NPS) personnel. The "confusion matrix" indicates the divergence between the field-site classification (aggregated according to Table 4) and the USGS-produced map. The aggregated classes based on field sites are provided in the first column, and the same classes as they were mapped by USGS scientists are provided in the first row. Entries along the matrix trace (in gray shading) indicate the number of correctly mapped field sites, while entries off the trace denote misclassifications (errors of commission and omission). Overall user and producer accuracy rates are provided; the combined accuracy rate is estimated to be 65 percent.

[NPS, National Park Service; USGS, U.S. Geological Survey; no., number]

\begin{tabular}{|c|c|c|c|c|c|c|c|c|c|c|c|c|}
\hline \multicolumn{13}{|c|}{ Confusion matrix } \\
\hline \multirow{12}{*}{ 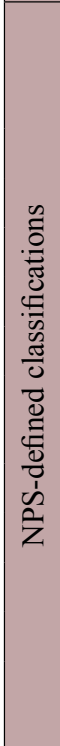 } & & $\begin{array}{l}\text { Grass- } \\
\text { lands }\end{array}$ & Oak & Pine-oak & Sweetgum & Pine & $\begin{array}{l}\text { Sweetgum- } \\
\text { oak }\end{array}$ & $\begin{array}{l}\text { White } \\
\text { oak }\end{array}$ & Cedar & $\begin{array}{c}\text { Total no. } \\
\text { of mapped } \\
\text { instances }\end{array}$ & $\begin{array}{l}\text { Producer } \\
\text { accuracy }\end{array}$ & $\begin{array}{c}\text { Omission } \\
\text { error }\end{array}$ \\
\hline & Grasslands & 10 & 0 & 0 & 0 & 0 & 0 & 0 & 0 & 10 & $100 \%$ & 0 \\
\hline & Oak & 0 & 42 & 7 & 1 & 0 & 0 & 5 & 0 & 55 & $76 \%$ & 0.24 \\
\hline & \begin{tabular}{|l|} 
Pine-oak \\
\end{tabular} & 0 & 6 & 16 & 0 & 3 & 2 & 0 & 0 & 27 & $59 \%$ & 0.41 \\
\hline & Sweetgum & 0 & 8 & 0 & 9 & 5 & 8 & 0 & 0 & 30 & $30 \%$ & 0.7 \\
\hline & Pine & 0 & 0 & 2 & 0 & 40 & 0 & 0 & 0 & 42 & $95 \%$ & 0.05 \\
\hline & $\begin{array}{l}\text { Sweetgum- } \\
\text { oak }\end{array}$ & 0 & 7 & 1 & 0 & 0 & 17 & 0 & 0 & 25 & $68 \%$ & 0.32 \\
\hline & White oak & 0 & 21 & 1 & 0 & 2 & 2 & 31 & 0 & 57 & $54 \%$ & 0.46 \\
\hline & Cedar & 0 & 3 & 0 & 0 & 6 & 1 & 0 & 4 & 14 & $29 \%$ & 0.71 \\
\hline & Total & 10 & 87 & 27 & 10 & 56 & 30 & 36 & 4 & 260 & & \\
\hline & User accuracy & $100 \%$ & $48 \%$ & $59 \%$ & $90 \%$ & $71 \%$ & $57 \%$ & $86 \%$ & $100 \%$ & & & \\
\hline & $\begin{array}{c}\text { Commission } \\
\text { error }\end{array}$ & 0 & 0.52 & 0.41 & 0.1 & 0.29 & 0.43 & 0.14 & 0 & & & \\
\hline
\end{tabular}

Table 6. Results from accuracy assessment of the landcover map of the Natchez Trace Parkway by U.S. Geological Survey scientists (also see table 5). The map was based upon a landcover classification provided by National Park Service (NPS) personnel. The results presented here were derived after merging the "sweetgum" and "sweetgum-oak" classes into a "sweetgum" class and the "pine" and "cedar" classes into a "pine-cedar" class. The "confusion matrix" indicates the divergence between the field-site classification (aggregated according to table 4) and the USGS-produced map. The aggregated classes based on the field sites are provided in the first column, and the same classes as they were mapped by USGS scientists are provided in the first row. Entries along the matrix trace (in gray shading) indicate the number of correctly mapped field sites, while entries off the trace denote misclassifications (errors of commission and omission). Overall user and producer accuracy rates are provided; the combined accuracy rate is estimated to be 70 percent.

[NPS, National Park Service; USGS, U.S. Geological Survey; no., number]

\begin{tabular}{|c|c|c|c|c|c|c|c|c|c|c|}
\hline \multicolumn{11}{|c|}{ Confusion Matrix } \\
\hline \multirow{8}{*}{ 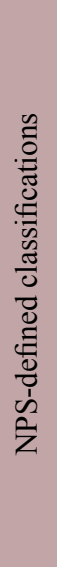 } & & Grasslands & Oak & Pine-oak & Sweetgum & Pine-cedar & White oak & $\begin{array}{l}\text { Total no. } \\
\text { of mapped } \\
\text { instances }\end{array}$ & $\begin{array}{l}\text { Producer } \\
\text { accuracy }\end{array}$ & $\begin{array}{c}\text { Omission } \\
\text { error }\end{array}$ \\
\hline & Grasslands & 10 & 0 & 0 & 0 & 0 & 0 & 10 & $100 \%$ & 0 \\
\hline & Oak & 0 & 42 & 7 & 1 & 0 & 5 & 55 & $76 \%$ & 0.24 \\
\hline & Pine-oak & 0 & 6 & 16 & 2 & 3 & 0 & 27 & $59 \%$ & 0.41 \\
\hline & Pine-cedar & 0 & 3 & 2 & 1 & 50 & 0 & 56 & $89 \%$ & 0.11 \\
\hline & White oak & 0 & 22 & 0 & 2 & 2 & 31 & 57 & $54 \%$ & 0.46 \\
\hline & Total & 10 & 88 & 26 & 40 & 60 & 36 & 260 & & \\
\hline & User accuracy & $100 \%$ & $48 \%$ & $62 \%$ & $85 \%$ & $83 \%$ & $86 \%$ & & & \\
\hline
\end{tabular}


Table 7. Results from accuracy assessment of the landcover map of the Natchez Trace Parkway by U.S. Geological Survey scientists (also see table 6). The map was based upon a landcover classification provided by National Park Service (NPS) personnel. The results presented here were derived after merging the "Sweetgum" and "Sweetgum-Oak" classes as a Sweetgum class, the "Pine" and "Cedar"classes as a Pine-Cedar class, and the "White Oak" and "Oak" classes as a Oak class. The "confusion matrix" indicates the divergence between the field-site classification (aggregated according to table 4) and the USGS-produced map. The aggregated classes based on the field sites are provided in the first column, and the same classes as they were mapped by USGS scientists are provided in the first row. Entries along the matrix trace (in gray shading) indicate the number of correctly mapped field sites, while entries off the trace denote misclassifications (errors of commission and omission). Overall user and producer accuracy rates are provided; the combined accuracy rate is estimated to be 70 percent.

[NPS, National Park Service; USGS, U.S. Geological Survey; no., number]

\begin{tabular}{|c|c|c|c|c|c|c|c|c|c|}
\hline \multicolumn{10}{|c|}{ Confusion Matrix } \\
\hline \multirow{8}{*}{ 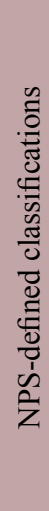 } & & Grasslands & Oak & Pine-oak & Sweetgum & Pine-cedar & $\begin{array}{l}\text { Total no. } \\
\text { of mapped } \\
\text { instances }\end{array}$ & $\begin{array}{l}\text { Producer } \\
\text { accuracy }\end{array}$ & $\begin{array}{c}\text { Omission } \\
\text { error }\end{array}$ \\
\hline & Grasslands & 10 & 0 & 0 & 0 & 0 & 10 & $100 \%$ & 0 \\
\hline & Oak & 0 & 100 & 7 & 3 & 2 & 112 & $89 \%$ & 0.11 \\
\hline & Pine-oak & 0 & 6 & 16 & 2 & 3 & 27 & $59 \%$ & 0.41 \\
\hline & Pine-cedar & 0 & 3 & 2 & 1 & 50 & 56 & $89 \%$ & 0.11 \\
\hline & Total & 10 & 124 & 26 & 40 & 60 & 260 & & \\
\hline & Users accuracy & $100 \%$ & $81 \%$ & $62 \%$ & $85 \%$ & $83 \%$ & & & \\
\hline & Commission error & 0 & 0.19 & 0.38 & 0.15 & 0.17 & & & \\
\hline
\end{tabular}

Table 8. Results from accuracy assessment of the landcover map of the Natchez Trace Parkway by U.S. Geological Survey scientists (also see table 5). The map was based upon a landcover classification provided by National Park Service (NPS) personnel. The results presented here were derived after the "white oak" class was retained as a separate class in the north and merged with the "oak" class in the south. The "confusion matrix" indicates the divergence between the field-site classification (aggregated according to table 4) and the USGS-produced map. The aggregated classes based on the field sites are provided in the first column, and the same classes as they were mapped by USGS scientists are provided in the first row. Entries along the matrix trace (in gray shading) indicate the number of correctly mapped field sites, while entries off the trace denote misclassifications (errors of commission and omission). Overall user and producer accuracy rates are provided; the combined accuracy rate is estimated to be 74 percent.

[NPS, National Park Service; USGS, U.S. Geological Survey; no., number]

\begin{tabular}{|c|c|c|c|c|c|c|c|c|c|c|}
\hline \multicolumn{11}{|c|}{ Confusion Matrix } \\
\hline \multirow{8}{*}{ 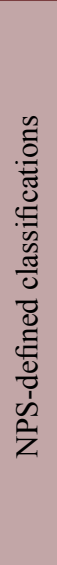 } & & Grasslands & Oak & Pine-oak & Sweetgum & Pine-cedar & White oak & $\begin{array}{l}\text { Total no. } \\
\text { of mapped } \\
\text { instances }\end{array}$ & $\begin{array}{l}\text { Producer } \\
\text { accuracy }\end{array}$ & $\begin{array}{c}\text { Omission } \\
\text { error }\end{array}$ \\
\hline & Grasslands & 10 & 0 & 0 & 0 & 0 & 0 & 10 & $100 \%$ & 0 \\
\hline & Oak & 0 & 51 & 7 & 1 & 0 & 5 & 64 & $80 \%$ & 0.2 \\
\hline & Pine-oak & 0 & 6 & 16 & 2 & 3 & 0 & 27 & $59 \%$ & 0.41 \\
\hline & Pine-cedar & 0 & 3 & 2 & 1 & 50 & 0 & 56 & $89 \%$ & 0.11 \\
\hline & White oak & 0 & 13 & 0 & 2 & 2 & 31 & 48 & $65 \%$ & 0.35 \\
\hline & Total & 10 & 88 & 26 & 40 & 60 & 36 & 260 & & \\
\hline & User accuracy & $100 \%$ & $58 \%$ & $62 \%$ & $85 \%$ & $83 \%$ & $86 \%$ & & & \\
\hline
\end{tabular}


The inadequate number of field-site observations (Van Genderen and Lock, 1977; Foody, 2002) resulted in two less than desirable outcomes. First, in the case of some NVC classes, the lack of an adequate number of field sites led to their elimination from the accuracy assessment (for example, swamp and pine-sweetgum) or to their being combined into one of the larger classes (for example, cedar with pine). Second, the field-site observations were used to both guide the mapping and produce accuracy assessments. The desired procedure would allow a set of field-site observations for mapping assessment and another independent set for accuracy assessment, but the number of field-site observations barely reached the minimum required for mapping assessment in the case of one alliance. Consequently, the ability to identify a separate set of field-site observations for accuracy assessment was not possible. However, the drawback of using the fieldsite observations for mapping and assessment may have been minimized by the logistics of the field classification site selections and the image processing employed.

According to Verbyla and Hammond (1995) and Hammond and Verbyla (1996), the problems using fieldbased classifications for both mapping and assessment is that typically field sites chosen for mapping are located in relatively homogeneous areas. If instead of homogeneous, the actual landscape was more of a heterogeneous mixture of vegetation types with variable canopy structure, the typical field sites would be inappropriate for accuracy assessment. In the field landcover classifications, the NPS classification teams did not consider extended spatial homogeneity of the landcover when choosing the field-site locations. This lack of association to homogeneous landscapes was highlighted by the limited spatial extents and the random selection of field sites used in the 2005 field trip but was also apparent in the 2004 field-site selections. The spatial heterogeneity of the Parkway was noted in the 2004 field reconnaissance. Consequently, the lack of consideration of field-site homogeneity and the spatial heterogeneity of the Parkway may have somewhat alleviated the problems in using the field-based classifications for both mapping and assessment.

In the Parkway mapping the lack of an adequate number of field-site observations and the spectral complexity of the Parkway prevented creation of spectral signatures corresponding to field-based landcover classes. The spectral signatures were created during unsupervised classifications and these migrated from one region of the Parkway to the next. Finally, in spatially heterogeneous landscapes, spatial aggregation into polygons can lower classification accuracy estimates (Verbyla and Hammond, 1995). Decreased accuracy results when polygons are created by incorporating similar classes and dissimilar classes of relatively small size in order to decrease the spatial complexity of the final mapping classification. The smaller polygons may have correctly identified a different landcover, but this landcover feature was eliminated when it was aggregated into a larger polygon representing a different landcover class (Fassnacht and others, 2006). This type of bias can lower accuracy estimates by greater than 50 percent (Verbyla and Hammond, 1995). Postprocessing to eliminate small, discrete class occurrences in order to create a more spatially continuous map classification may have inadvertently and unaccountably altered the actual class heterogeneity in some locations.

To provide an overall estimate of mapping performance, the same set of field-site observations were used in the mapping and in the accuracy assessments. Where multiple field sites were classified with a single landcover class, correspondences of 65 to 85 percent between the field-based classification and the map classification were considered fully successful (base-goal standard, Schwind and others, 2004).

\section{Results and Discussion}

\section{Initial Image Mapping Classification}

Each of the 100 clusters generated during the initial unsupervised cluster procedure was assigned a class value based on its spatial association with a spectral feature in the original nonspatially averaged CIR photography. On average, at the end of assigning each of the 100 original clusters, about 11 or 12 spectrally distinct CIR hues, intensities, and saturation features were identified and associated (examples shown in fig. $9 A$ and figs. $18 C$ and $D$ ) with the initial landcover classes received in 2004 from NPS (table 3).

Even though spectrally distinct, not all designated classes were distinctly associated with a single landscape feature. The most common cases of spectral confusion among obviously different landcover classes were between the "bright" forest and grassland classifications. In these cases, the classes were spectrally and at times texturally similar but visually distinguishable on the CIR photography. As discussed previously, application of texture filters alleviated some of this type of confusion and at times improved mapping accuracy.

Mapping classification confusion also existed between mature forests and tree plantations (fig. 10). These land covers are assigned separate alliances in the NVC. As with confusion between forest and grassland, texture information gained from filtering helped distinguish some plantations from forests; however, in most cases, texture was not a unique modifier. Primarily, plantations were manually classified throughout the Parkway.

General observations indicated broad groupings of photographic hue, intensity, and texture associated with different forests types. Darker CIR photographic features were often associated with pines (mostly loblolly, short- and longleaf pines) and cedars. Younger pine stands with relatively open canopy showed a hummocky texture. Brighter CIR returns generally depicted hardwood forests, while bluish tones with some texture depicted cypress tupelo swamps and/ or beaver-impounded sites with dead trees in very wet areas 
or standing water. Even these broad groupings, however, were not consistent throughout the Parkway.

\section{Undefined Landcover}

In mapping the Parkway based on the NPS landcover classification, USGS scientists identified landscapes that were not spectrally aligned with any of the classes defined by NPS. As part of the migration of class means from section to section, a null class was retained for spectral outliers. The final mapping identified two landcover classes, one occurring throughout the Parkway and the other primarily occurring in the northern section of the Parkway that exhibited a unique spectral-textural pattern on the CIR photography. No field sites classified by NPS corresponded with these undefined landcover categories. Because of the close spatial association of one of the undefined classes and the sweetgum class, the undefined class was aggregated into the sweetgum class during the final mapping aggregations. A second undefined class did not spectrally align with any major NPS-defined class and was, therefore, retained as a class called "scattered trees" (fig. 20). Because NPS personnel were solely authorized to designate NVC-based landcover classes, a separate GIS mask for the "undefined class" was included in final mapping products so that NPS personnel could locate and confirm this class designation during future field-site reconnaissance.

\section{Kudzu Landcover}

As discussed in the Methods section, there was only a single field site classified as kudzu by NPS personnel, and that site was hidden by shadows on the CIR photography. Responding to a request by NPS, USGS scientists performed manual detection and digitization of kudzu occurrences on the 2004 CIR DOQQs. The kudzu mapping included only the "ground-kudzu" vine that is described in Mapping Kudzu vine. The highest occurrences of kudzu were in the most southern sections of the Parkway that contained some of the most spatially extensive and relatively recently disturbed areas. Because of the lack of field observations and the application of manual mapping, the kudzu class was excluded from the mapping accuracy assessment. The kudzu distribution is contained as a polygon overlay in the final map products.
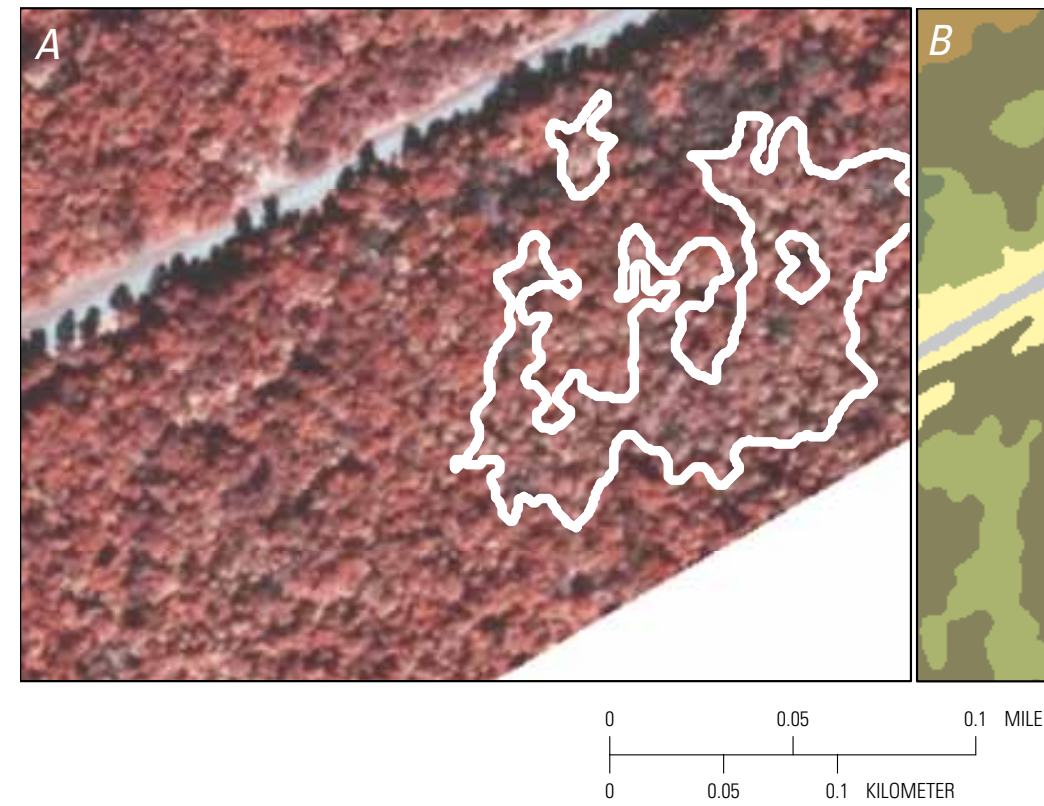

Figure 20. Example classification of the "scattered trees" class defined by U.S. Geological Survey scientists. A, Color-infrared digital orthophoto quarter quandrangle from an area of the "4 north" mosaic (see fig. 3). Indicated by the polygon (white) is a forest area with a distinct spectral and texture pattern. $B$, The polygon mapped as scattered trees because no field-site classification points were provided for this category of trees. 


\section{Plantation Landcover}

Even though only four field sites were classified as plantation by NPS personnel, an attempt was made to map plantations based on the associated textural uniqueness observed on the CIR photography. Although many plantations exhibited unique textures, the textures differed from plantation to plantation. In addition, many of the texture patterns associated with relatively mature plantations were not as distinct as those exhibited by seemingly younger plantations. Even though visually observable on the CIR photography, most plantations were not consistently distinguishable (spectrally) from other forest classes with spectral-textural classifiers. In order to more thoroughly map pine plantations, manual mapping methods were employed. Because the mapping involved manual methods, the plantation class was not included in the accuracy assessments. The plantation classification was included as a class on the final map product.

\section{Scrubland Landcover}

As discussed in Mapping Kudzu vine, kudzu, an invasive shrubland, was manually mapped where visually identified. Chinese privet (Ligustrum sinense), a second invasive shrubland, was not mapped because even at the sole field site where this vegetation was classified by NPS personnel, it was not visually identifiable on the CIR photography; therefore, no spectral key could be created and tested. The four native shrubland alliances identified at eight field sites by NPS personnel (five sites were associated with one alliance) could not be mapped by using the progressive mapping technique. At five of the eight sites, spectral contrast surrounding the pertinent field sites that was visible on the CIR DOQQs was used to digitize spatial occurrence of the shrubland. At three of the shrubland field sites, the lack of spectral contrast did not allow determination of the the class extent; therefore, these sites were not classified as shrubland.

\section{Addition of a USGS-defined Scrub-Shrub Class}

Although no field site was classified as scrub-shrub by NPS personnel, USGS scientists created this class to describe and map highly disturbed areas containing mixed vegetations of variable age. The high composition variability (for example, shrubs, grasses, bare ground) and disturbed state of these areas resulted in nearly total confusion of the scrub-shrub class with almost all other classes when using supervised or unsupervised mapping techniques. The scrub-shrub class was mapped manually as was done for the shrubland class discussed above. The USGS-defined scrub-shrub class and NVC shrubland class were not included in the accuracy assessment because they were manually mapped.

\section{Swamp and Water Landcovers}

Although swamps and water bodies should be distinguishable spectrally, the mix of canopy densities within the swamps along the Parkway prevented consistent mapping of the swamp class and particularly its distinction from the water classes. The lack of an adequate number of field-site observations hindered the suitable development of a spectral method that provided mapping separation of the swamp class. In order to provide consistent mapping of these classes, manual mapping was conducted. Although swamp and water classes are included on the produced map, these classes are not included in the map accuracy assessment.

\section{"Irregular" Landcovers}

A list of the noncorresponding forest classes pertaining to 15 alliances with a total of 30 field sites is presented in table 2. As discussed in Mapping "Irregular" classes, these atypical or "irregular" forest alliances were represented most of the time by only one or two field sites. In addition, the forest alliances comprising the irregular classes did not align with any of the major forest classes (for example, oaks, sweetgum, and pine) and for the most part did not contain species that were common to other alliances. The combination of their composition uniqueness and the lack of field-site observations prevented successful application of progressive mapping for these alliances. Where a spectral hue or texture could be identified at the NPS-defined field-site location of the irregular class, manual mapping was performed; however, at 22 locations, the lack of a visually distinct spatial pattern prevented manual mapping of the irregular classes. In those cases, these alliances were not mapped and are not included on the final map product. Whether mapped manually or not, the overlay polygon depicting the irregular classes locates all nongrouped forest alliances. Where possible, the location is associated with a polygon estimated by visual interpretation.

\section{Field-Site Classification Data from NPS}

\section{Field-Site Distribution}

The combined 2004 and 2005 classification data received by USGS scientists from NPS personnel included a catalogue of 346 field sites within the Parkway that were classified into $83 \mathrm{NVC}$ associations and 61 alliances. After some necessary exclusions, 301 field sites comprising 49 alliances and 68 associations remained (table 4). USGS scientists excluded 30 field sites in the irregular classes, along with 12 corresponding alliances and 15 associations; also excluded were 7 field sites incorrectly located outside photographic coverage, 6 field sites 
for which there were missing alliance and association codes, and 2 forest-classified field sites that were outside the forest range.

The 301 field sites normalized by mapping-section length (the number of NVC plots per kilometer) showed an uneven distribution from south to north along the Parkway (fig. 21). The southern portion of the Parkway was not as well represented by field sites as were the more northern sections. In addition, 43.5 percent of the total number of field sites was located nearer the roadway than the Parkway boundary, even when excluding the grass buffer that runs along the roadway (fig. 22). In essence, field sites were on average more numerous in the northern portion of the Parkway and more likely representative of the front edge of the forest stands.

\section{Physiognomic Class Descriptions for the NPS Landcover Classification}

The upland evergreen physiognomic class included two cedar and two pine associations dominated by various pine species, six pine-oak associations dominated by various pine and oak species combinations, and one pine-sweetgum association. The upland deciduous physiognomic class included 19 oak associations dominated by various oak species, 6 white oak associations, 2 sweetgum associations, and 5 sweetgum-oak associations. The wetland-forest physiognomic class included five swamp associations that were composed of various dominant species. The planted forest physiognomic class included one pine plantation association. The herbaceous physiognomic class included 16 associations (table 4). Within the herbaceous class, USGS scientists grouped seven associations into the grassland class and eight associations into the aquatic vegetation class.

Water-hyacinth associated in the herbaceous physiognomic class and two associations, namely kudzu and Chinese privet, in the shrubland physiognomic class, and one upland deciduous physiognomic class association (the tree-of-heaven [Ailanthus altissima]) were defined as invasive species by NPS personnel. At the request of NPS personnel, USGS scientists separated the invasive species as a separate class. The invasive class is retained as a separate overlay in the USGS products.

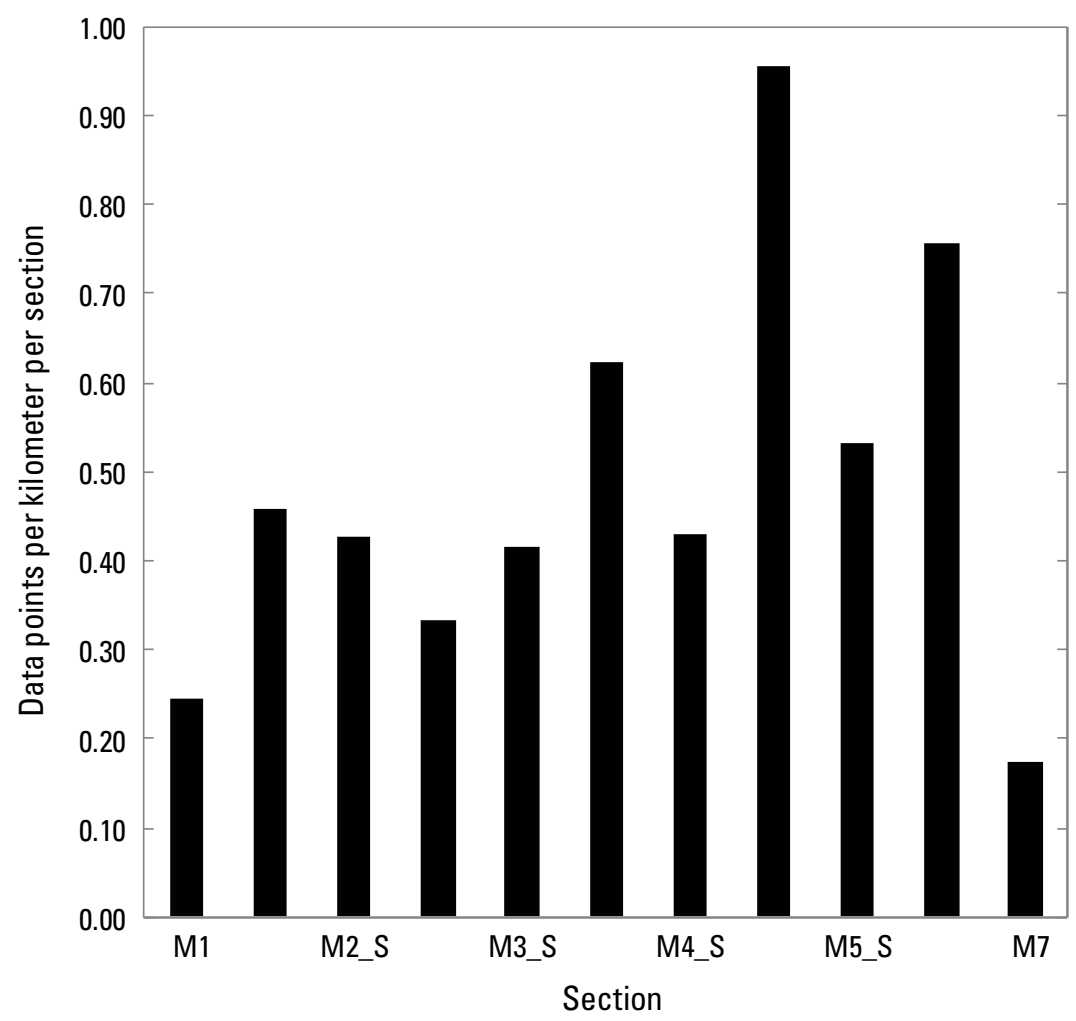

Figure 21. Distribution of field points (total of 331) for which data were provided by National Park Service personnel. The graph indicates that there were relatively more points per section as we moved from south (see mosaics 1 to 3 south) to north (see mosaic 4 north to mosaic 7). (See fig. 3 for locations of mosaic sections; in this figure mosaics are coded, for example, such that M2_S is the same as the "2 south" mosaic in fig. 3.) 


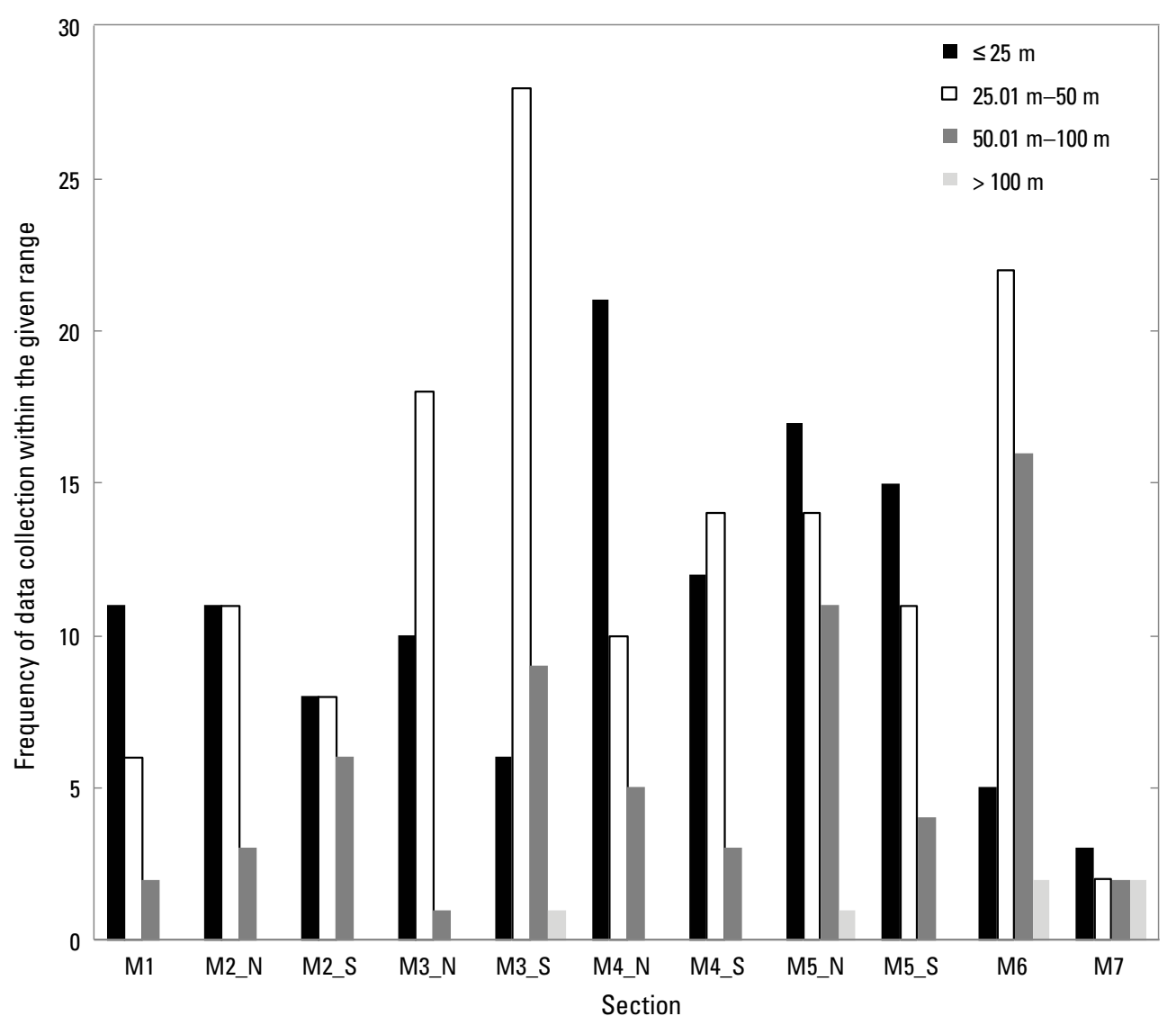

Figure 22. Frequency of measurement ranges (in meters) indicating distance from the tree line to field sites where classification data were collected by National Park Service personnel. Most of the field sites were located at the front edge of forests within the range of 25 to $50 \mathrm{~m}$. (Field-site locations are referenced to mosaic sections illustrated in fig. 3; in this figure mosaics are coded, for example, such that M2_S is the same as the "2 south" mosaic in fig. 3.)

\section{Field Data for NPS Landcover Classification}

A total of 301 field sites were visited for data collection, but only the Early- to Mid-Successional Loblolly Pine forest association was observed at more than 30 sites, while Southern Red Oak-White Oak-Mixed Oak and Successional Sweetgum Floodplain forest associations were observed at over 20 sites. Among other association classes, Dry Acid Eastern Coastal Plain Oak-Hickory forest was observed at 17 field sites; Successional Loblolly Pine-Oak forest was observed at 14 sites; Interior Dry-Mesic White Oak-Hickory forest was observed at 13 sites; and East Gulf Coastal Plain Oak-Sweetgum Small Stream Floodplain forest was observed at 12 sites. Of the remaining 61 association classes, only 16 were represented by 4 or more field sites.

Within alliance classes, the Pine forest alliance was observed at 59 field sites; the Oak (Red oak, Hickory) forest alliance was observed at 32 sites; the White Oak

(Southern Red Oak) forest alliance was observed at 22 sites; the Sweetgum Floodplain forest alliance was as observed at 22 sites; and the Southern Red Oak forest alliance was observed at 20 sites. Only four additional forest alliances were observed at over 10 field sites (table 4).

\section{Spectral Relationships Among NPS-Defined Alliance Classes}

As discussed in the Final mapping classification, USGS scientists used a class-refinement strategy to include as many NPS-defined classes as possible in the mapping classification. A necessary restriction of class inclusion was that the spectral character of any given class be uniquely transferable throughout the Parkway. In other words, USGS scientists 
attempted to select classes defined by a set of unique spectral features that could be fairly consistently migrated from any starting point out in either direction along the Parkway.

Numerous complexities existed that worked to reduce mapping performance; however, the lack of sufficient fieldsite observations per class at the association level was the most limiting factor. Where only a few field observations of associations existed and spectral-textural distinctiveness was lacking, the ability to map these classes throughout the Parkway could not be adequately tested. Another complexity was related to the limited $11.3-\mathrm{m}$ radius field-observation used in the 2005 field plots. Where the landcover was spatially complex and changed relatively rapidly across small distances, the limited plot size increased difficulties associated with the lack of field samples. Mapping performance was also affected by the fact that aggregation of spectrally complex associations does not necessarily increase mapping performance; therefore, at each step in the progressive mapping, the aggregation of classes into a combined class had to be examined repeatedly in order to determine whether addition of certain classes into a large single class enhanced or degraded mapping performance. If the aggregation made sense and the mapping performance increased, the aggregation was accepted, but otherwise it was rejected.

Working within these constraints, extensive trial and error testing determined that eight aggregate classes was the maximum number that could be reliably mapped throughout the Parkway by using the progressive mapping strategy. The eight aggregated classes included (1) grasses (including weeds), (2) oaks, (3) white oak, (4) sweetgum, (5) sweetgumoak, (6) pine-oak, (7) pine, and (8) cedar. As discussed in the Methods section, nine additional classes, including swamp forest, water, aquatic vegetation, plantation, invasive species, road and developed, and two unclassified landcoversscrub-shrub and scattered trees - added by USGS scientists were manually mapped. Another category defined by USGS scientists termed "irregular classes" included forest alliances consisting of unique associations that could not be spectrally mapped. Within the irregular classes, only two associations were supported by more than one or two field observations. Even so, supervised classification was attempted with each irregular class, but none was successful; therefore, these manual classifications were not included in the calculation of mapping accuracy.

The combination of spectral migration of the means and progressive classification produced an organization of alliances that were highly internally consistent. The organization was not a function of mapper intervention; it was a result of the natural patterns or alignments of spectral variance and the focused definition of those spectral patterns. Even though availability of field-site data was severely limited, the spatial consistency generated by the migration of spectral means coupled with the progressive isolation of unique variances focused the highly mixed spectral variance cloud into related compositional groups. Those groups formed classes of NVC-defined alliances that were compositionally similar within the dominant landcover species; that is, the oak class was dominated by oaks, the sweetgum class by sweetgums, the pine class by pines, and the pine-oak class by pines and oaks.

As discussed throughout this report, the simple fact that the classes were a composite of alliances that were themselves assigned to a composition of species challenged the success of any useful map production. Given the additional challenges posed by the spectral complexity of overlapping species and varying compositions within and among associations, along with numerous other complexities, the mapping strategy employed demonstrated a high performance level, as demonstrated by compositional similarity within classes.. One particular example highlights that high performance.

Even though alliances comprised a mixture of species and at times a mixture of associations, when the associations were compositionally similar, the mapping placed that alliance and its related associations in a single class (for example, the A.234 alliance comprised three associations; see table 4). In contrast, the three associations comprising the A.130 alliance were each placed in different classes with similar compositions, with the successional Loblolly Pine-Oak forest association in the Pine-Oak class, the early- to midsuccessional Loblolly Pine forest association in the Pine class, and the mid- to late-successional Loblolly Pine-Sweetgum forest association in the Pine-Sweetgum class. Without mapper intervention, the mapping strategy produced a good representation of compositionally common classes. Inspection of these classes and their makeup may provide insight into the spectral and structural equivalences of these classes and the comprised alliances and associations.

The results of the mapping strategy revealed a number of classes that could not be consistently mapped even if aggregated. The plantation association at four sites, the four invasive-species associations (kudzu and Chinese Privet shrubland) at five sites, along with the Tree of Heaven (a forest alliance) and the Water hyacinth (an herbaceous alliance) classes, could not be consistently mapped with the progressive strategy. The four invasive-species alliances were manually mapped where they were visually detectable on the CIR photography. Similarly, the swamp class that included five associations with highly varying compositions was not amenable to automated mapping but could be mapped manually as a single aggregate class. Four native shrubland alliances identified at eight field sites by NPS personnel could not be mapped with automated processing but were manually classified. Although not identified by NPS personnel, a scrubshrub class was manually mapped because of high variability in composition and canopy structure. Another class called "scattered trees" was introduced by USGS scientists to include all the single trees and forest areas that were spectrally distinct but not classified by NPS personnel. Also, upon the request of NPS personnel, six herbaceous aquatic alliances were manually mapped and aggregated as an aquatic vegetation class. Because of the lack of field observations and the 
necessity to apply manual mapping to these classes, they were not included in the mapping accuracy assessments.

\section{Correspondence of the USGS Landcover Map and the NPS Landcover Classification}

Assessment of the mapping performance based on the eight aggregated classes and correspondence to the 301 NPS NVC field-site classifications determined 65 percent overall mapping classification accuracy (table 5). User accuracies per mapped forest class ranged from 100 percent to 48 percent. The lowest map accuracy of 48 percent was associated with the oak mix class. The next lowest user accuracies of 57 percent to 59 percent were associated with sweetgum-oak and pine-oak mix classes. Higher accuracies exhibited by single classes, such as sweetgum, white oak, pine, and cedar contrasted with the lower oak class accuracy. The oak mix class, however, contained 12 separate associations while sweetgum, pine, and cedar contained only two or three each. Although encompassing canopies dominated by oak species, the wide variety of included oak species resulted in the oak class resembling more mixed classes like pine-oak.

Producer-accuracy assessment results were not as high. Although the pine class had 95 percent and the oak class 76 percent producer accuracies, and the remaining classes had reasonable producer accuracies (54 percent), cedar and sweetgum-mix producer's accuracies were of concern. Sweetgum and cedar classes had producer accuracies of 30 percent and 29 percent, respectively. At the same time, the omission errors associated with these two classes were 70 percent and 71 percent. Over half of the time, sweetgum-mix was mistakenly mapped as primarily oak-mix and sweetgumoak and cedar primarily as pine. Normally, user accuracies are used as the more appropriate evaluator of the map product usability. The very low producer accuracies associated with cedar and sweetgum classes, however, resulted in a decision to further aggregate the eight classes.

The sweetgum and sweetgum-oak classes were combined and the pine and cedar classes were combined (table 6). Combining these classes raised the overall mapping accuracy to 70 percent. The oak mix class had the lowest user accuracy at 48 percent and the pine-oak the next lowest at 62 percent. The remaining classes had user accuracies 83 percent and higher. All producer accuracies increased to acceptable levels with the white oak class having the lowest producer accuracy of 54 percent.

Further consolidation of the oak mix and white oak classes resulted in an overall mapping accuracy to 81 percent (table 7). User and producer accuracies of the five remaining classes, grasses, oak mix, pine-oak, sweetgum mix, and pine-cedar were reasonable at 59 percent or higher. The oak mix user and producer accuracies had increased to 81 percent and 89 percent, respectively. Combining the oak mix and white oak classes produced a reasonable mapping accuracy; however, the loss of the white oak class throughout the
Parkway eliminated the fairly high mapping performance related to these classes in the northern half of the Parkway.

Considering the white oak class as spectrally inseparable from the oak mix class in the southern half of the Parkway, the white oak and oak mix classes were combined into the oak mix class in the southern Parkway and considered as two separate classes in the northern Parkway. The separation is reasonable given the extensive south to north expanse of the Parkway. The enhanced mapping performance in the north versus the south with respect to these two oak classes may be related to the physical separation and increased expansiveness of the white oak class in the north or other unknown factors. In either case, the retainment of the white oak and mixed oak classes in the north and the combining of these oak classes in the south increased the useful landcover information available for resource management.

By using this reasoning to retain the white oak class in the northern Parkway, the overall mapping accuracy became 74 percent and resulted in user and producer accuracies above 58 percent (table 8). Even with the physical division, both sweetgum and white oak (limited to the northern Parkway) classes were most often mistakenly mapped as oak accounting for 27 percent of the total omission errors (38 percent and 35 percent, respectively) in these classes. On the other hand, oak exhibited a high commission error or lower user accuracy due to its mistaken replacement of pine-oak, sweetgum, and white oak. The only other substantial confusion was the oak mix class mapped as the pine-oak class. The spatial extensiveness of the oak class was too high and most of the mistaken expansion came at the expense of the pine-oak, sweetgum and white oak class occurrences. Conversely, the pine-oak expansion into the oak mix class offset the oak mix expansion into the pine-oak class.

Within the herbaceous landcover classes, the grassland class, comprising the nonaquatic and noninvasive major portion of the herbaceous physiognomic class, was mapped at 100 percent (tables 5 to 8). Even though the grassland class exhibited visibly different CIR hues throughout the Parkway, their spatial variation did not align with any defined NVC association. In contrast, the spectral distinctions seemed associated with grooming history or possibly soil water content.

\section{Parkway Landscape Overview Based on the USGS Map}

The spatial coverage of each mapped class was calculated for the Parkway including (1) the 100-m buffer and (2) solely within the Parkway boundary (table 9). Compared by spatial coverages, grasses, oaks, and pines (including the cedar class) made up the primary class covers, while sweetgums (including the sweetgum-oak class), pine-oaks, white oaks, and scrub-shrubs made up the secondary; plantations, water, developed areas, and canopy gaps made up the tertiary classes comprising the 100-m buffer of the Parkway. All other classes comprised minor portions of the Parkway buffer (fig. 23). The 
Table 9. Total area of each class in the landcover map of the Natchez Trace Parkway produced by U.S. Geological Survey scientists.

\begin{tabular}{|c|c|c|c|c|c|}
\hline & \multirow[t]{2}{*}{ Landcover class } & \multicolumn{2}{|c|}{$\begin{array}{l}\text { With } 100-m \\
\text { buffer }\end{array}$} & \multicolumn{2}{|c|}{$\begin{array}{l}\text { Within park } \\
\text { boundary }\end{array}$} \\
\hline & & $\left(\mathbf{k m}^{2}\right)$ & $\%$ & $\left(\mathrm{~km}^{2}\right)$ & $\%$ \\
\hline 1 & Grasslands & 72.73 & $22 \%$ & 41.15 & $22 \%$ \\
\hline 2 & Road-developed & 8.37 & $3 \%$ & 6.03 & $3 \%$ \\
\hline 3 & Scrub-shrub & 16.84 & $5 \%$ & 4.2 & $2 \%$ \\
\hline 4 & Shrubland & 0.0753 & $0.02 \%$ & 0.0453 & $0.02 \%$ \\
\hline 5 & Plantation & 7.28 & $2 \%$ & 1.29 & $1 \%$ \\
\hline 6 & Water & 3.06 & $1 \%$ & 1.82 & $1 \%$ \\
\hline 7 & White oak & 14.21 & $4 \%$ & 14.13 & $8 \%$ \\
\hline 8 & Oak & 80.3 & $24 \%$ & 41.75 & $22 \%$ \\
\hline 9 & Sweetgum & 29.7 & $9 \%$ & 17.9 & $10 \%$ \\
\hline 10 & Pine-oak & 32.91 & $10 \%$ & 19.58 & $10 \%$ \\
\hline 11 & Pine-cedar & 61.69 & $19 \%$ & 37.07 & $20 \%$ \\
\hline 12 & Pine-sweetgum & 0.76 & $0.23 \%$ & 0.41 & $0.22 \%$ \\
\hline 13 & Scattered trees & 1.09 & $0.33 \%$ & 0.593 & $0.32 \%$ \\
\hline 14 & Swamp forest & 0.921 & $0.28 \%$ & 0.3608 & $0.19 \%$ \\
\hline 15 & Irregular classes & 0.06 & $0.02 \%$ & 0.06 & $0.03 \%$ \\
\hline 16 & Aquatic vegetation & 0.121 & $0.04 \%$ & 0.061 & $0.03 \%$ \\
\hline 17 & Invasive species & 0.21 & $0.06 \%$ & 0.12 & $0.06 \%$ \\
\hline 18 & Gaps & 1.61 & $0.48 \%$ & 0.84 & $0.45 \%$ \\
\hline 19 & Clouds & 0.17 & $0.05 \%$ & 0.1 & $0.05 \%$ \\
\hline & Total Area & 332.11 & $100 \%$ & 187.51 & $100 \%$ \\
\hline
\end{tabular}

landcover map of the Parkway (all mosaic sections as listed in fig. 3) is available on-line in PDF format on the Web page of USGS Open-File Report 2011-1276.

Forests dominate the Parkway, making up 66 percent of the landcover (table 9) and consisting of 24 percent oak (includes white oak in the southern sections), 19 percent pinecedar, 10 percent pine-oak, 9 percent sweetgum, and 4 percent white oak (as mapped in mosaics 4 to 7; see fig. 3). Grass is the second largest Parkway cover at 22 percent (table 9). The USGS-defined scrub-shrub and the NVC-defined shrubland classes cover a sizeable portion (5 percent) of the Parkway. Pine plantations comprise 2 percent of the Parkway.

Oak classes, the dominant forests over the entire Parkway, also individually dominate the southern, middle, and northern sections (table 10) (refer to fig. 3 for spatial reference of the mosaic sections). Oak classes, including white oak, decrease somewhat from the southern to middle section and then increase dramatically in the northern-most section of the Parkway. Conversely, the pine-cedar class declines dramatically from the southern and middle sections to the northern-most section of the Parkway. Within these contrasting oak and pine-cedar cover trends, cover of the pine-oak class tended to progressively increase slightly from the southern to northern sections. Coverage of the USGS-defined scrub-shrub and NVC-defined shrubland classes decreased overall from the southern to northern sections, while the plantation occurrences dropped in the northern section.

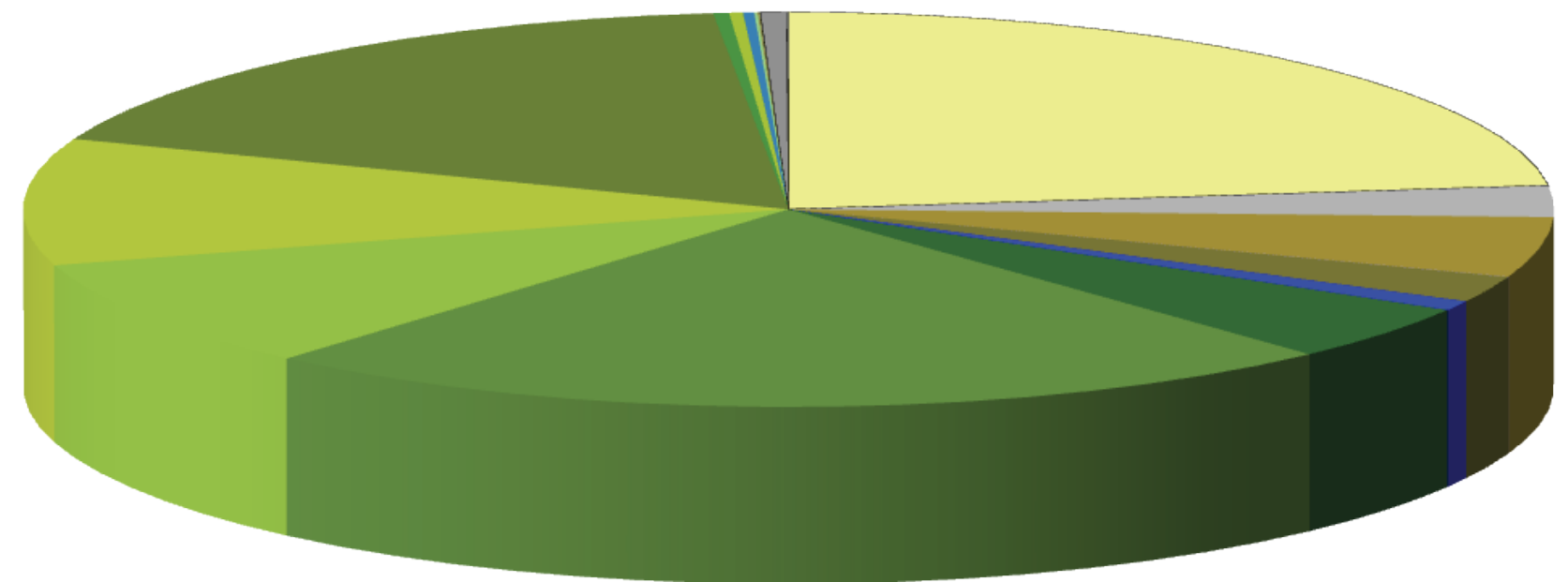

EXPLANATION
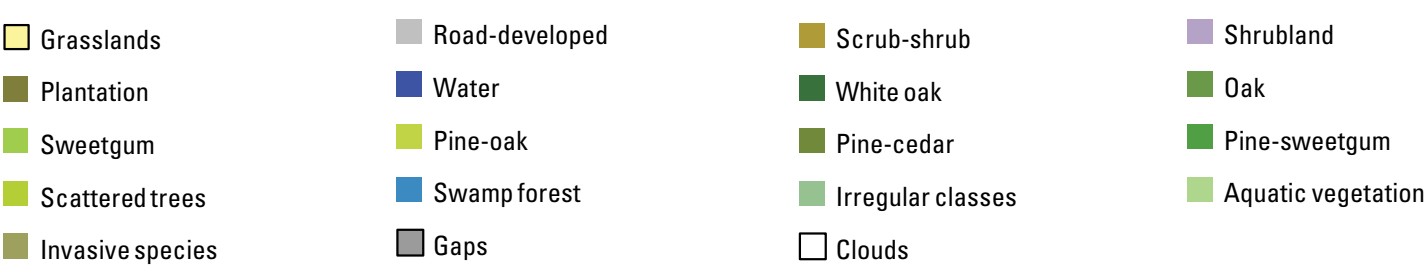

Figure 23. The graphic distribution of mapped classes within the Natchez Trace Parkway. 
Table 10. Landcover classes mapped for each of the southern, middle, and northern sections of the Natchez Trace Parkway by U.S. Geological Survey scientists.

[N, north; S, south]

\begin{tabular}{|c|c|c|c|c|c|}
\hline \multicolumn{2}{|c|}{ Landcover class } & \multirow{2}{*}{$\begin{array}{c}\begin{array}{c}\text { Southern } \\
\text { (1-3N) }\end{array} \\
20 \%\end{array}$} & \multirow{2}{*}{$\begin{array}{l}\text { Middle } \\
\text { (4S-4N) }\end{array}$} & \multirow{2}{*}{$\begin{array}{c}\text { Northern } \\
\text { (5S-7) } \\
22 \%\end{array}$} & \multirow{2}{*}{$\frac{\text { Total }}{22 \%}$} \\
\hline 1 & Grasslands & & & & \\
\hline 2 & $\begin{array}{l}\text { Road- } \\
\text { Developed }\end{array}$ & $2 \%$ & $3 \%$ & $2 \%$ & $3 \%$ \\
\hline 3 & Scrub Shrub & $6 \%$ & $5 \%$ & $4 \%$ & $5 \%$ \\
\hline 4 & Shrubland & $0.02 \%$ & $0.01 \%$ & $0.04 \%$ & $0.02 \%$ \\
\hline 5 & Plantation & $3 \%$ & $3 \%$ & $1 \%$ & $2 \%$ \\
\hline 6 & Water & $1 \%$ & $1 \%$ & $0 \%$ & $1 \%$ \\
\hline 7 & White Oak & $0 \%$ & $0.2 \%$ & $14 \%$ & $4 \%$ \\
\hline 8 & Oak & $26 \%$ & $20 \%$ & $24 \%$ & $24 \%$ \\
\hline 9 & Sweetgum & $10 \%$ & $11 \%$ & $7 \%$ & $9 \%$ \\
\hline 10 & Pine-Oak & $8 \%$ & $10 \%$ & $13 \%$ & $10 \%$ \\
\hline 11 & Pine-Cedar & $23 \%$ & $19 \%$ & $11 \%$ & $19 \%$ \\
\hline 12 & $\begin{array}{l}\text { Pine- } \\
\text { Sweetgum }\end{array}$ & $0.13 \%$ & $0.82 \%$ & $0.05 \%$ & $0.23 \%$ \\
\hline 13 & Scattered trees & $0.40 \%$ & $0.15 \%$ & $0.32 \%$ & $0.33 \%$ \\
\hline 14 & Swamp Forest & $0.44 \%$ & $0.22 \%$ & $0.04 \%$ & $0.28 \%$ \\
\hline 15 & $\begin{array}{l}\text { Irregular } \\
\text { Classes }\end{array}$ & $0.00 \%$ & $0.00 \%$ & $0.06 \%$ & $0.02 \%$ \\
\hline 16 & $\begin{array}{l}\text { Aquatic } \\
\text { Vegetation }\end{array}$ & $0.04 \%$ & $0.08 \%$ & $0.00 \%$ & $0.04 \%$ \\
\hline 17 & $\begin{array}{l}\text { Invasive } \\
\text { Species }\end{array}$ & $0.05 \%$ & $0.07 \%$ & $0.08 \%$ & $0.06 \%$ \\
\hline 18 & Gaps & $0.41 \%$ & $0.89 \%$ & $0.38 \%$ & $0.48 \%$ \\
\hline 19 & Clouds & $0.10 \%$ & $0.00 \%$ & $0.00 \%$ & $0.05 \%$ \\
\hline
\end{tabular}

\section{Southern Section Map Description}

As noted, the southern section exhibits the highest occurrences of oak and pine-cedars. Although representing much lower coverages, swamp forest occurrences are highest in the southern Parkway as well. Scrub-shrubs and shrubland occurrences are also highest in the southern section, exemplifying the higher and more recent disturbance observed in the most southern section of the Parkway. In contrast, grass and weed occurrences are lowest in the southern section.

\section{Middle Section Map Description}

From the southern to middle portions of the Parkway, grass and weed covers, including agricultural fields, increased to their highest cover proportions. The middle section is also the most developed portion of the Parkway (fig. 24 is an example from the section mosaic 4 south [see fig. 3]). With these increases in grass and weed covers, the overall forest cover declined. The forests in this section exhibited a higher proportion of canopy gaps, possibly suggesting more recent or more severe disturbance, and importantly, the smallest continuous forest stands (table 11). The sweetgum forest occurrence was highest in the middle section, and although a minor class, the pine-sweetgum class was observed and mapped only in this section. Again, although minor, the middle section contains the highest proportion of aquatic vegetation.

\section{Northern Section Map Description}

The northern section differed from the middle section in a number of ways and from the southern section in a few ways. The northern section was the most forested, with 69 percent compared to 67 percent forest cover in the southern section. As noted, the northern forested section contained the highest proportion of oaks when the oak and white oak classes were combined. It also contained the lowest proportion of pines and cedars. The northern section contained the only extensive stands of white oak. The increase in white oak contiguous extents may be the primary reason white oak could be separated from the oak mix class in the northern Parkway. The northern section exhibited slightly larger contiguous forest stands than those found in the southern forest. In addition, larger stands were more prevalent in the northern forests than in the southern forests (table 11). The northern section had the highest proportion of oaks, the largest and most numerous forest stands, and the fewest occurrences of scrub-shrub and shrubland covers and plantation occurrences.

\section{Minimum Mapping Unit}

The minimum mapping unit (MMU) defines the extent of the smallest spatial feature that can be consistently mapped as a discrete unit (for example, Fassnacht and others, 2006). The choice of an appropriate MMU is the subject of continuing and extensive research and discussion (for example, Fassnacht and others, 2006). As noted in the Introduction, the preferred and most appropriate MMUs in forested regions range from 25 to $900 \mathrm{~m}^{2}$, most often dependent on the target forest species. In many cases, however, the MMU is chosen to match a selected need. For instance, the National Wetlands Inventory employs a MMU ranging from 1 to 3 acres $(4,047$ to 12,141 $\mathrm{m}^{2}$ ) (National Oceanic \& Atmospheric Administration Coastal Services Center, n.d)

Because of the high spatial resolution (1-m) of the base DOQQs, the MMU was not restricted to the base spatial resolution. In addition, the 1-m rendition was not desirable for mapping forest canopies of mixed species (with mixed crown shapes). The nature of the mapping, performed by combining various species with varying compositions, was 


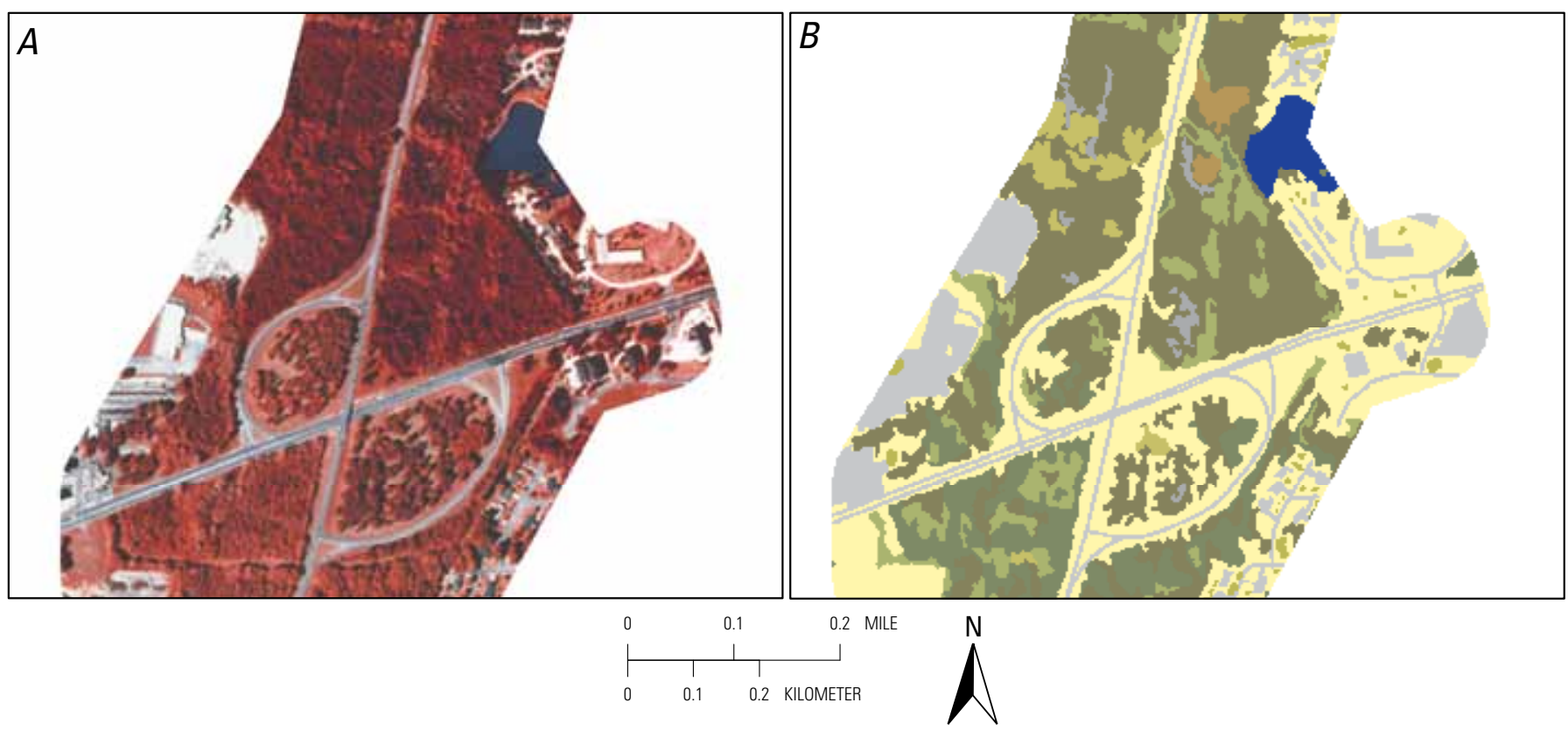

Figure 24. Example of mapping landcover classification within an area of the Natchez Trace Parkway (the "Parkway"). A, Colorinfrared digital orthophoto quarter quadrangle from the section 4 mosaic (see fig. 3). $B$, The final classes mapped by U.S. Geological Survey scientists based on the landcover classification of the Parkway by National Park Service personnel.

Table 11. Size of the largest area of continuous forest stands within each mapped section (southern, middle, and northern) of the Natchez Trace Parkway, as mapped by U.S. Geological Survey scientists. See figure 3 for spatial location of mosaics.

[M, mosaic; N, north; S, south]

\begin{tabular}{lccc} 
Section & $\begin{array}{c}\text { Largest forest } \\
\text { polygon }\left(\mathbf{k m}^{2}\right)\end{array}$ & Section & $\begin{array}{c}\text { Sum of the } \\
\text { largest forest } \\
\text { polygons }\left(\mathbf{k m}^{2}\right)\end{array}$ \\
\hline M1 & 2.56 & Southern & 9.41 \\
M2_S & 3.3 & & \\
M2_N & 0.78 & & \\
M3_S & 1.65 & & \\
M3_N & 1.11 & & \\
M4_S & 1.77 & Middle & 2.61 \\
M4_N & 0.84 & & \\
M5_S & 1.4 & Northern & 9.59 \\
M5_N & 2.28 & & \\
M6 & 3.65 & & \\
M7 & 2.26 & & \\
\hline
\end{tabular}

not amenable to setting a fixed MMU before conducting the mapping. Our strategy was to use spatial filters to simulate the dimensions and orientation of the initial field-sites visited by NPS personnel and to dampen spectral variability due to uneven crown illumination. The postclassification aggregation of polygons was applied, in part, to accomplish more spatially contiguous mapped classes as desired by NPS personnel. The final map preparation minimized canopy gaps and shadows by dissolving these features into the surrounding forest and eliminated many smaller class polygons by again dissolving these into the surrounding larger contiguous class polygons. The accumulated effect of these premapping and postmapping procedures was not directly calculable. To provide an overall estimate of the MMU while avoiding classification artifacts, the smallest nondigitized forest polygon mapped consistently throughout Parkway was calculated. From this calculation, the forest MMU was defined as $300 \mathrm{~m}^{2}$, and the grassland MMU was defined as $50 \mathrm{~m}^{2}$. 


\section{Summary}

Mapping challenges included limited availability of field observations, spatial and spectral complexity of the Parkway, and inherent composition variability contained in the $\mathrm{NVC}$ definitions. To accomplish high mapping performance with a limited set of calibration and verification data and inherently high spectral-texture variability, a mapping strategy was implemented based on the migration of class-related spectraltextural signatures and the congruent progressive refinement of the class signatures along the Parkway.

In order to maintain a consistent and quantifiable map product throughout the Parkway extent, mapping criteria were established. First, the spectral character of a selected class had to be uniquely transferable throughout the Parkway; that is, even though the class may have defined a compositional mixture, it should be recognized as the same class from one end of the Parkway to the other. Second, the map had to accurately portray the landcover types and distributions of the Parkway while maintaining a consistent conformity within created classes. Within the mapping process, the progressive aggregation of alliances into combined classes had to enhance mapping performance (or accuracy). If the aggregation was logical, was compositionally similar, and the mapping performance increased, the aggregation was accepted, but otherwise it was rejected. Along these same lines, alliance classes that lacked distinct spectral features and did not compositionally conform to any other alliance class were mapped manually (and termed "irregular" class). Third, the mapping procedure had to minimize bias and be reproducible and transferable. Excluding manual classifications, defined map classes were not to be based on interpretation but on quantifiable spectral processing.

Guided by the mapping criteria, the progressive classification strategy provided a method to evaluate the spectral-textural distinctiveness of the association classes and provided a consistent classification while incorporating dynamic spectral-textural patterns and the introduction of new classes along the 715-km Parkway. The combination of spectral migration of the means and progressive classification methods produced a map that conformed well to the Parkway landscape. Although some manual classifications were applied, they made up less than 8 percent of the mapped Parkway landcover. Even though important for NPS Parkway management, manual classifications were a minor contribution; the Parkway landcover map was an imageprocessing product based on methods and techniques only available within raster-based image processing (IP) and geographic information systems (GIS). By creating the map by using raster-based processing and limited mapper intervention, we produced an unbiased product rather than a subjective one. Furthermore, although the mapping strategy was complex, the processes applied are reproducible and are, therefore, transferable to other similar mapping projects or subsequent landcover classifications of the Parkway. Overall, the mapclass composition indicated the existent spectral-textural patterns that defined and encompassed the complex variety of compositional alliances and associations of the Parkway. The map provides a good representation of the landcover patterns and their changes over the $715-\mathrm{km}$ extent.

The implemented mapping strategy accommodated the limited field data and compositional class variability and produced a good landcover map of the Parkway. To provide some additional guidance for future mapping of similar landscapes with remote sensing and image processing techniques, we have added some summary insights gained in this and other similar mapping classifications. These summary insights are meant to provide information concerning issues that may arise in future mapping.

An additional factor influencing the mapping performance was the leaf-on timing of CIR photography acquisition. In most instances mapping during leaf-off conditions enhances the discernment between pines and broad-leaf forests; however the timing was selected by NPS personnel in order to conform to the NVC mapping criteria. If the Parkway mapping had been performed during leaf-off conditions discernment among the broad leaf forest species would have been severely diminished if not eliminated. Although USGS scientists were not able to separate alliances within the oak class, there was reasonable discernment among the oak, sweetgum, and pine-oak classes. This mapping classification provides a basis for continued separation of alliances contained within these aggregate classes.

Another issue was the spatial continuity of the mapped classification. One goal of the mapping classification was to produce as cohesive a map as possible while maintaining the highest class-cover detail as possible; however, some transitional artifacts remained in the final map product. Unless the mapping detail is at the tree level, these artifacts will always be present in natural environmental mapping. As pointed out in Verbyla and Hammond (1995) and stated previously in this report, in many cases these transitions and spatially smaller features actually exist; however, in interpretation of the aerial photography these features are not included. In image-based mapping, postprocessing can eliminate most of these features, as was done in this mapping. Other methods may use rules-based classifications that provide absolute limits of class inclusion, somewhat mimicking photointerpretation.

A final issue concerns consistency of field-site landcover classification. As pointed out by Congalton (1991) and Verbyla and Hammond (1995), no reference dataset is completely accurate. Errors or inconsistencies in the original classification directly change the mapping accuracy assessment. For instance, a 10 percent error in the landcover classification (or reference data) will result in a 10 percent error in the mapping accuracy assessment. A mapping classification that may have been 85 percent correct would be incorrectly reported as 75 percent correct given the 10 percent classification (or reference) error. As also stated in Congalton (1991), accuracy reference data should be considered in any mapping accuracy assessment. 


\section{Landscape Classification Protocols and Metadata}

As mandated by the NPS, the landcover and landuse classification protocols followed the NVC (for example, Federal Geographic Data Committee, 1997; Ramsey and others, 2002). The NVC-based landcover classification of the Parkway was carried out by NPS personnel. Methods used to map the NPS classification to the Parkway area and interpret the accuracy of the classified map were developed in previous mapping projects conducted for the National Park Service and as described within this report (Ramsey and others, 2001a,b, 2002; Ramsey and Yan, 2006; Ramsey and Rangoonwala, 2007). Although map classes are composites of NVC-defined alliances and associations, each composite map class can be traced to the initial NVC-defined classes. Thus, the created map follows national protocols for landcover classification. Following Federal Geographic Data Committee geospatial guidelines (2010), a metadata record was created to capture the basic characteristics of pertinent data or information resources. The metadata record is available on-line on the Web page of USGS Open-File Report 2011-1276.

\section{References}

Barrette, J., August, P., and Golet, F., 2000, Accuracy assessment of wetland boundary delineation using aerial photography and digital orthophotography: Photogrammetric Engineering and Remote Sensing, v. 66 , no. 4 , p. $409-416$.

Congalton, R., 1991, A review of assessing the accuracy of classifications of remotely sensed data: Remote Sensing of Environment, v. 37, 35-47.

Congalton, R., and Green, K., 1999, Assessing the accuracy of remotely sensed data: Principles and Practices: Boca Raton, Fla., Lewis Publisher.

Chamberlain, K., 2002a, Performance testing of the Garmin GPSMAP 76 Global Positioning System Receiver: U.S. Forest Service, accessed August 5, 2011, at http://www.fs.fed.us/database/gps/mtdc/map76/garmin gpsmap_76_rev.pdf.

Chamberlain, K., 2002b, Performance testing of the Trimble GPS Pathfinder Pocket Global Positioning System Receiver: U.S. Forest Service, accessed August 5, 2011, at http://www.fs.fed.us/database/gps/mtdcrept/documents/ trimpckt.pdf.

Fassnacht, K.S., Cohen, W.B., and Spies, T.A., 2006, Key issues in making and using satellite-based maps in ecology: a primer: Forest Ecology and Management, v. 222, p.167-181.
Federal Geographic Data Committee, 1997, Vegetation classification standard: Federal Geographic Data Committee Web site, accessed on August 5, 2011, at http://www.fgdc.gov/standards/projects/FGDC-standardsprojects/vegetation/vegclass.pdf/view.

Federal Geographic Data Committee, 2008, National Vegetation Classification Standard: Federal Geographic Data Committee Web site, accessed October 17, 2011, at http://www.fgdc.gov/standards/projects/FGDC-standardsprojects/vegetation.

Federal Geographic Data Committee, 2010, Geospatial metadata: Federal Geographic Data Committee Web site, accessed October 17, 2011, at http://www.fgdc. gov/metadata.

Foody, G., 2002, Status of landcover classification accuracy assessment: Remote Sensing of the Environment, v. 80, p. 185-201.

Grenier, M., Labrecque, S., Benoit, M., and Allard, M., 2008, Accuracy assessment method for wetland object-based classification, in Hay G.J., Blaschke, T., and Marceau, D., eds., [Proceedings of] GEOBIA 2008-Pixels, objects, intelligence, GEOgraphic Object Based Image Analysis for the 21st Century, Calgary, Alberta, Canada, University of Calgary, August 5-8, 2008: International Society for Photogrammetry and Remote Sensing, v. 38 , no. 4/C1, p.1-6, accessed October 17, 2011, at http://www.isprs. org/proceedings/XXXVIII/4-C1/content/GEOBIA_ Proceedings_RP10_FINALc.pdf.

Hammond, T. O., and Verbyla, D. L., 1996, Optimistic bias in classification accuracy assessment: International Journal of Remote Sensing, v. 17, p. 1261-1266.

Karsky, D., Chamberlain, K., Mancebo, S., Patterson, D., and Jasumback, T., 2000, Comparison of GPS receivers under a forest canopy with selective availability off: U.S. Department of Agriculture, Forest Service, Technology and Development Program Project Report 7100.

Mancebo, S., and Chamberlain, K., 2000, Perfomance testing of the Garmin eTrex, Garmin GPSIII Plus, Magellan GPS 2000XL, and Magellan Blazer Recreatin Type Global Positioning System Receiver, U.S. Forest Service, accessed 5 August 2011 at http://www.fs.fed.us/database/gps/mtdc/ gps2000/Nav_3-2001.htm.

National Oceanic \& Atmospheric Administration Coastal Services Center, n.d., Data—Land Cover,

National Wetlands Inventory: NOAA Coastal Services Center Digital Coast Web site, accessed June 2, 2011, at http://www.csc.noaa.gov/digitalcoast/data/nwi/index.html.

PCI Geomatics, 1998, Using PCI Software, Ver. 6.3 EASI/ PACE: Richmond Hill, Ontario, Canada, PCI Geomatics. 
Ramsey, E., III, and Laine, S., 1997, Comparison of Landsat Thematic Mapper and high resolution photography to identify change in complex coastal marshes: Journal of Coastal Research, v. 13, no. 2, p. 281-292.

Ramsey, E., III, Nelson, G., and Sapkota, S., 1998, Classifying coastal resources by integrating optical and radar imagery and color infrared photography: Mangroves and Salt Marshes, v. 2, no. 2, p. 109-119.

Ramsey, E., III, Nelson, G., Sapkota, S., Strong, M., Phillips, W., and Schmersahl, K., 2001a, Landcover classification of Lake Meredith National Recreation Area: U.S. Geological Survey, Biological Resources Division, Biological Science Report USGS/BRD/BSR--2001-0003.

Ramsey E., III, Nelson, G., and Sapkota, S., 2001b, Coastal Change Analysis Program implemented in Louisiana: Journal of Coastal Research, v. 17, no. 1, p. 55-71.

Ramsey, E., III, Echols, D., Nelson, G., and Sapkota, S., 2002, The National Vegetation Classification Standard applied to the remote sensing classification of two semiarid environments: Environmental Management: vol. 29, no. 5, p. 703-715.

Ramsey, E., III, and Yan, Y., 2006, Palo Alto Battlefield National Historic Site landscape classification and historical analysis - Proceedings of the $20^{\text {th }}$ Biennial workshop on Aerial photography, Videography, and High Resolution Digital imagery for Resource Assessment, October 4-6, 2005, Weslaco, Tex.: Tex.: Bethesda, Maryland, ASPRS, p $1-10$.
Schwind, B., Warbington, R., and Brohman, R., 2004. USDA Forest Service mapping standards for existing vegetation-A test of base level mapping standards, in Proceedings of the Tenth Forest Service Remote Sensing Applications Conference, Salt Lake City, Utah, April 5-9, 2004: Bethesda, Md., American Society for Photogrammetry and Remote Sensing.

U.S. Geological Survey Rocky Mountain Mapping Center, 2000, National Geospatial Program Standards_-Digital Orthophoto Standards: U.S. Geological Survey Rocky Mountain Mapping Center Web site, accessed on May 5, 2011, at http://rockyweb.cr.usgs.gov/nmpstds/doqstds.html.

Van Genderen, J., and Lock, B., 1977, Testing land-use map accuracy: Photogrammetric Engineering and Remote Sensing, v. 43, p. 1135-1137.

Verbyla, D. L., and Hammond, T.O., 1995, Conservative bias in classification accuracy assessment due to pixel-bypixel comparison of classified images with reference grids: International Journal of Remote Sensing, v. 16, p. 581-587. 


\section{Appendix 1. Color-infrared photograph centers.}

Table. Locations of photograph centers from the Natchez Trace Parkway landcover mapping project. [no., number; long, longitude; dec, decimal; min, minute; lat, latitude; deg, degree]

\begin{tabular}{|c|c|c|c|c|c|c|c|c|}
\hline $\begin{array}{l}\text { No. of } \\
\text { frames }\end{array}$ & Frame no. & Long dec & Long min & Lat dec & Lat min & $\begin{array}{c}\text { Direction of } \\
\text { flight }\end{array}$ & Long dec deg & Lat dec deg \\
\hline 1 & 027-001 & -88 & 18 & 34 & 32 & 36 & 34.528556 & -88.291944 \\
\hline 3 & 027-003 & -88 & 16 & 34 & 34 & 40 & 34.560194 & -88.263389 \\
\hline 4 & 027-004 & -88 & 15 & 34 & 35 & 39 & 34.575528 & -88.248472 \\
\hline 7 & 028-001 & -88 & 13 & 34 & 36 & 63 & 34.602750 & -88.217889 \\
\hline 8 & 028-002 & -88 & 12 & 34 & 37 & 62 & 34.612028 & -88.196778 \\
\hline 9 & 028-003 & -88 & 11 & 34 & 37 & 63 & 34.621250 & -88.175639 \\
\hline 10 & 028-004 & -88 & 9 & 34 & 38 & 62 & 34.630528 & -88.154667 \\
\hline 14 & 029-001 & -88 & 6 & 34 & 40 & 45 & 34.658444 & -88.095611 \\
\hline 15 & 029-002 & -88 & 5 & 34 & 40 & 46 & 34.672333 & -88.078694 \\
\hline 16 & 029-003 & -88 & 4 & 34 & 41 & 47 & 34.686167 & -88.061556 \\
\hline 17 & 029-004 & -88 & 3 & 34 & 42 & 47 & 34.699750 & -88.044250 \\
\hline 18 & 029-005 & -88 & 2 & 34 & 43 & 46 & 34.713556 & -88.027250 \\
\hline 19 & 018-001 & -89 & 24 & 33 & 18 & 45 & 33.292528 & -89.406722 \\
\hline 20 & 018-002 & -89 & 23 & 33 & 18 & 48 & 33.306111 & -89.389722 \\
\hline 21 & 018-003 & -89 & 22 & 33 & 19 & 48 & 33.319444 & -89.372333 \\
\hline 22 & 018-004 & -89 & 21 & 33 & 20 & 48 & 33.332722 & -89.354944 \\
\hline 28 & 019-001 & -89 & 17 & 33 & 24 & 36 & 33.393667 & -89.277472 \\
\hline 29 & 019-002 & -89 & 16 & 33 & 25 & 34 & 33.409778 & -89.263889 \\
\hline 30 & 019-003 & -89 & 15 & 33 & 26 & 34 & 33.426194 & -89.250778 \\
\hline 31 & 019-004 & -89 & 14 & 33 & 27 & 36 & 33.442250 & -89.237083 \\
\hline 32 & 019-005 & -89 & 13 & 33 & 28 & 35 & 33.458389 & -89.223500 \\
\hline 33 & 019-006 & -89 & 13 & 33 & 28 & 35 & 33.474667 & -89.210139 \\
\hline 34 & 019-007 & -89 & 12 & 33 & 29 & 34 & 33.490944 & -89.196861 \\
\hline 35 & 019-008 & -89 & 11 & 33 & 30 & 35 & 33.507222 & -89.183583 \\
\hline
\end{tabular}


Table. Locations of photograph centers from the Natchez Trace Parkway landcover mapping project.-Continued [no., number; long, longitude; dec, decimal; min, minute; lat, latitude; deg, degree]

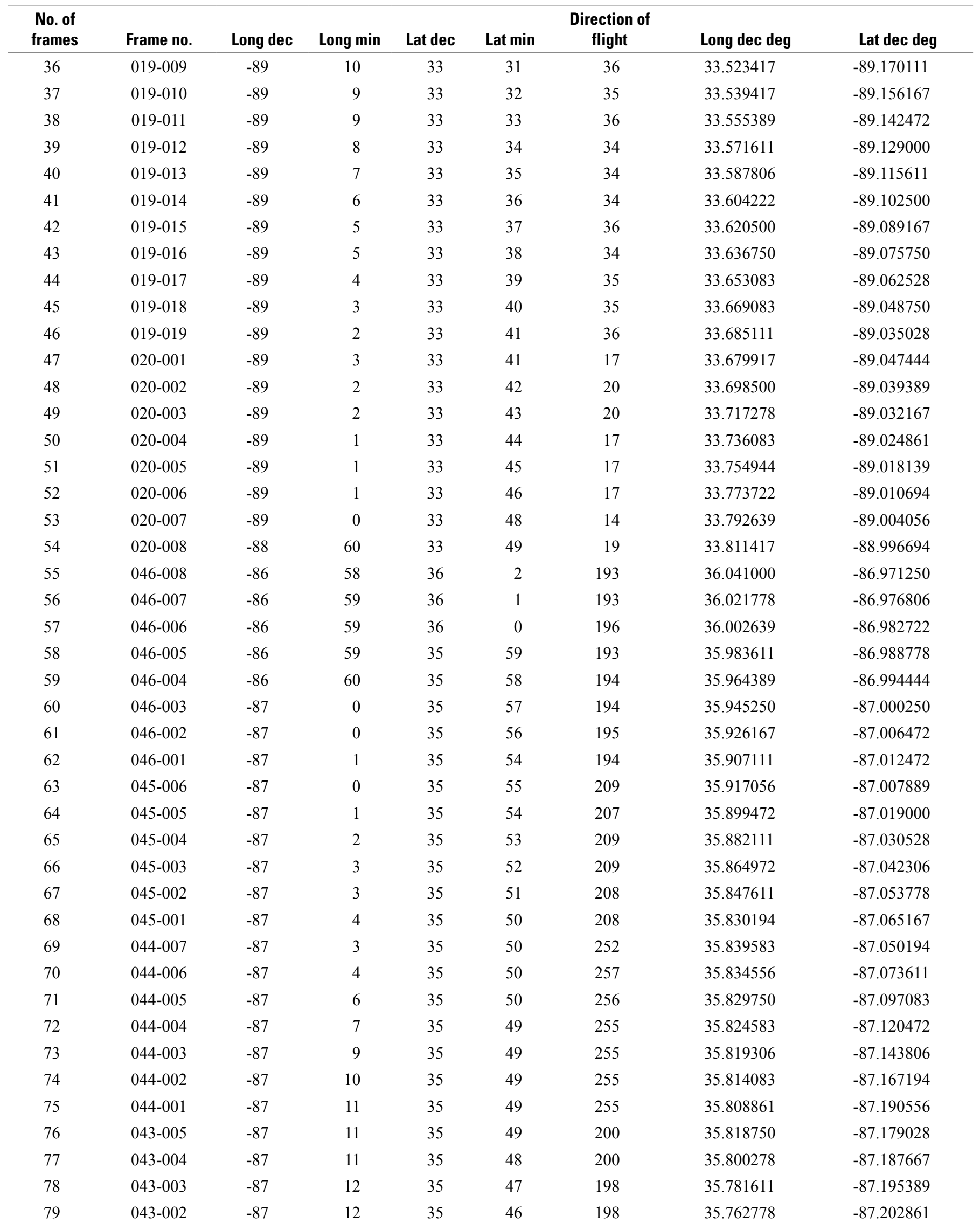


Table. Locations of photograph centers from the Natchez Trace Parkway landcover mapping project.-Continued [no., number; long, longitude; dec, decimal; min, minute; lat, latitude; deg, degree]

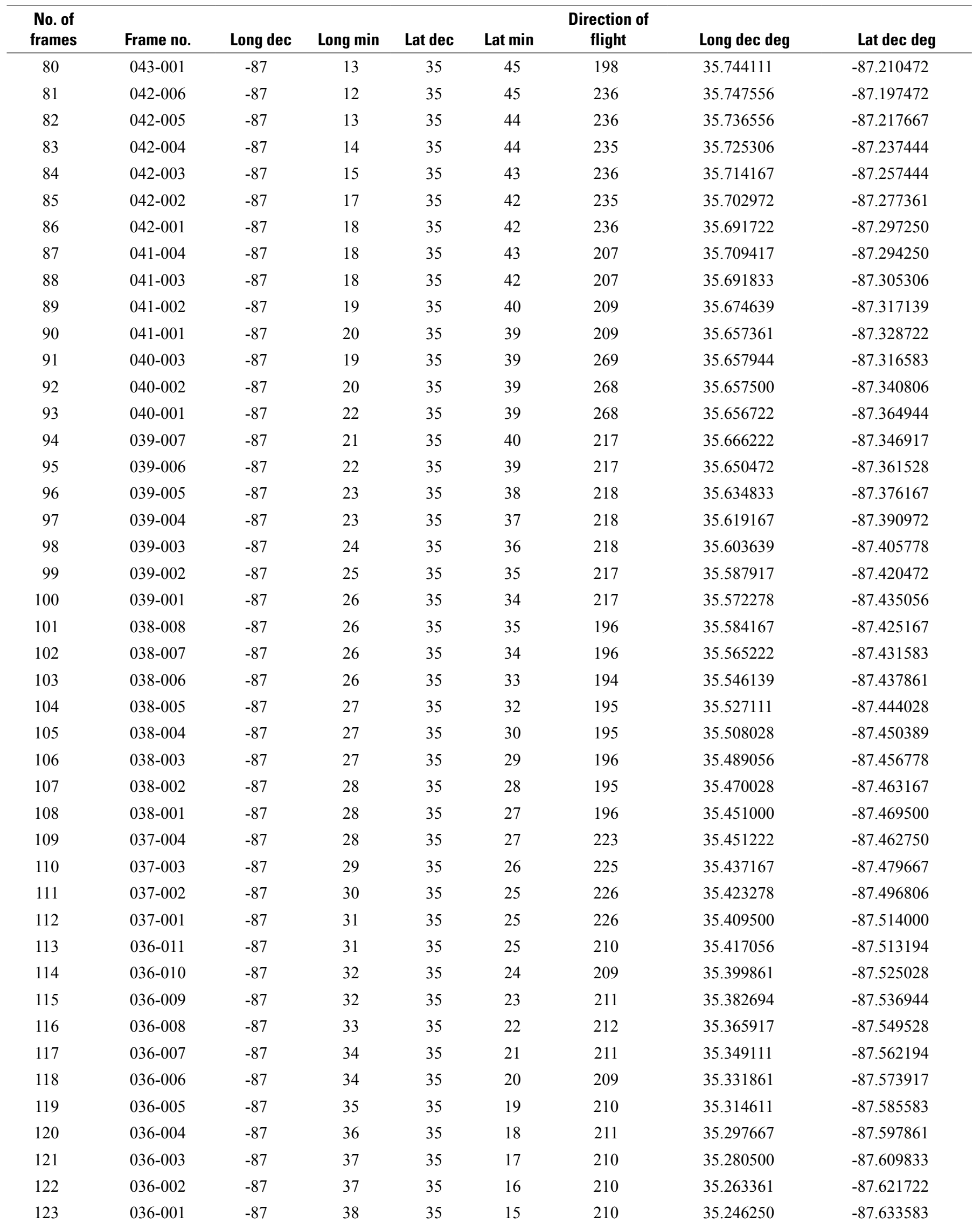


$50 \quad$ Mapping Landcover of the National Park Service's Natchez Trace Parkway

Table. Locations of photograph centers from the Natchez Trace Parkway landcover mapping project.-Continued [no., number; long, longitude; dec, decimal; min, minute; lat, latitude; deg, degree]

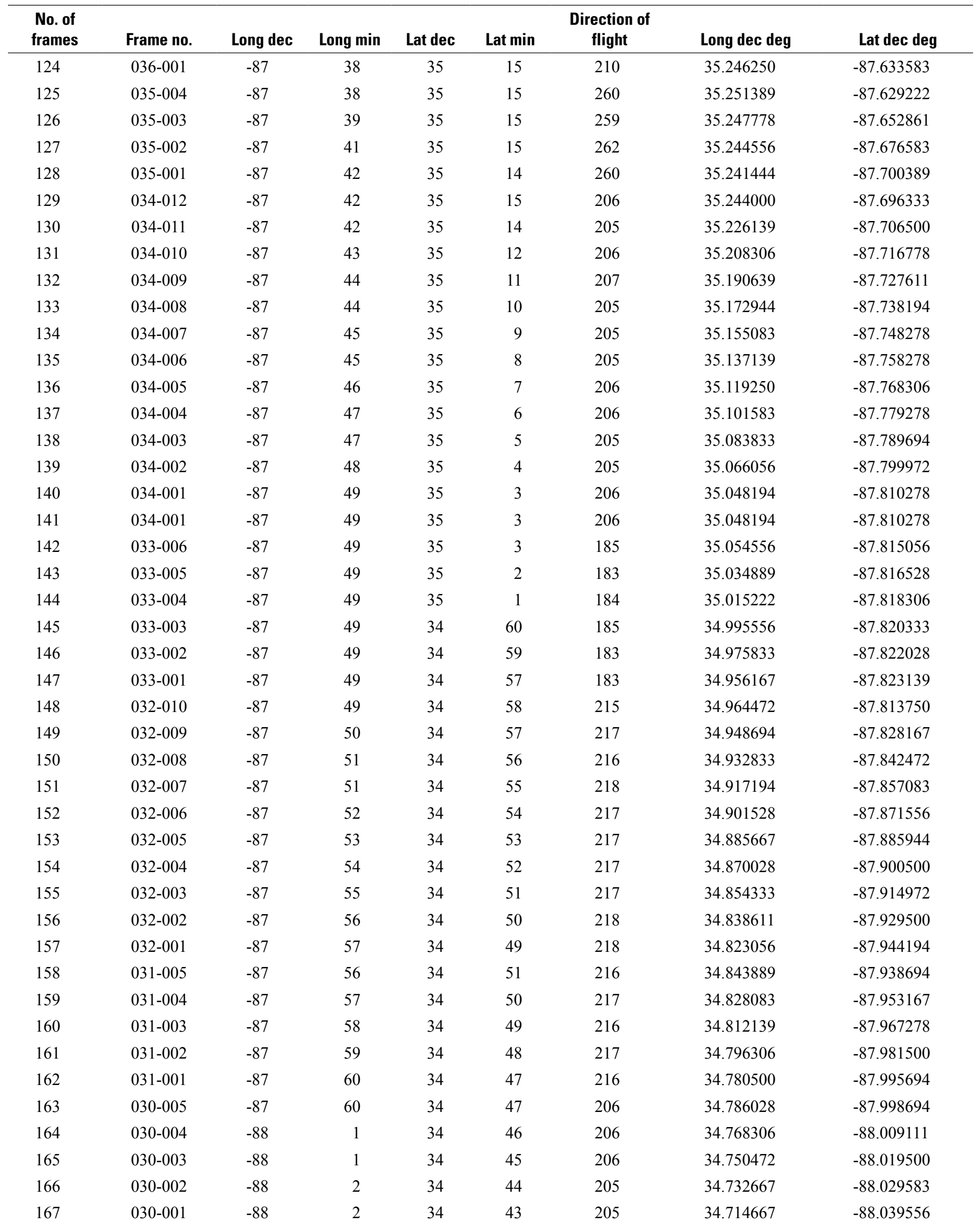


Table. Locations of photograph centers from the Natchez Trace Parkway landcover mapping project.-Continued [no., number; long, longitude; dec, decimal; min, minute; lat, latitude; deg, degree]

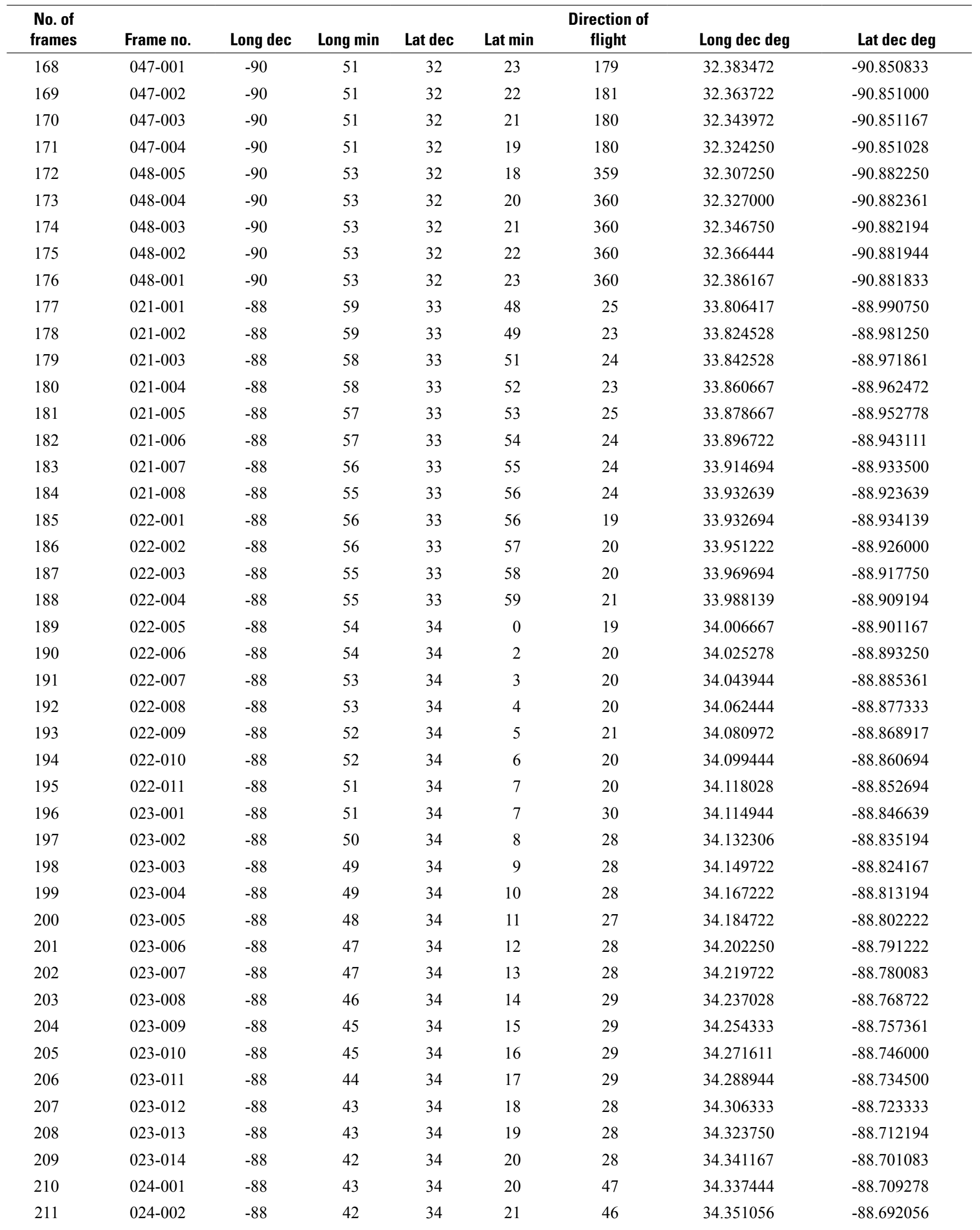




\section{Mapping Landcover of the National Park Service's Natchez Trace Parkway}

Table. Locations of photograph centers from the Natchez Trace Parkway landcover mapping project.-Continued [no., number; long, longitude; dec, decimal; min, minute; lat, latitude; deg, degree]

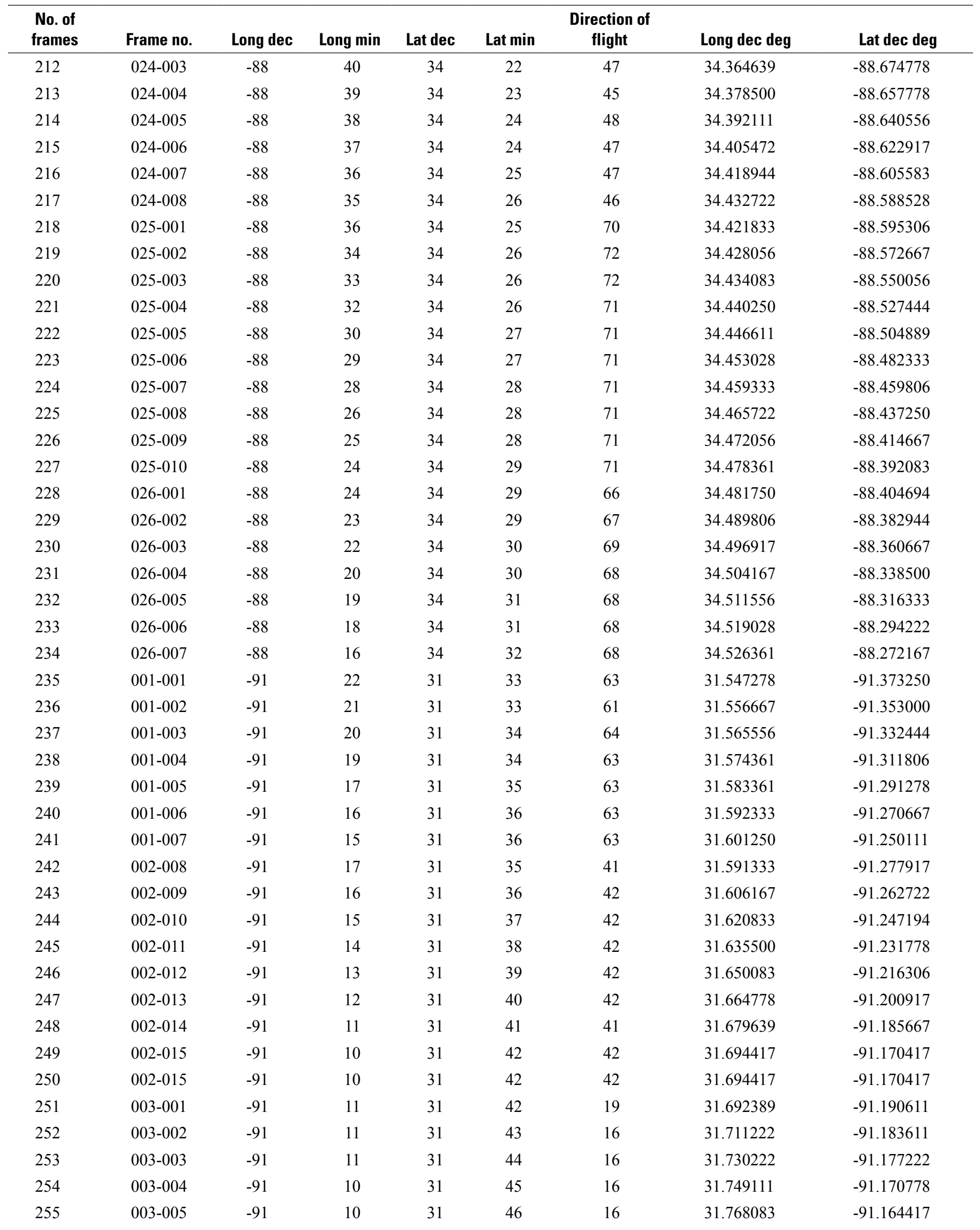


Table. Locations of photograph centers from the Natchez Trace Parkway landcover mapping project.-Continued [no., number; long, longitude; dec, decimal; min, minute; lat, latitude; deg, degree]

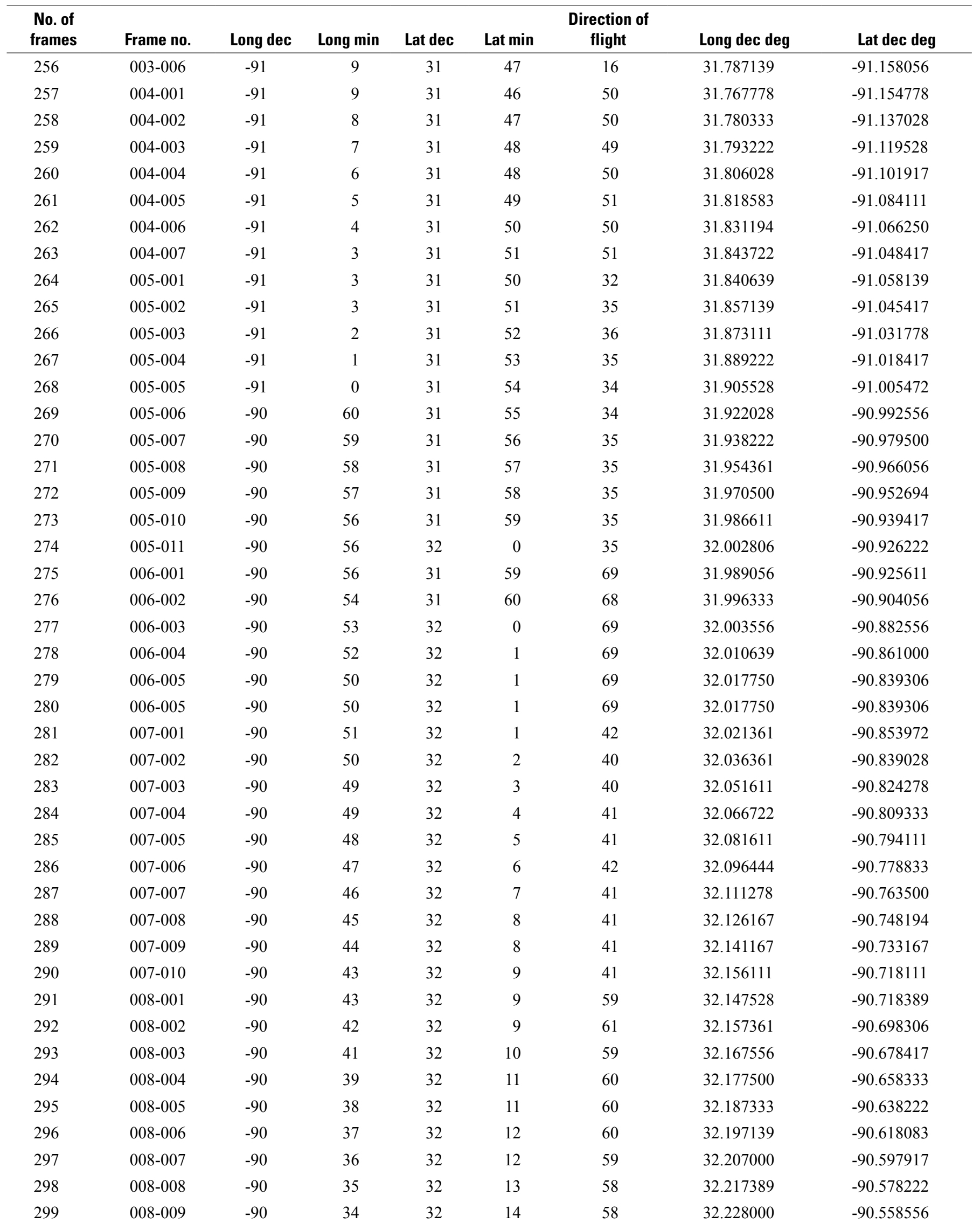


$54 \quad$ Mapping Landcover of the National Park Service's Natchez Trace Parkway

Table. Locations of photograph centers from the Natchez Trace Parkway landcover mapping project.-Continued [no., number; long, longitude; dec, decimal; min, minute; lat, latitude; deg, degree]

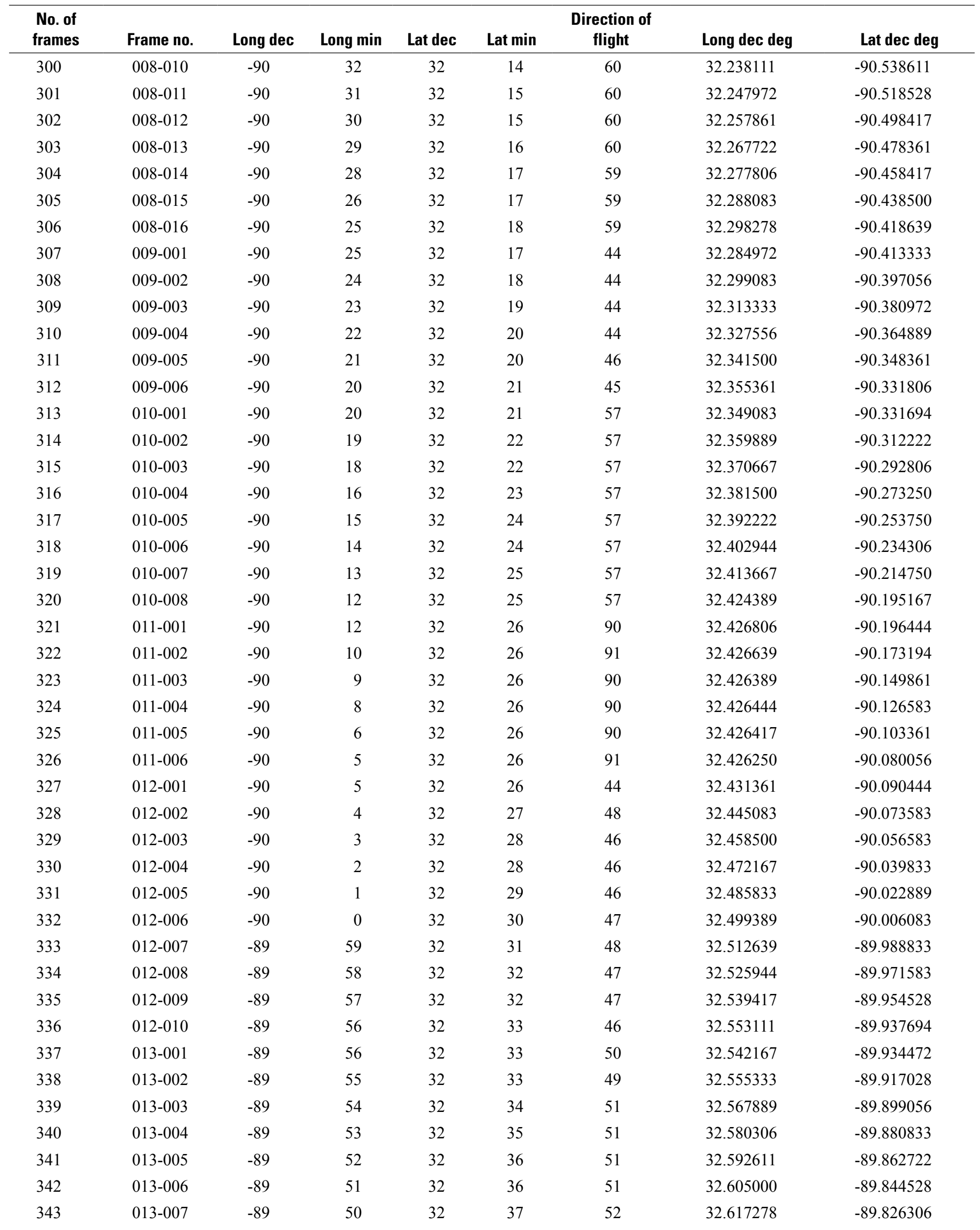


Table. Locations of photograph centers from the Natchez Trace Parkway landcover mapping project.-Continued [no., number; long, longitude; dec, decimal; min, minute; lat, latitude; deg, degree]

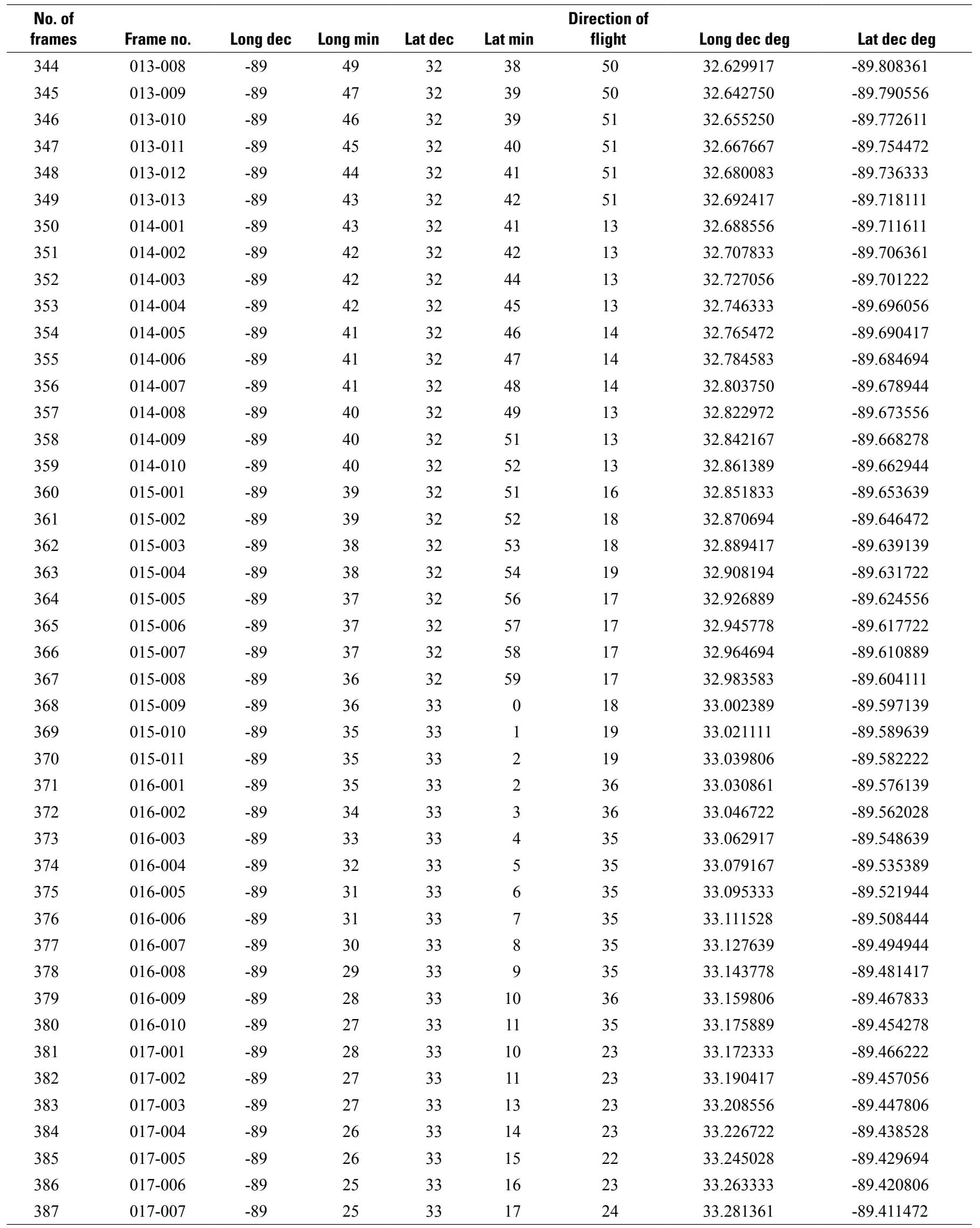





\section{Appendix 2. Photography collection and processing.}

\section{Aerial Photography of the Natchez Trace Parkway}

The color infrared (CIR) aerial data were collected during leaf-on conditions with no visible senescence onset, as was required by NPS personnel to accomplish their groundbased landcover classification following the NVC protocols. For the study, 386 photographic frames, including 9 frames over the Vicksburg National Military Park, were collected on September 29 and 30 and on October 6 and 15, 2004. The CIR photography contains three spectral bands, including a green band, a red band, and a near-infrared band.

For testing, aerial photography of selected sections of the Parkway was collected on September 9, 2004. This exercise was conducted so that acquisition of the best color CIR film rendition was assured. To find the best camera settings, the film was developed at different exposures, and several test products were made with different contrast levels until optimal contrast, tone, and color was achieved. These camera settings were then used as a template for subsequent aerial coverage and film development of the entire area.

\section{Equipment and Logistics for Collecting Aerial Photographs}

Cessna 206 \# N4803U fitted with Leica RC-30 precision camera (calibrated in September 2004) was used to collect the CIR photographic data.

Kodak Aerochrome 1443 color infrared film was used for the aerial photography.

Aerial sorties were conducted on September 29 and 30 and on October 6 and 15, 2004.

The 386 photographic frames acquired have a 60 percent end lap and a 30 percent side lap (side overlap is only relevant to the Vicksburg National Military Park coverage).

A 1:24,000 photographic scale was selected to obtain a ground resolution of $1 \mathrm{~m}$ or better.

During postprocessing, two sets of aerial film rolls were generated, one original and one duplicate roll. (Details provided in the interim report of January 24,2005 )

\section{Orthophoto Production}

\author{
Preprocessing-Original Film Roll
}

To determine the best photographic results for brightness, saturation, and hue, a number of frames were developed by using different photographic processing settings. We then selected frames having the correct contrast, color, and tone for different land cover categories (for example, harvested agriculture fields, forested lands, and plantations). Another set of test film frames was developed by using our indicated contrast and brightness levels. Final calibrations for the film development were set after re-examining several sets of test frames.

Photographic frame centers were calculated and converted to an ESRI ArcInfo format. The coordinate system is spherical. A representation in a Universal Transverse Mercator (UTM) North American Datum 1983 (NAD83) coordinate system was produced from the photographic frames with referenced spherical coordinates.

\section{Postprocessing-Duplicate Film Roll}

Test film frames were also first created for the duplicate film roll. The best results for contrast and hue were selected, and this constant contrast and hue adjustment was then applied for developing the entire duplicate roll. The option of individual dodging of the duplicate film frames was not available.

\section{Digital Orthophoto Quarter Quadrangles}

In addition to the required products listed in the contract agreement with NPS, digital orthophoto quarter quadrangles (DOQQs) were produced from the aerial photographic frames. In orthophotographic production, the effects of tilt and relief were removed from the aerial photos by a mathematical process called rectification. The transformation of the photographic frames to DOQQ representation provided uniform scale. Uniform scale allowed the direct measure of true distance and direction. The DOQQs are terrain-corrected images that are used as precision base maps.

The 235 DOQQs created from the 386 aerial frames were mosaiced to create full coverage of the Parkway graphic (fig. 3). Production of DOQQs provided enhanced registration of the mosaiced frames. This allowed exact 
alignment of the linear features that transverse multiple frames (for example, roads).

The Parkway crosses two UTM zones. Heading north, UTM zone 15 is replaced by UTM zone 16 at Canton, Mississippi. The quads from Goshen Springs, Mississippi, onwards to Bellevue, Tennessee, are in zone 16. All frames were projected in the correct UTM zone.

\section{Scanning of the Aerial Photographic Frames}

Scanning of the duplicate film roll was done at 25 microns by using a true color, true optics scanner to generate a 1,000-dot per inch (dpi) product. Analytical triangulation was performed by using controls from existing DOQQs. Elevation data was used to rectify, mosaic, and tone balance the tiles. The tiles were cut to match DOQQs in the UTM projection zones (fig. 2).

The DOQQs generated are compliant with the digital orthophoto standard as defined by the USGS Rocky Mountain Mapping Center (2000). (http://rockyweb.cr.usgs. gov/nmpstds/doqstds.html).

\section{Color Balancing}

Manipulation of the intensity per color in a frame was accomplished by selective shading or masking to match appearance of the frames for mosaic. Effort was made to eliminate frame line appearances (the point at which one frame ends and another frame starts). 


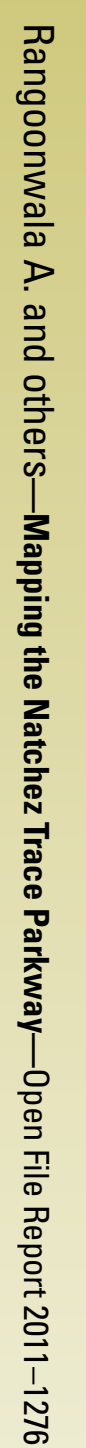

